\title{
Instrumentation to Enhance Advanced Test Reactor Irradiations
}

\author{
J. L. Rempe \\ D. L. Knudson \\ K. G. Condie \\ J. E. Daw \\ S. C. Taylor
}

September 2009

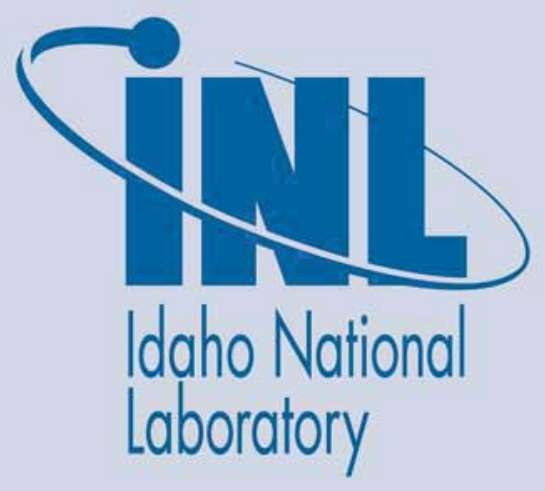

The INL is a U.S. Department of Energy National Laboratory operated by Battelle Energy Alliance 
INL/EXT-08-13985

\title{
Instrumentation to Enhance Advanced Test Reactor Irradiations
}

\author{
J. L. Rempe \\ D. L. Knudson \\ K. G. Condie \\ J. E. Daw \\ S. C. Taylor
}

September 2009

\begin{abstract}
Idaho National Laboratory
Idaho Falls, Idaho 83415
\end{abstract}

http://www.inl.gov

Prepared for the

U.S. Department of Energy

Office of Nuclear Energy

Under DOE Idaho Operations Office

Contract DE-AC07-05ID14517 


\begin{abstract}
The Department of Energy (DOE) designated the Advanced Test Reactor (ATR) as a National Scientific User Facility (NSUF) in April 2007 to support U.S. leadership in nuclear science and technology. By attracting new research users - universities, laboratories, and industry - the ATR will support basic and applied nuclear research and development, further advancing the nation's energy security needs. A key component of the ATR NSUF effort is to prove new in-pile instrumentation techniques that are capable of providing real-time measurements of key parameters during irradiation. To address this need, an assessment of instrumentation available and under-development at other test reactors has been completed. Based on this review, recommendations are made with respect to what instrumentation is needed at the ATR and a strategy has been developed for obtaining these sensors. Progress toward implementing this strategy is reported in this document. It is anticipated that this report will be updated on an annual basis.
\end{abstract}


INL/EXT-08-13985 


\section{CONTENTS}

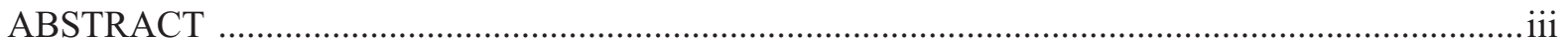

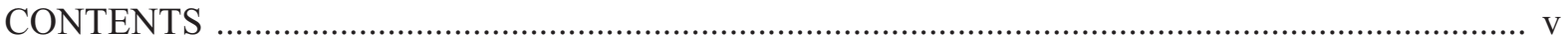

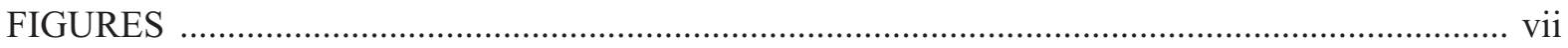

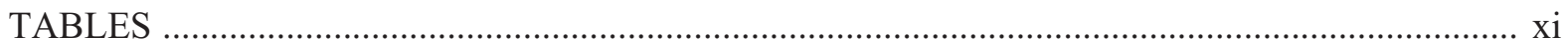

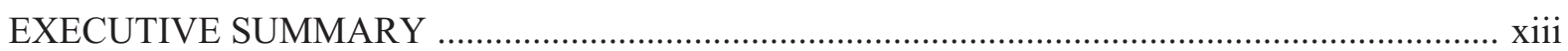

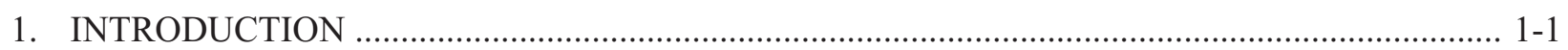

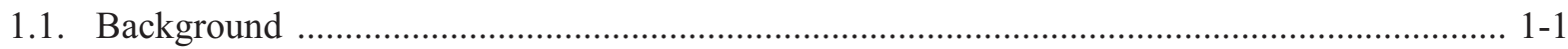

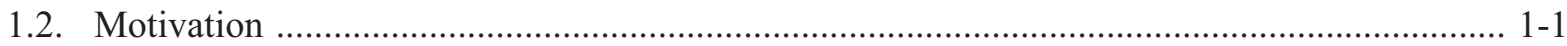

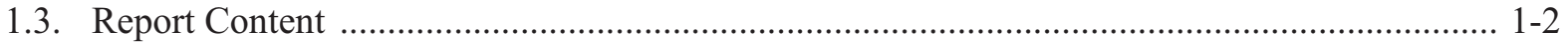

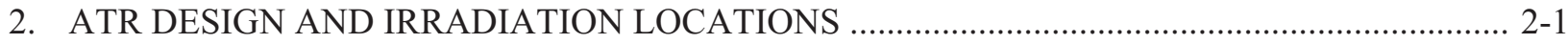

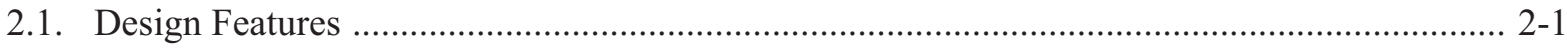

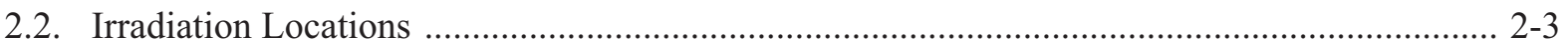

3. TEST REACTOR DESIGN PARAMETERS AND MISSIONS …............................................ 3-1

4. INTERNATIONAL DEVELOPMENT EFFORTS …............................................................... 4-1

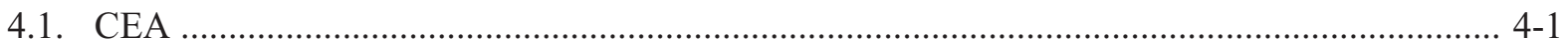

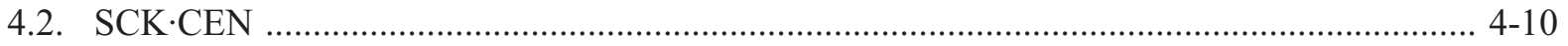

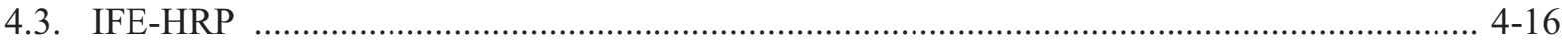

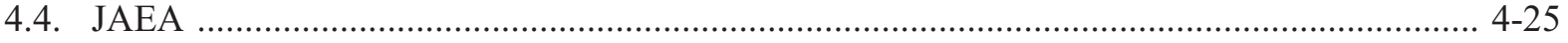

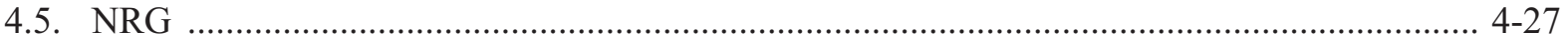

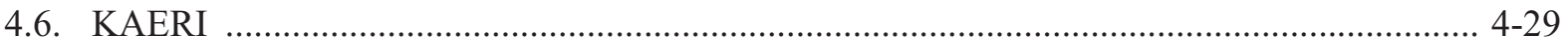

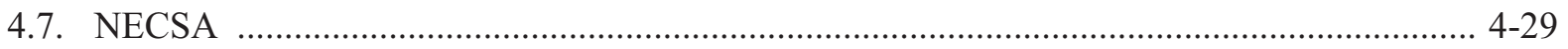

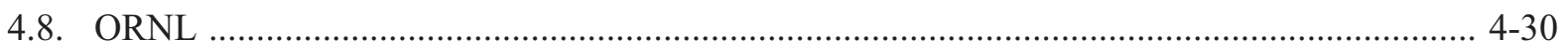

5. PATH FORWARD FOR ENHANCED ATR INSTRUMENTATION .......................................... 5-1

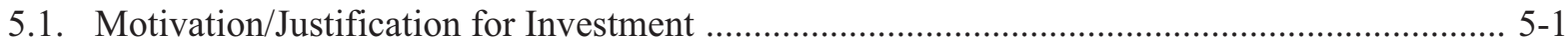

5.2. Currently Available ATR Instrumentation ......................................................................... 5-2

5.3. Current Prioritization for Instrumentation Development ....................................................... 5-5

6. DEVELOPMENT - IDAHO NATIONAL LABORATORY ….................................................. 6-1

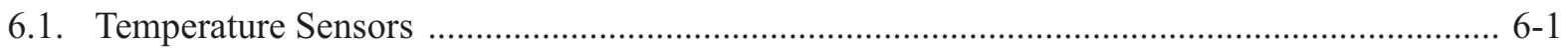

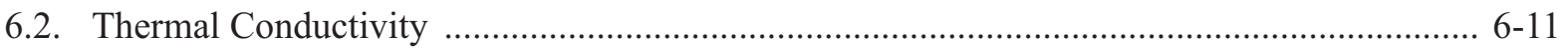

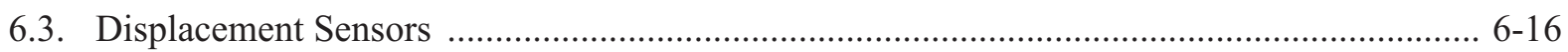

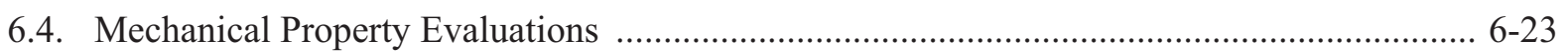

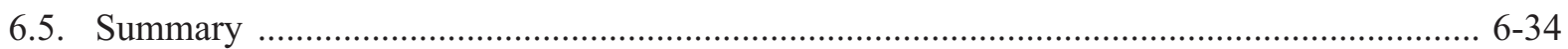

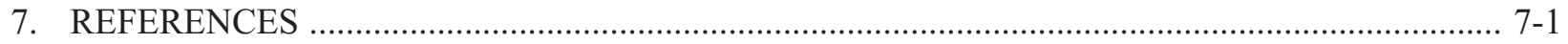


INL/EXT-08-13985 


\section{FIGURES}

ES-1 Current schedule for ATR NSUF advanced instrumentation research and development. ......... xvii

2-1 ATR core cross section identifying irradiation locations. ..................................................... 2-3

2-2 Representative static capsule experiment containing samples stacked in aluminum baskets. .... 2-4

2-3 ATR instrumented lead experiment configuration. ........................................................... 2-5

2-4 Cross section of the in-core portion of a typical pressurized water loop experiment. ............... 2-6

2-5 Pressurized water loop experiment and associated equipment. ............................................. 2-7

3-1 Test trains under development for JHR. .................................................................... 3-3

4-1 In-pile instrumentation needs for future irradiation experiments. ......................................... 4-1

4-2 CEA-developed sub-miniature fission chamber ................................................................ 4-3

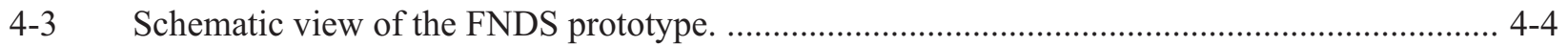

4-4 Partial view of the FICTIONS device to be irradiated in the BR2 reactor .............................. 4-5

4-5 THERMEX experiment device: stainless steel capsule (1), graphite barrel (3) filled with pure copper (2), additional electric heating elements (4), thermocouples (5) ....................................... 4-6

4-7 Proposed sensor for detecting elongation and diameter changes in OSIRIS testing. ................ 4-8

4-6 Wiring schematic for LVDTs using the five-wire method. ................................................... 4-8

4-8 CEA counter-pressure sensor for detecting fission gas release amount. ................................. 4-9

4-9 Principle of in-pile fission gas release acoustic measurement. ............................................... 4-10

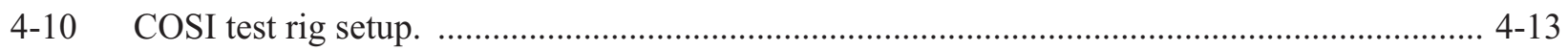

4-11 Representative results from COSI-Change in loss for the STU2 fiber (22 days corresponds to

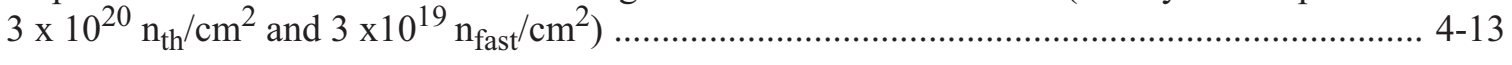

4-12 Optical fiber based elongation detection sensor developed by CEA and SCK-CEN. ............. 4-14

4-13 Schematic of tensile test module: (1) gas line, (2) pneumatic loading unit, (3) firm specimen fixing point, (4) specimen, (5) movable specimen fixing point, (6) LVDT plunger and

(7) LVDT holder.

4-14 Tensile test rig for BR-2 irradiations: (a) simplified layout and operational features including necessary instrumentation; and (b) final assembly of test module prior to installation in the test rig. $\quad 4-16$

4-15 High temperature calibration device of the pneumatic loading unit. .................................... 4-16

4-16 Principle design of a Linear Voltage Differential Transformer. …........................................ 4-18

4-17 Fuel thermal conductivity derived from fuel centerline temperature measurements. .............. 4-19

4-18 Thermal expansion thermometer. .......................................................................................... 4-20

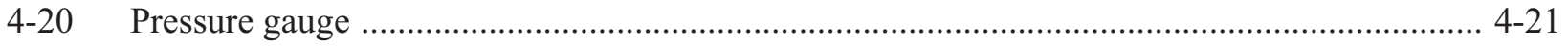

4-19 Fuel stack elongation detector. ................................................................................. 4-2

4-21 Representative HRP fuel pellet cladding interaction or crud deposition test rig. .................. 4-22 
4-22 Diameter gauge used at HRP.

4-24 Crack growth test rig

4-23 Fuel rod diameter traces showing cladding creep down and crud deposition. ........................ 4-24

4-25 I-I type irradiation unit with weight loading equipment ................................................... 4-26

4-26 Signals obtained with optical fiber detector and Au foil activation methods. ........................ 4-27

4-27 Electrical resistivity technique applied over a range of irradiation temperatures. .................. 4-31

5-1 Current schedule for ATR NSUF advanced instrumentation research and development. .......... 5-5

6-1 Representative thermocouple response in $1200^{\circ} \mathrm{C}$ test. ...................................................... 6-2

6-2 HTIR-TCs installed in AGR-1 capsule and representative HTIR-TC and Type N data. .......... 6-3

6-3 Various thermocouple fabrication processes. ......................................................................... 6-4

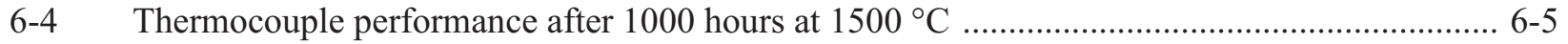

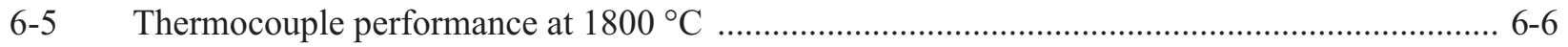

6-6 Setup for annealing and measuring electrical resistivity of $\mathrm{SiC}$ temperature monitors. ............ 6-7

6-7 Fiber optic pressure sensor tip diagram. ........................................................................... 6-9

6-8 Sensitivity of pressure sensors in OSURR test ( $\mathrm{T}$ designates resistance heating, $\mathrm{R}$ designates gamma heating; $0 \mathrm{~T}$ or $0 \mathrm{R}$ designates absence of resistance heating or gamma heating, $\begin{array}{ll}\text { respectively). } & 6-10\end{array}$

6-9 Configuration for evaluating in-pile thermal conductivity techniques. ................................. 6-11

6-10 Setup for evaluating viability of multiple thermocouple method .......................................... 6-13

6-12 Abaqus temperature predictions for different gap heat transfer coefficients. ......................... 6-14

6-11 CFOAM thermal conductivity values obtained using two thermocouple approach (in red) compared with average values from standard laboratory material property measurement $\begin{array}{lr}\text { systems (in blue). } & 6-14\end{array}$

6-13 Typical time versus temperature plot for hot wire method .................................................. 6-15

6-14 HTTL setup for room temperature evaluation of THWM. .................................................... 6-16

6-15 Setup for LVDT calibration and long duration performance evaluations. ............................. 6-18

6-16 Calibration data for 'standard' and 'non-standard' $500{ }^{\circ} \mathrm{C}$ calibration data. ........................... 6-19

6-17 Comparison of LVDT response during long duration testing at $500^{\circ} \mathrm{C}$. .............................. 6-20

6-18 Typical setup for detecting sample length changes with an ultrasonic transducer. ................. 6-21

6-20 Candidate magnetostrictive sleeve designs investigated. ................................................... 6-22

6-19 UT testing equipment evaluating specimen attached to acoustic horn and $30 \mathrm{ft}$ wave guide. .. 6-22

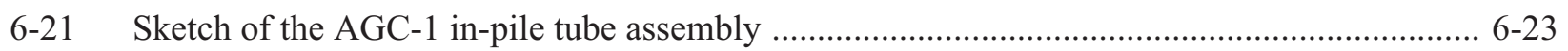

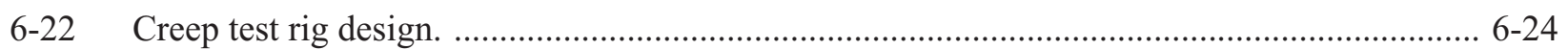

6-23 Estimated stress for candidate specimen sizes assuming 2250 psi test pressure. .................. 6-25

6-24 Schematic of test rig positioned in autoclave for testing. ..................................................... 6-27

6-25 Pumping system to pressurize autoclave coolant. ............................................................... 6-28 
6-26 Section and exterior views of a passively loaded, double cantilever beam crack growth specimen used for in-core EAC experiments

6-28 Isometric and dimensioned drawing of proposed crack growth specimen.

6-27 Cutaway 3-D rendering of an in-core crack growth measurement test rig incorporating two crack growth specimens with two ECP electrodes. Note that this design is for the MITR, but it is anticipated that a similar concept would easily fit within an ATR PWR loop............

6-29 Isometric and dimensioned drawing of proposed crack growth specimen. 6-33 
INL/EXT-08-13985 


\section{TABLES}

ES-1 Instrumentation available at ATR and proposed advanced technologies.................................

ES-2 Instrumentation technologies at IFE-HRP, CEA, SCK-CEN, and JAEA ................................

ES-3 ATR NSUF sensor development and evaluation effort status........................................... xviii

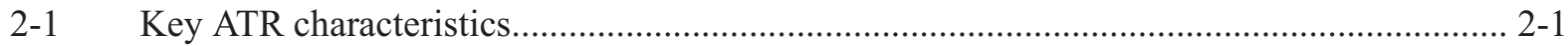

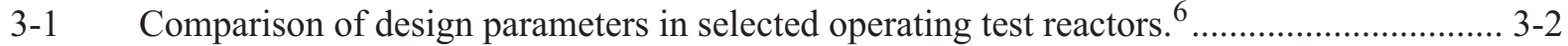

3-2 Representative research reactor irradiation programs................................................... 3-4

4-1 Current INSNU in-pile instrumentation research ..................................................... 4-2

4-2 Single mode and multimode optical fibers tested in OSIRIS COSI test.......................... 4-12

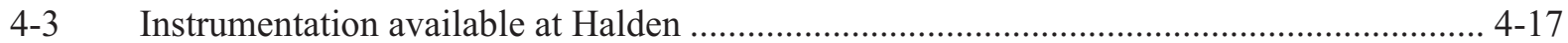

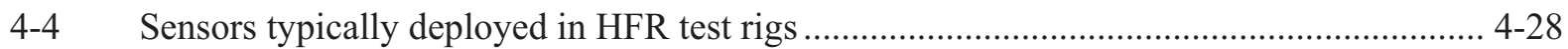

5-1 Funding sources and potential collaborators for INL instrumentation elements................. 5-2

5-2 Current and developmental instrumentation for ATR irradiations..................................... 5-3

5-3 Candidate sensors to Enhance ATR User Irradiations ..................................................... 5-7

6-1 Current and planned ATR NSUF sensor development and evaluation efforts...................... 6-1

6-2 Room temperature results from THWM probe.......................................................... 6-16

6-3 Representative ATR test conditions compared with candidate LVDT characteristics........ 6-17

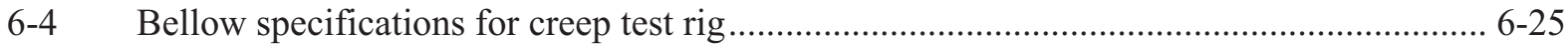

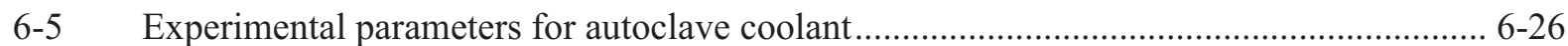

6-6 Bellow Specification for Use in In-Pile Crack Growth Test Rig ..................................... 6-33 
INL/EXT-08-13985 


\section{EXECUTIVE SUMMARY}

The Department of Energy (DOE) designated the Advanced Test Reactor (ATR) as a National Scientific User Facility (NSUF) in April 2007 to support the growth of nuclear science and technology in the United States (U.S.) By attracting new research users - universities, laboratories, and industry - the ATR will facilitate basic and applied nuclear research and development, further advancing the nation's energy security needs. A key component of the ATR NSUF effort is to develop new in-pile instrumentation techniques that are capable of providing real-time measurements of key parameters during irradiation. It is recognized that new in-pile instrumentation will enhance the ATR's ability to attract new customers from the commercial power, defense, and manufacturing sectors. This report identifies what instrumentation is needed and presents a strategy for obtaining these sensors. Progress toward implementing this strategy is also reported.

As noted within this document, the ATR is unique with respect to irradiation testing capabilities. The test volumes and flux levels in each of its irradiation locations [Static Capsules, Instrumented Lead Tests, and Pressurized Water Reactor (PWR) loops] are unsurpassed by few, if any, test reactors in the world. Despite its long history for developing highly specialized instrumentation to meet demands of customers conducting unique tests in one-of-a-kind test facilities, INL instrumentation research funding decreased significantly in the 1980s when large nuclear test facility programs ended. Until recently, ATR irradiations relied primarily on commercial vendors for instrumentation.

In 2004, an effort was restarted that allowed INL to develop unique instrumentation required for ATR irradiations. INL efforts to enhance ATR instrumentation began by first completing a review to identify instrumentation available to users at other test reactors located in the U.S. and abroad. Table ES-1 summarizes results from this review. The column labeled "Technology Available at ATR" indicates the types of sensors currently available to ATR users. The column "Proposed Advanced Technology" includes two categories: "Available at Other Reactors" identifies several technologies employed at other test reactors that could be adapted to enhance ATR instrumentation capabilities. The column labeled "Developmental" under "Proposed Instrumentation Advancement" lists developmental or non-nuclear technologies that could be used in ATR irradiation tests. Technologies listed in this column are considered to be less "ready" for implementation. Blue text denotes the instrumentation currently being pursued as part of ATR NSUF research activities, and red text denotes new instrumentation developed by INL and deployed in the ATR. Note that many of these instrumentation development efforts are in collaboration with other organizations. The instrumentation currently being evaluated for the ATR NSUF (denoted by blue text in Table ES-1) was selected based on anticipated user needs and 'technology readiness' (providing ATR users needed instrumentation in the near-term). 
Table ES-1. Instrumentation available at ATR and proposed advanced technologies.

\begin{tabular}{|c|c|c|c|c|c|c|}
\hline \multirow[b]{2}{*}{ Parameter } & \multicolumn{3}{|c|}{ Location } & \multirow[b]{2}{*}{ ATR Technology } & \multicolumn{2}{|c|}{ Proposed Advanced Technology } \\
\hline & \begin{tabular}{|c|} 
Static \\
Capsule
\end{tabular} & $\begin{array}{l}\text { Instr. } \\
\text { Lead }\end{array}$ & $\begin{array}{l}\text { PWR } \\
\text { Loop }\end{array}$ & & $\begin{array}{l}\text { Available at Other } \\
\text { Reactors }\end{array}$ & Developmental \\
\hline \multirow[t]{2}{*}{ Temperature } & $\checkmark$ & $\checkmark$ & $\checkmark$ & $\begin{array}{l}\text {-Melt wires (peak) } \\
\text {-Paint spots (peak) } \\
\text {-SiC Temperature } \\
\text { Monitors (range) }\end{array}$ & & -Wireless ${ }^{a}$ \\
\hline & & $\checkmark$ & $\checkmark$ & $\begin{array}{l}\text {-Thermocouples } \\
\text { (Type N, K, C }{ }^{b} \text {, and } \\
\text { HTIR-TCs) }\end{array}$ & & $\begin{array}{l}\text { - Fiber Optics } \\
\text {-Ultrasonic Thermometers }\end{array}$ \\
\hline $\begin{array}{l}\text { Thermal } \\
\text { Conductivity }\end{array}$ & & $\checkmark$ & $\checkmark$ & $\begin{array}{l}\text {-Out-of-pile } \\
\text { examinations }\end{array}$ & $\begin{array}{l}\text {-Degradation using signal } \\
\text { changes in thermocouples }\end{array}$ & -Hot wire techniques \\
\hline \multirow[t]{2}{*}{$\begin{array}{l}\text { Fluence } \\
\text { (neutron) }\end{array}$} & $\checkmark$ & $\checkmark$ & $\checkmark$ & $\begin{array}{l}\text {-Flux wires (Fe, Ni, } \\
\mathrm{Nb})\end{array}$ & -Activating foil dosimeters & \\
\hline & & $\checkmark$ & $\checkmark$ & & $\begin{array}{l}\text {-Self-Powered Neutron } \\
\text { Detectors (SPNDs) } \\
\text {-Subminiature / miniature } \\
\text { fission chambers }\end{array}$ & \\
\hline $\begin{array}{l}\text { Gamma } \\
\text { Heating }\end{array}$ & & $\checkmark$ & $\checkmark$ & & $\begin{array}{l}\text {-Degradation using signal } \\
\text { changes in thermocouples }\end{array}$ & \\
\hline \multirow[t]{2}{*}{ Dimensional } & $\checkmark$ & $\checkmark$ & $\checkmark$ & $\begin{array}{l}\text {-Out-of-pile } \\
\text { examinations }\end{array}$ & & \\
\hline & & $\checkmark$ & $\checkmark$ & & $\begin{array}{l}\text {-LVDTs (stressed and } \\
\text { unstressed) } \\
\text {-Diameter gauge } \\
\text {-Hyper-frequency } \\
\text { resonant cavities }\end{array}$ & $\begin{array}{l}\text { - Ultrasonic Transducers } \\
\text {-Fiber Optics }\end{array}$ \\
\hline \begin{tabular}{|l|} 
Fission Gas \\
(Amount, \\
Composition)
\end{tabular} & & $\checkmark$ & $\checkmark$ & $\begin{array}{l}\text {-Gas } \\
\text { Chromatography } \\
\text {-Pressure sensors } \\
\text {-Gamma detectors / } \\
\text { Sampling }\end{array}$ & $\begin{array}{l}\text {-LVDT-based pressure } \\
\text { gauge }\end{array}$ & $\begin{array}{l}\text {-Acoustic measurements } \\
\text { with high-frequency } \\
\text { echography }\end{array}$ \\
\hline $\begin{array}{l}\text { Loop } \\
\text { Pressure }\end{array}$ & & & $\checkmark$ & $\begin{array}{l}\text {-Differential pressure } \\
\text { transmitters } \\
\text {-Pressure gauges } \\
\text { with impulse lines }\end{array}$ & & \\
\hline $\begin{array}{l}\text { Loop } \\
\text { Flowrate }\end{array}$ & & & $\checkmark$ & $\begin{array}{l}\text {-Flow venturis } \\
\text {-Orifice plates }\end{array}$ & & \\
\hline $\begin{array}{l}\text { Loop Water } \\
\text { Chemistry }\end{array}$ & & & $\checkmark$ & $\begin{array}{l}\text {-Off-line sampling / } \\
\text { analysis }\end{array}$ & $\begin{array}{l}\text {-Electrical chemical } \\
\text { potential probes }\end{array}$ & \\
\hline $\begin{array}{l}\text { Crud } \\
\text { Deposition }\end{array}$ & & & $\checkmark$ & $\begin{array}{l}\text {-Out-of-pile } \\
\text { examinations }\end{array}$ & $\begin{array}{l}\text {-Diameter gauge with } \\
\text { neutron detectors and } \\
\text { thermocouples }\end{array}$ & \\
\hline $\begin{array}{l}\text { Crack Growth } \\
\text { Rate }\end{array}$ & & & $\checkmark$ & $\begin{array}{l}\text {-Out-of-pile } \\
\text { examinations }\end{array}$ & $\begin{array}{l}\text {-Direct Current Potential } \\
(\mathrm{DCP}) \text { drop technique }\end{array}$ & \\
\hline
\end{tabular}

a. Although listed under temperature, wireless technologies could be pursued for many parameters.

b. Type C thermocouple use requires a "correction factor" to correct for decalibration during irradiation.

For example, other test reactors have sensors available for real-time detection of parameters such as neutron flux (thermal and fast) and geometry changes (length and diameter). As indicated by the blue text in Table ES-1, efforts are underway to explore using these technologies at the ATR. However, it should be noted that adapting instrumentation used at other test reactors often 
requires laboratory demonstrations because of ATR-specific irradiation conditions (e.g., higher neutron fluxes, higher temperatures, etc.) and test capsule geometries.

Section 4 provides detailed information about instrumentation available and under development at other test reactors. Table ES-2 highlights existing and developmental sensors provided by four countries with sophisticated instrumentation available at their test reactors. As reported in Section 4 of this document, several test reactor programs in Europe and Asia, such as the Institute for Energy Technology at the Halden Reactor Program (IFE-HRP) have maintained their instrumentation development and evaluation research capability. The Japan Atomic Energy Agency and Studiecentrum voor Kernenergie - Centre d'Étude de l'énergie Nucléaire (SCK·CEN) also offer a suite of instrumentation to users performing irradiations in their test reactors. Finally, the french Atomic Energy Commission (CEA), which supports the existing OSIRIS test reactor and the new Jules Horowitz Reactor, not only offer users a suite of instrumentation, but are rapidly trying to increasing their capabilities. Clearly, if the INL wishes the ATR to remain competitive, enhanced instrumentation must be made available to its users.

Table ES-2. Instrumentation technologies at IFE-HRP, CEA, SCK-CEN, and JAEA

\begin{tabular}{|c|c|c|c|}
\hline \multirow{2}{*}{\begin{tabular}{|c|} 
Research \\
Organization/ \\
Country
\end{tabular}} & \multicolumn{3}{|c|}{ Technology } \\
\hline & Sensor & Parameter Detection & Status \\
\hline \multirow[t]{6}{*}{$\begin{array}{l}\text { Institute for Energy } \\
\text { Technology (IFE- } \\
\text { HRP)/ Norway }\end{array}$} & $\begin{array}{l}\text { LVDT (stressed with } \\
\text { bellows and } \\
\text { unstressed) }\end{array}$ & $\begin{array}{l}\text { Length / Creep- } \\
\text { induced elongation } \\
\text { Diameter }\end{array}$ & $\begin{array}{l}\text { Operational (Enhancements explored with } \\
\text { CEA and INL) }\end{array}$ \\
\hline & $\begin{array}{l}\text { Thermocouples (Type } \\
\mathrm{K}, \mathrm{N} \text {, and C) }\end{array}$ & $\begin{array}{l}\text { Temperature and } \\
\text { Thermal conductivity } \\
\text { degradation }\end{array}$ & $\begin{array}{l}\text { Operational (Subject to high temperature or } \\
\text { transmutation-induced signal degradation) } \\
\text { Can place in previously irradiated fuel rods. }\end{array}$ \\
\hline & SPNDS & $\begin{array}{l}\text { Thermal flux, power, } \\
\text { fuel heatup rate }\end{array}$ & Operational \\
\hline & $\begin{array}{l}\text { Electrical chemical } \\
\text { potential probes }\end{array}$ & Water chemistry & Operational \\
\hline & Gamma thermometers & Gamma flux & Operational \\
\hline & $\begin{array}{l}\text { DCP drop method with } \\
\text { CT specimens and } \\
\text { bellows loading }\end{array}$ & Crack growth & Operational \\
\hline \multirow[t]{5}{*}{$\begin{array}{l}\text { Commissariat à } \\
\text { l’Energie Atomique } \\
\text { (CEA)/France }\end{array}$} & $\begin{array}{l}\text { Fission Chambers } \\
\text { (Miniature and } \\
\text { Subminiature) }\end{array}$ & Thermal and fast flux & $\begin{array}{l}\text { Operational (fast detectors still being qualified } \\
\text { for long duration tests in high fluxes) }\end{array}$ \\
\hline & Activating Foils & Integral flux & $\begin{array}{l}\text { Operational (desires comparisons with other } \\
\text { test reactors) }\end{array}$ \\
\hline & Thermocouples & Temperature & $\begin{array}{l}\text { Type K, N, and C TCs - Operational (Subject } \\
\text { to high temperature or transmutation-induced } \\
\text { degradation); Can place in previously } \\
\text { irradiated fuel rods. } \\
\text { Doped } \mathrm{Mo} / \mathrm{Nb} \text { - Under development (limited } \\
\text { long-duration testing and no irradiation } \\
\text { testing) }\end{array}$ \\
\hline & Piezoelectric & $\begin{array}{l}\text { Fission gas } \\
\text { composition }\end{array}$ & $\begin{array}{l}\text { Under development (evaluation piezoelectric } \\
\text { degradation) }\end{array}$ \\
\hline & $\begin{array}{l}\text { LVDTs (stressed with } \\
\text { bellows and } \\
\text { unstressed) }\end{array}$ & $\begin{array}{l}\text { Length / Creep- } \\
\text { induced elongation } \\
\text { Diameter }\end{array}$ & $\begin{array}{l}\text { Operational with additional development } \\
\text { underway (testing enhanced IFE-HRP LVDTs } \\
\text { with and without bellows) } \\
\text { Under development ((testing enhanced IFE- } \\
\text { HRP LVDTs) }\end{array}$ \\
\hline
\end{tabular}


Table ES-2. Instrumentation technologies at IFE-HRP, CEA, SCK-CEN, and JAEA

\begin{tabular}{|c|c|c|c|}
\hline \multirow{2}{*}{$\begin{array}{l}\text { Research } \\
\text { Organization/ } \\
\text { Country }\end{array}$} & \multicolumn{3}{|c|}{ Technology } \\
\hline & Sensor & Parameter Detection & Status \\
\hline $\begin{array}{l}\text { Studiecentrum voor } \\
\text { Kernenergie } \bullet \text { Centre } \\
\text { d'Étude de l'énergie }\end{array}$ & $\begin{array}{l}\text { Fission Chambers } \\
\text { (down to } 1.5 \mathrm{~mm} \\
\text { diameter) }\end{array}$ & Thermal and fast flux & $\begin{array}{l}\text { Participating in qualification testing, but not } \\
\text { clear that all detectors are available for BR- } 2 \\
\text { tests. }\end{array}$ \\
\hline \multirow[t]{2}{*}{ Nucléaire (SCK·CEN) } & Fiber Optics & Length & Under development \\
\hline & $\begin{array}{l}\text { LVDTs (stressed with } \\
\text { bellows and } \\
\text { unstressed) }\end{array}$ & $\begin{array}{l}\text { Length / Creep- } \\
\text { induced elongation }\end{array}$ & $\begin{array}{l}\text { Participating in qualification testing, but not } \\
\text { clear that all detectors are available for BR- } 2 \\
\text { tests. }\end{array}$ \\
\hline \multirow[t]{6}{*}{$\begin{array}{l}\text { Japan Atomic Energy } \\
\text { Agency / Japan }\end{array}$} & $\begin{array}{l}\text { Fission Chambers }(1.8 \\
\text { mm diameter) }\end{array}$ & $\begin{array}{l}\text { Thermal flux (with U- } \\
235 \text { deposits) }\end{array}$ & $\begin{array}{l}\text { Participating in qualification testing, but not } \\
\text { clear that all detectors are available for BR-2 } \\
\text { tests. }\end{array}$ \\
\hline & SPNDS & $\begin{array}{l}\text { Thermal flux (Rh, Co, } \\
\text { and Pt-40\%Rh } \\
\text { emitters) }\end{array}$ & Operational \\
\hline & Flux wires & $\begin{array}{l}\text { Integral fast (Fe) and } \\
\text { thermal (AL-Co, V-Co, } \\
\text { and Ti-Co) flux }\end{array}$ & \\
\hline & $\begin{array}{l}\text { Thermocouples (Type } \\
\mathrm{K}, \mathrm{N} \text {, and C) }\end{array}$ & Temperature & $\begin{array}{l}\text { Operational (Subject to high temperature or } \\
\text { transmutation-induced signal degradation) } \\
\text { Can place in previously irradiated fuel rods. }\end{array}$ \\
\hline & $\begin{array}{l}\text { LVDT (stressed with } \\
\text { bellows and } \\
\text { unstressed) }\end{array}$ & $\begin{array}{l}\text { Length / Creep- } \\
\text { induced elongation } \\
\text { Diameter }\end{array}$ & $\begin{array}{l}\text { Operational (using Japanese-made LVDTs } \\
\text { and bellows) }\end{array}$ \\
\hline & $\begin{array}{l}\text { DCP drop method with } \\
\text { CT specimens and } \\
\text { bellows loading }\end{array}$ & Crack growth & Operational \\
\hline
\end{tabular}

It should be noted that the philosophy for obtaining sensors differs in these four countries. Although JAEA does not fabricate any sensors at their own facilities, all sensors are procured from Japanese vendors. IFE-HRP fabricates many of their own sensors, such as Linear Variable Differential Transformer (LVDT)-based detection technologies. Although IFE-HRP has in-house capabilities for fabricating Self-Powered Neutron Detectors (SPNDs) and thermocouples, they often procure these sensors from foreign vendors. SCK-CEN appears to procure all sensors from external vendors, and CEA appears to primarily focus on procuring sensors from French vendors, although some exceptions exist such as the LVDTs obtained from IFE-HRP. At this point, it is planned for INL to maintain some in-house capability but to rely on vendors with proven technologies. Nevertheless, it is planned to identify multiple sources for each type of detector pursued by INL.

An instrumentation research and development plan was developed in 2007 so that ATR users have access to enhanced real-time in-pile sensors, comparable to (and, in some cases, superior to) that available at other materials and test reactors, by 2015. Figure ES-1 presents the schedule for developing and demonstrating this instrumentation. There are three major activities identified: "Nearer-Term Instrumentation Development", "Developmental Technologies", and "Irradiation Capsule / Test Train Deployment". Qualitative judgments with respect to ATR capabilities compared to other test reactors are shown at the bottom of this figure. As indicated, it is hoped to have comparable instrumentation by Fiscal Year 2012 (FY12) and "world class" (e.g., comparable, and 
in some cases, superior) irradiation capabilities by FY15. As noted in Section 5, sensor development activities have been prioritized based on user need and technology readiness. In addition, sensor development and evaluation activities rely heavily on collaborations with foreign organizations and universities. Collaborations with other research organizations, such as IFE-HRP and CEA, have been established by INL to maximize the benefit from research expenditures.

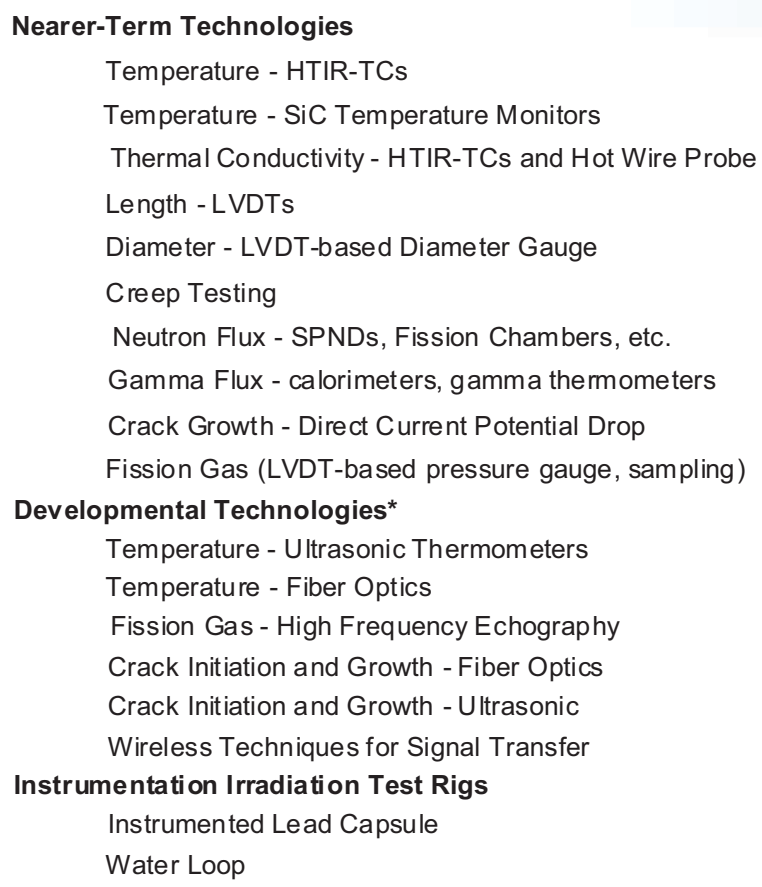

Key parameter instrumentation comparable to other test reactors

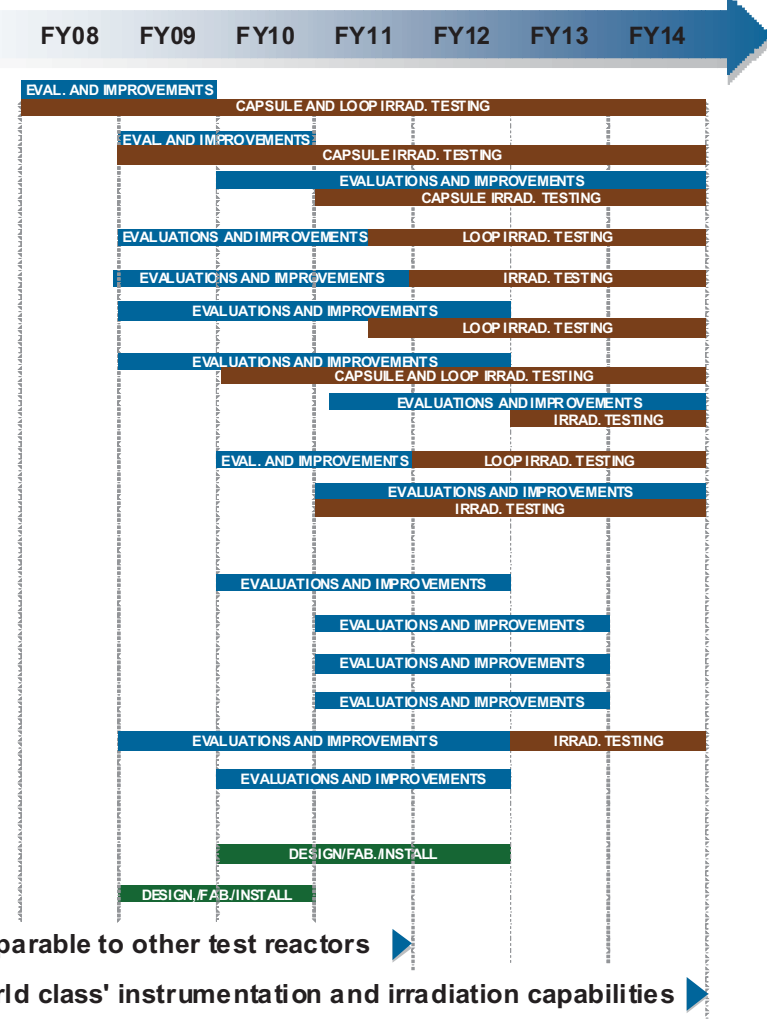

*Irradiation testing for some technologies to be determined based on evaluation results and user priorities.

Figure ES-1. Current schedule for ATR NSUF advanced instrumentation research and development.

Table ES-3 summarizes the status of on-going sensor development and evaluation efforts at INL shown in Figure ES-1. Most of these activities are conducted in INL's High Temperature Test Laboratory (HTTL) which has specialized equipment and trained staff for sensor fabrication and evaluation. As noted above, many of these activities are collaborative efforts with other research organizations, such as IFE-HRP and CEA. In addition, collaborations have also been initiated with universities possessing specialized capabilities in sensor development and evaluation areas, such as the Massachusetts Institute of Technology (MIT), Idaho State University (ISU), Utah State University (USU), and the Pennsylvania State University (PSU). More detailed information about the status of various sensor development activities are provided in Section 6. 
Table ES-3. ATR NSUF sensor development and evaluation effort status.

\begin{tabular}{|c|c|c|}
\hline Parameter & Sensor & Status \\
\hline \multirow[t]{3}{*}{ Temperature } & $\begin{array}{l}\text { High Temperature Irradia- } \\
\text { tion Resistant Thermocou- } \\
\text { ples (HTIR-TCs) }\end{array}$ & $\begin{array}{l}\text { Initial out-of-pile testing completed. In-pile testing (in the AGR-1 gas } \\
\text { reactor fuel irradiation test) and sensor enhancement evaluations } \\
\text { underway to increase reliability for higher temperature (up to } \\
1800{ }^{\circ} \mathrm{C} \text { applications) }\end{array}$ \\
\hline & $\begin{array}{l}\text { Silicon Carbide Tempera- } \\
\text { ture Monitors }\end{array}$ & $\begin{array}{l}\text { Initial in-pile irradiations underway. Development and evaluation of } \\
\text { post-irradiation measurement capability underway. }\end{array}$ \\
\hline & Fiber-Optics $^{a}$ & $\begin{array}{l}\text { Initial testing completed by a vendor. Additional out-of-pile and in-pile } \\
\text { testing investigated as part of several STTR/SBIR projects. Because } \\
\text { of cost considerations, Phase II R\&D to be pursued by a vendor at } \\
\text { the MIT research reactor. }\end{array}$ \\
\hline \multirow[t]{2}{*}{$\begin{array}{l}\text { Thermal } \\
\text { Conductivity }\end{array}$} & Dual thermocouples & $\begin{array}{l}\text { Initial laboratory testing underway as a collaborative effort between } \\
\text { IFE-HRP, USU, and INL. Anticipate that inclusion of HTIR-TCs could } \\
\text { allow detection at higher temperatures than current methods used by } \\
\text { IFE-HRP. }\end{array}$ \\
\hline & Hot-wire method & $\begin{array}{l}\text { Initial laboratory testing underway as a collaborative effort with USU } \\
\text { and INL. Anticipated that inclusion of HTIR-TCs could allow detec- } \\
\text { tion at higher temperatures. }\end{array}$ \\
\hline \multirow{2}{*}{$\begin{array}{l}\text { Elongation, Crud } \\
\text { deposition, Corro- } \\
\text { sion }\end{array}$} & LVDTs $^{a}$ & $\begin{array}{l}\text { Out-of-pile testing underway as a collaborative effort between IFE- } \\
\text { HRP and INL. }\end{array}$ \\
\hline & $\begin{array}{l}\text { Ultrasonic Transducers } \\
\text { (UTs) }\end{array}$ & $\begin{array}{l}\text { Scoping tests completed and prototype conceptual design devel- } \\
\text { oped; additional prototype out-of-pile testing funded in FY10 as a } \\
\text { collaborative effort between PSU and INL. }\end{array}$ \\
\hline $\begin{array}{l}\text { In-pile Creep } \\
\text { Test Rig }\end{array}$ & $\begin{array}{l}\text { LVDT-based rig with bel- } \\
\text { lows }\end{array}$ & $\begin{array}{l}\text { Design developed as a collaborative effort between IFE-HRP, } \\
\text { KAERI, and INL. Prototype being manufactured for evaluations in } \\
\text { FY10. }\end{array}$ \\
\hline Neutron Flux & $\begin{array}{l}\text { SPNDs and Fission } \\
\text { Chambers }\end{array}$ & $\begin{array}{l}\text { Proposal for new activity awarded for FY10 as a CEA, ISU, and INL } \\
\text { collaborative effort. }\end{array}$ \\
\hline Crack propagation & $\begin{array}{l}\text { Direct current potential } \\
\text { drop method with CT }^{\text {specimens }^{\text {a }}}\end{array}$ & Preliminary design (based on HRP method) developed by MIT. \\
\hline
\end{tabular}

a. Fiber optics also offer the potential to measure geometry changes and crack propagation.

As indicated Table ES-3 (and in Section 6), all of the instrumentation development activities were completed as planned during FY09. If proposed funding levels are maintained, it is anticipated that the Figure ES-1 schedule for this effort will continue to be fulfilled. 


\section{INTRODUCTION}

The Department of Energy (DOE) designated the Advanced Test Reactor (ATR) as a National Scientific User Facility (NSUF) in April 2007 to support U.S. leadership in nuclear science and technology. By attracting new research users - universities, laboratories, and industry - the ATR will support basic and applied nuclear research and development, further advancing the nation's energy security needs. A key component of the ATR NSUF effort is to prove new in-pile instrumentation techniques that are capable of providing real-time measurements of key parameters during irradiation. This report identifies what instrumentation is needed and presents a strategy for obtaining these sensors. Progress toward implementing this strategy is also reported.

\subsection{Background}

The ATR is a pressurized, light-water moderated, beryllium-reflected research reactor located at the Idaho National Laboratory (INL) Reactor Technology Complex (RTC). Its ability to produce an extremely high neutron flux makes it possible to subject materials to the equivalent of years of radiation exposure, as would take place in a commercial nuclear reactor, in a matter of weeks or months. The ATR core design allows many experiments to run concurrently, with each experiment receiving a different and carefully controlled level of neutron irradiation. Originally commissioned in 1967 to evaluate fuels and materials performance for the Navy Nuclear Propulsion Program, the ATR is expected to continue operating until at least 2050.

As noted above, DOE's decision to designate the ATR as a NSUF is expected to increase the ATR's customer base, although it is anticipated that irradiations will still primarily support nuclear science and technology programs. New in-pile instrumentation will enhance the ATR's ability to attract new customers from the commercial power, defense, and manufacturing sectors.

\subsection{Motivation}

As noted above, it is recognized that new instrumentation techniques are needed to support ATR in-pile irradiations. For decades, irradiation tests at material test reactors (MTRs) have used in-pile instrumentation to measure parameters, such as temperature, dimensional changes, fission gas release, neutron fluence, and gamma heating. However, most in-pile instrumentation was developed decades ago, and efforts to enhance in-pile instrumentation were reduced in the 1980s. Furthermore, in several cases, ATR instrumentation for in-pile testing lags behind instrumentation available at other materials test reactors. Hence, a key component of the ATR NSUF is to develop, fabricate, and demonstrate the performance of new real-time sensor technologies required to measure key parameters for irradiation testing.

As discussed in this report, INL's existing High Temperature Test Laboratory (HTTL) is a unique facility for developing, fabricating, and performing laboratory demonstrations of proposed new instrumentation. This facility already features specialized sensor fabrication and evaluation 
equipment and trained staff with an established reputation for fabricating unique sensors. The HTTL is playing a key role in helping the ATR obtain the instrumentation needed to become a 'world class' NSUF.

\subsection{Report Content}

As a first step in this effort, a review was completed to document what in-pile instrumentation is currently available at the ATR and other material test reactors and what instrumentation could be developed or transferred from other applications to enhance in-pile irradiation testing. This report documents results from this review. Section 2 provides an overview of irradiation locations available in the ATR, what materials are typically irradiated for various experimental configurations, and what instrumentation is typically available for each configuration. Section 3 highlights irradiation capabilities of other test reactors in the U.S. and abroad. As part of this overview, instrumentation typically used in these reactors is described along with efforts to develop new instrumentation to support these test reactors. Section 4 summarizes instrumentation currently used to support test reactor programs and on-going efforts to enhance this instrumentation at non-INL locations. This section also identifies efforts to develop innovative instrumentation that could enhance data obtained from in-pile irradiations and discusses what steps are required to demonstrate their viability. Section 5 outlines a program for obtaining all of the higher priority instrumentation, based on customer input, required for nearterm and long term irradiations at ATR and other test reactors. Where possible, potential collaborators are identified for obtaining this instrumentation. Section 6 summarizes INL progress on accomplishing objectives in the plan presented in Section 5, identifying new in-pile instrumentation researched by INL to support ATR irradiations and reporting on the status of each research effort. References for this document are listed in Section 7. 


\section{ATR DESIGN AND IRRADIATION LOCATIONS}

This section provides an overview of irradiation locations available in the ATR, what materials are typically irradiated in representative experimental configurations, and what instrumentation is typically available for each configuration.

\subsection{Design Features}

The ATR is a versatile tool in which a variety of nuclear reactor, nuclear physics, reactor fuel, and structural material irradiation experiments can be conducted. The cumulative effect of years of irradiation in a commercial power reactor can be duplicated in a few weeks or months in the ATR due to its unique design, power density, and operating flexibility. The reactor was designed to provide a large number of large-volume, high-flux test locations. Key ATR operating characteristics are listed in Table 2-1. 1 through 5

Table 2-1. Key ATR characteristics

\begin{tabular}{|c|c|}
\hline Parameter & Value \\
\hline \multicolumn{2}{|l|}{ Reactor: } \\
\hline Thermal power & $250 \mathrm{MW}_{\mathrm{th}}{ }^{\mathrm{a}}$ \\
\hline Power density & 1.0 MW/liter \\
\hline Maximum thermal neutron flux & $1.0 \times 10^{15} \mathrm{n} / \mathrm{cm}^{2}-\mathrm{sec}^{\mathrm{b}}$ \\
\hline Maximum fast flux & $5.0 \times 10^{14} \mathrm{n} / \mathrm{cm}^{2}-\mathrm{sec}^{\mathrm{b}}$ \\
\hline Number of flux traps & 9 \\
\hline Number of experiment positions & $68^{\mathrm{C}}$ \\
\hline \multicolumn{2}{|l|}{ Core: } \\
\hline Number of fuel assemblies & 40 \\
\hline Fuel material & UAI in aluminum matrix \\
\hline Active length of assemblies & $1.22 \mathrm{~m}$ (4 feet) \\
\hline Number of fuel plates per assembly & 19 \\
\hline Uranium-235 content of an assembly & $1075 \mathrm{~g}$ \\
\hline Total core load & $43 \mathrm{~kg}^{\mathrm{d}}$ \\
\hline \multicolumn{2}{|l|}{ Coolant: } \\
\hline Design pressure & 2.7 MPa (390 psig) \\
\hline Design temperature & $115^{\circ} \mathrm{C}\left(240^{\circ} \mathrm{F}\right)$ \\
\hline \multicolumn{2}{|l|}{ Reactor Coolant: } \\
\hline Light water maximum coolant flow rate & $3.09 \mathrm{~m}^{3} / \mathrm{s}(49,000 \mathrm{gpm})$ \\
\hline Coolant temperature (operating) & $<52^{\circ} \mathrm{C}\left(125^{\circ} \mathrm{F}\right)$ inlet, $71^{\circ} \mathrm{C}\left(160^{\circ} \mathrm{F}\right)$ outlet \\
\hline
\end{tabular}
a. Maximum assigned power. ATR is seldom operated above $110 \mathrm{MW}_{\text {th }}$.
b. Parameters based on the full $250 \mathrm{MW}_{\text {th }}$ power level. Values proportionally reduced for lower reactor power levels.
c. Only 66 available for irradiations.
d. Total U-235 always less due to burn-up. 
Designed to simulate long neutron radiation exposures in a short period of time, the ATR's maximum thermal power rating is $250 \mathrm{MW}_{\text {th }}$ with a maximum unperturbed thermal neutron flux of $1 \times 10^{15} \mathrm{n} / \mathrm{cm}^{2}$-s. Since most contemporary experimental objectives do not require the limits of its operational capability, the ATR typically operates at lower power levels (nominally $110 \mathrm{MW}_{\text {th }}$ ). The ATR operates $\sim 75 \%$ of the year, in cycles that average seven weeks in length, with outages lasting one or two weeks.

The ATR is cooled by pressurized $(2.5 \mathrm{MPa} / 360 \mathrm{psig})$ water that enters the reactor vessel bottom at an average temperature of $52^{\circ} \mathrm{C}\left(125^{\circ} \mathrm{F}\right)$, flows up outside cylindrical tanks that support and contain the core, passes through concentric thermal shields into the open part of the vessel, then flows down through the core to a flow distribution tank below the core. When the reactor is operating at full power, the primary coolant exits the vessel at a temperature of $71^{\circ} \mathrm{C} /\left(160^{\circ} \mathrm{C}\right)$.

Figure 2-1 shows a cross section of the ATR core. This core consists of 40 curved plate fuel elements arranged in a serpentine arrangement, around a $3 \times 3$ array of primary testing locations, the high-intensity neutron flux traps. The unique ATR control device design permits large power variations among its nine flux traps using a combination of control cylinders (drums) and neck shim rods. The beryllium control cylinders contain hafnium plates that can be rotated toward and away from the core, and hafnium shim rods, which withdraw vertically, can be individually inserted or withdrawn for minor power adjustments. Within bounds, the power level in each corner lobe of the reactor can be controlled independently to allow for different power and flux levels in the four corner lobes during the same operating cycle.

In summary, some of the key ATR design features include:

- Large test volumes - up to 48 " long and up to 5.0" diameter

- Large number (e.g., 75) irradiation positions available for testing

- High neutron flux - up to $1 \times 10^{15} \mathrm{n} / \mathrm{cm}^{2}$-s thermal, up to $5 \times 10^{14} \mathrm{n} / \mathrm{cm}^{2}$-s fast

- Variety of fast/thermal flux ratios (0.1 to 1.0$)$

- Constant axial power profile - rotating control drums instead of vertical control rods

- Individual experiment control, including power tilt capability - different power levels for experiments in the same operating cycle

- Frequent experiment changes

- Core internals replacement every 7 to 10 years - all core internal equipment is replaced

- Solid stainless steel reactor vessel position - 48" from the active core region to minimize vessel embrittlement

- High reactor availability

- Accelerated testing for fuels and materials

Clearly, this reactor design offers advantages not available at other test reactors. With additional in-pile instrumentation to support these testing capabilities, it should be possible to more fully utilize features offered by this reactor user facility. 


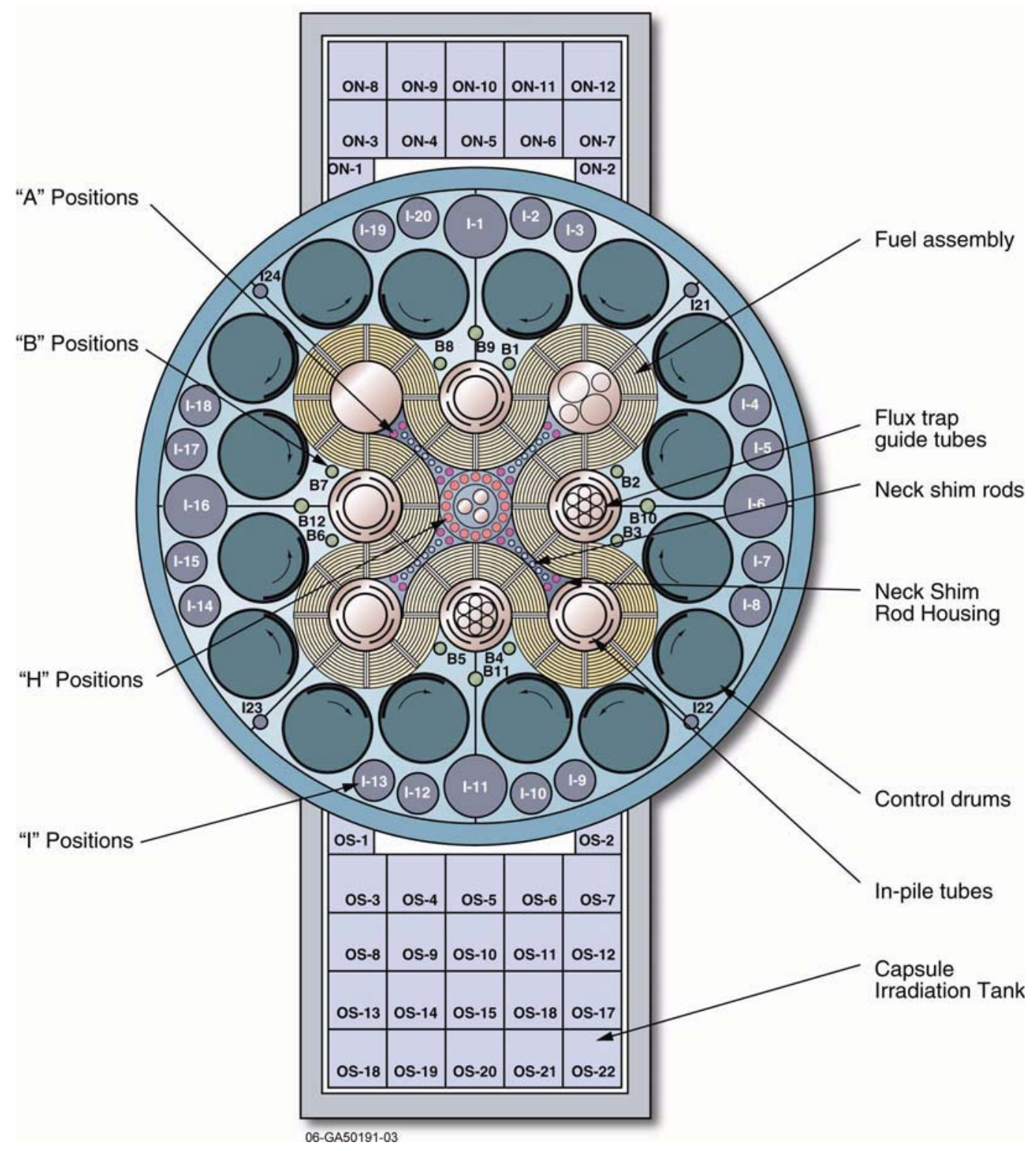

Figure 2-1. ATR core cross section identifying irradiation locations.

\subsection{Irradiation Locations}

As shown in Figure 2-1, the curved fuel arrangement of the ATR places reactor fuel closer on all sides of the flux trap positions than is possible in a rectangular grid. The ATR has nine of these high-intensity neutron flux traps and 66 additional irradiation positions inside the reactor core reflector tank. In addition, there are also two capsule irradiation tanks outside the core with 34 additional low-flux irradiation positions. It should also be noted that a Hydraulic Shuttle Irradiation System (HSIS), more commonly referred to as a "Rabbit", testing capability was recently installed in the ATR to restore the reactor's capability to perform irradiations of small capsules in 
selected "B" positions of the reactor for materials research, rapid activations, isotope production. It is expected that this system will become available to users in 2010.

Irradiated samples are enclosed in test capsules that are then typically placed in a basket to facilitate positioning within the reactor. There are three basic types of test assembly configurations currently used in the ATR:

- Static Capsule Experiment

- Instrumented Lead Experiment

- Pressurized Water Loop Experiment

Brief descriptions of the three types of test configurations are provided below along with representative materials typically irradiated and instrumentation included.

\subsubsection{Static Capsule Experiment}

A static capsule experiment may contain a number of small samples, or particularly, if a large "I" position is used, it may contain engineered components. In static capsule experiments, the material to be irradiated is sealed in aluminum, zircaloy, or stainless steel tubing (see Figure 2-2). The sealed tube is then placed in a holder that sits in a chosen test position in the ATR. Some of the capsule experiments contain material that can be in contact with the ATR primary coolant. Such capsules are in an open configuration without being sealed. Capsules may be any length, up to $122 \mathrm{~cm}$ (48 in.) and may be irradiated in any of the core positions, including the flux traps.

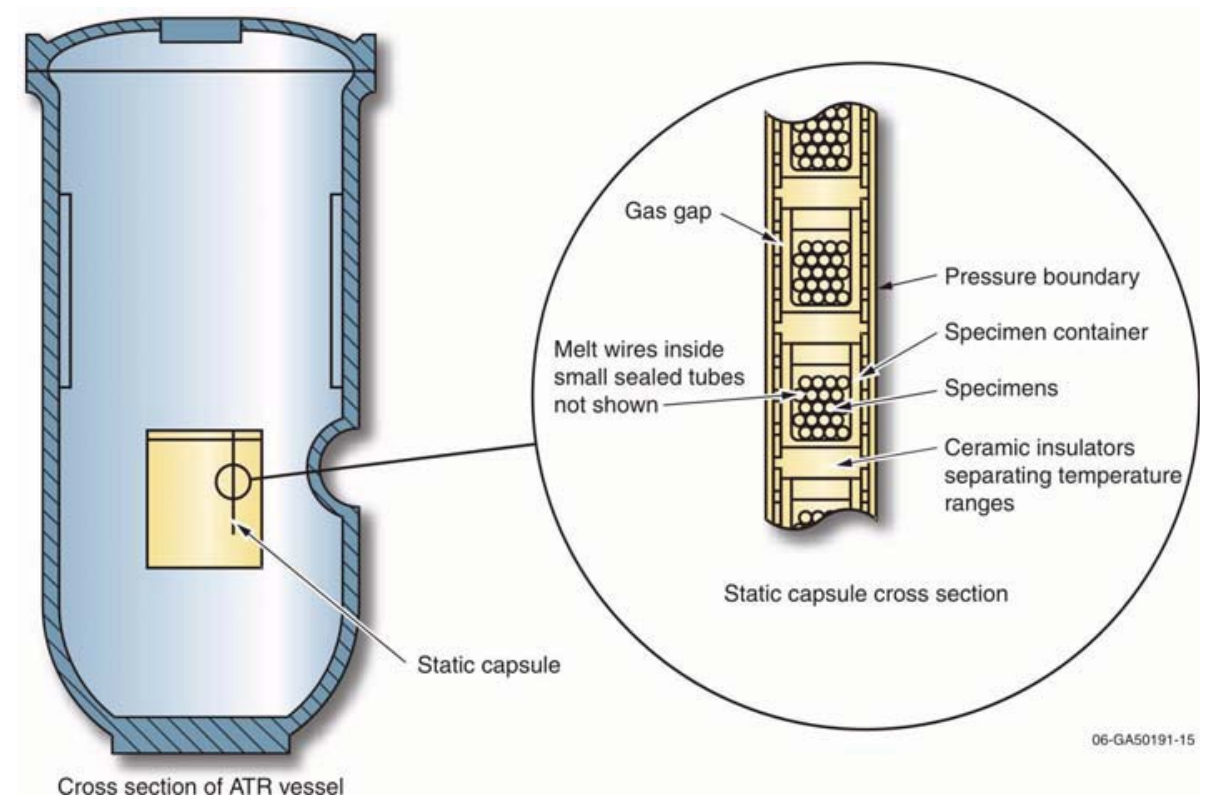

Figure 2-2. Representative static capsule experiment containing samples stacked in aluminum baskets. 
Temperature within a static capsule experiment may be controlled by providing a gas gap with a known thermal conductance. Peak temperatures can be indicated using a series of temperature sensitive paint spots or melt wires. Thermal bonding media such as liquid metals may be used in capsule experiments to keep temperatures uniform inside the experiment. Flux-wire monitors in the experiments can give good measurements of neutron fluence at particular locations.

\subsubsection{Instrumented Lead Experiment}

Active control of experiments and data from test capsules during irradiation is achieved using tubes containing instrumentation cables and temperature control gases in ATR instrumented lead experiments (see Figure 2-3). Such experiments can have instrumentation, such as thermocouples, connected to individual capsules or single specimens. This instrumentation can be used to control and sample conditions within the capsule. For example, temperature control in individual zones is performed by varying the gas mixture (typically helium and neon) in the gas gap that thermally links the capsule to the water-cooled reactor structure.

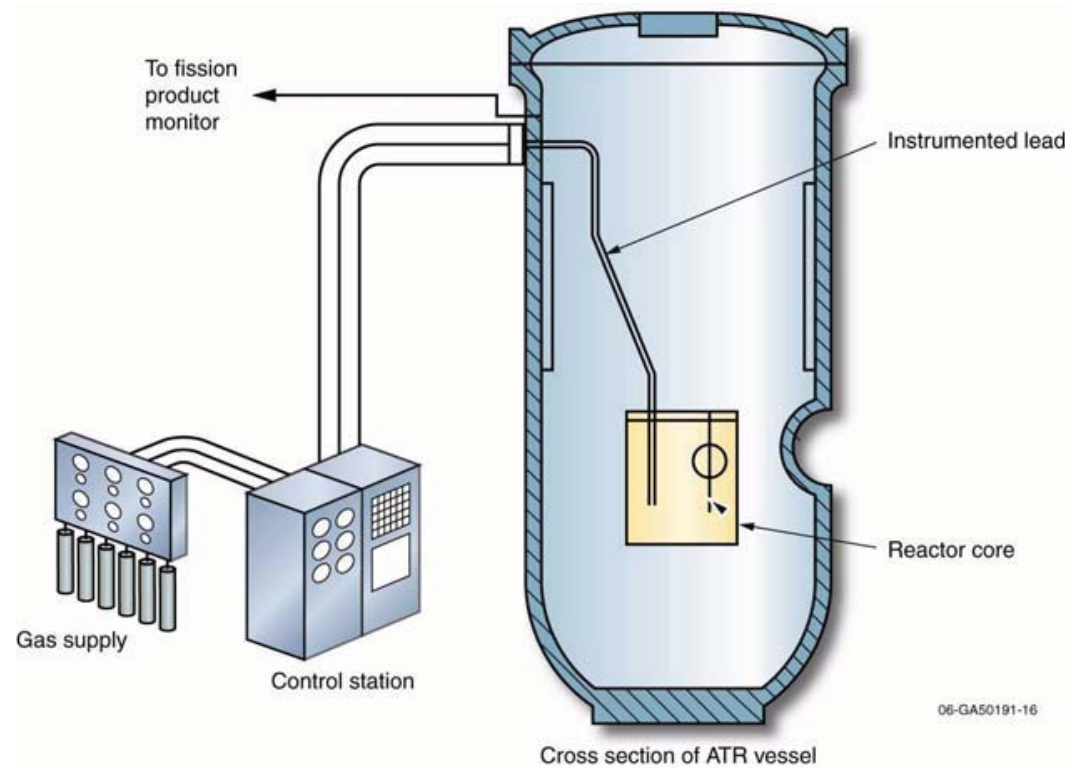

Figure 2-3. ATR instrumented lead experiment configuration.

In addition to temperature, the gas around the test specimen can be monitored in an instrumented lead experiment. In a fueled experiment, the presence of fission gases due to fuel failures or oxidation can be detected via gas chromatography. Instrument leads allow real time display of experimental parameters in the control room.

\subsubsection{Pressurized Water Loop Experiment}

Five of the nine ATR flux traps used for materials and fuels testing are equipped with pressurized water loops (at the NW, N, SE, SW, and W locations). Each of these five loops can be oper- 
ated with different temperatures, pressures, flow rates, or water chemistry requirements. These loops can operate above the standard temperatures and pressures of a commercial PWR power plant. The great advantage of loop tests is the ease with which a variety of samples can be subjected to conditions specified for any PWR design. Many samples can be tested at once (in several loops or one loop, depending on the size of samples) with variations in the samples, thickness of cladding, etc., and the samples can be compared afterward for optimum design.

Figure 2-4 shows the cross section of a typical loop design. Three concentric tubes form the piping assembly for each water loop in the ATR. The assembly penetrates the vessel's bottom closure plate and has an inlet and an outlet below the vessel. Coolant comes up through the innermost tube, the flow tube, and passes the sample. Near the top of the vessel, on four of the five loops, the coolant passes through holes in the flow tube into the annulus enclosed by the pressure tube and returns down that annulus to the outlet. On the fifth loop, the water passes only one way, up through the flow tube and out through the side of the reactor vessel. Helium flows through the annulus enclosed by the outermost tube, which also serves as the insulating jacket. Insulation is essential because the inside of the pressure tube is in contact with loop coolant at temperatures up to $360^{\circ} \mathrm{C}\left(680^{\circ} \mathrm{F}\right)$, whereas the outside of the insulating jacket is in contact with primary system coolant at $52^{\circ} \mathrm{C}\left(125^{\circ} \mathrm{F}\right)$. The helium is monitored for moisture to detect any leaks in the tubes.

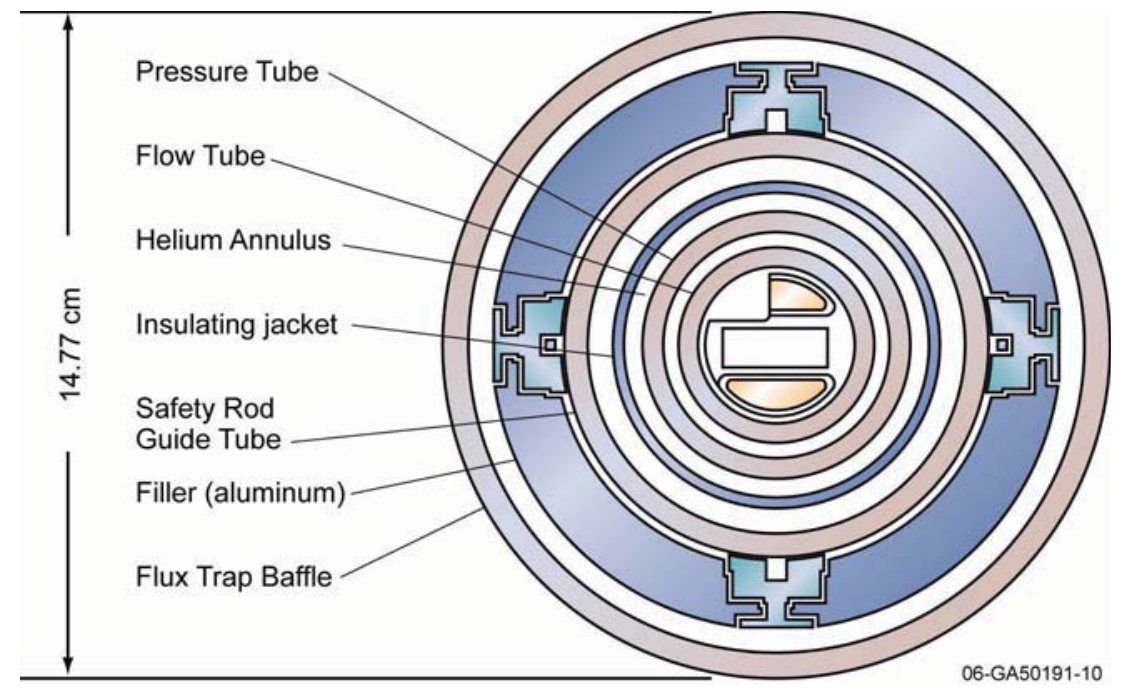

Figure 2-4. Cross section of the in-core portion of a typical pressurized water loop experiment.

Loop cubicles and equipment occupy the space around the reactor on two basement floors. The pressurized water loop equipment includes piping within the reactor vessel and pumps, heat exchangers, a pressurizer, and demineralizers within a shielded cubicle (Figure 2-5). Line heaters are capable of raising the loop coolant temperature from 38 to $360{ }^{\circ} \mathrm{C}\left(100\right.$ to $\left.680{ }^{\circ} \mathrm{F}\right)$ in 3 hours. Normally, these heaters are used to capacity only when preparing the loop for startup. After the reactor begins operation, fission and gamma heating of the samples typically provides much of the required heat. 


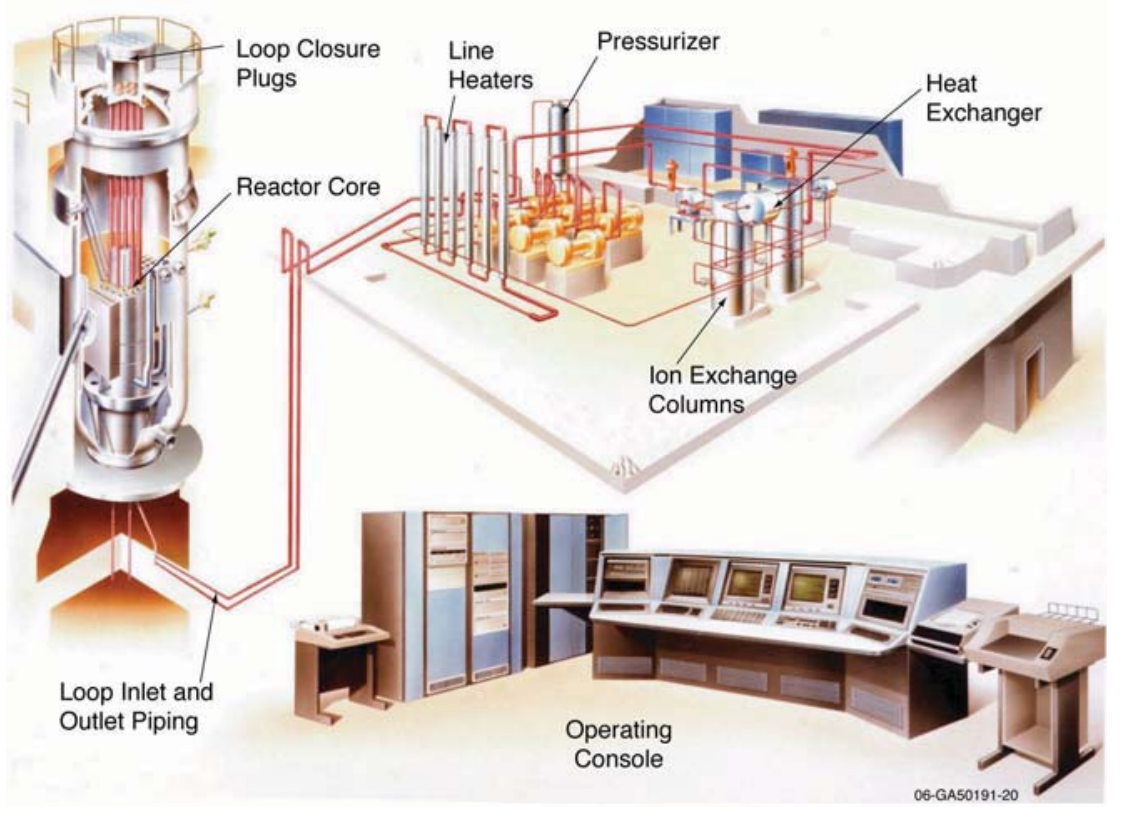

Figure 2-5. Pressurized water loop experiment and associated equipment.

Each loop in the ATR is instrumented to measure and control (both helium and water) coolant flows, temperatures, and pressures and sample test data. Loop instrumentation and controls are located in the southwest portion of the ATR second basement in a controlled environment room. Precise control of the loop coolant temperature is achieved by automatic regulation of the amount of coolant bypassing the loop heat exchangers.

A sample irradiated in an ATR in-pile tube can be subjected to high neutron fluxes, but the fluxes can be controlled. An added refinement is the ease of adjusting the neutron energy spectrum by using shielding. The ability to produce different neutron energy spectra in ATR loops can be valuable.

Another advantage of the ATR loops is the ease with which samples can be changed when the ATR is shutdown. To remove a sample, it is necessary only to remove a shield plug from the transfer plate, disconnect the lead wires to the sample, unlock the closure plug, install a transfer sleeve, and then draw the sample up into a removal cask. 
INL/EXT-08-13985 


\section{TEST REACTOR DESIGN PARAMETERS AND MISSIONS}

Material test reactors and prototype reactors have provided essential support for nuclear power programs for over 50 years. They are needed to develop and qualify new materials and fuels for nuclear power plants. Table 3-1 compares operating parameters for selected test and prototype reactors used (or under construction) throughout the world. Information in this table was primarily obtained from the IAEA Nuclear Research Reactor Database, ${ }^{6}$ which contains information from nearly 280 research reactors (operating, shutdown, and proposed). Although these reactors range in power levels from 0 to several hundred MWt, nearly 200 of them have power levels below 5 MWt. Most of the reactors listed in Table 3-1 achieved criticality in the 1960s (or earlier). Among the operating reactors, there are two exceptions: the Hanaro reactor in South Korea, which went critical in 1995 and the prototype High Temperature Test Reactor (HTTR) in Japan, which went critical in 1998. For illustrative purposes, testing capabilities of selected test reactors are highlighted in this section.

The Jules Horowitz Reactor (JHR), ${ }^{8}$ which is scheduled to go critical in 2014 , is another exception with respect to initial date for achieving criticality. The JHR is being built to replace materials irradiation capabilities of older reactors in Europe as they are retired from service. This $100 \mathrm{MWt}$ reactor is designed to include static capsules, instrumented capsules, and in-pile loops. To support irradiation programs anticipated for the JHR, CEA is developing four types of test trains (see Figure 3-1):

- MADISON - A test train in an in-core loop for fuel testing under nominal LWR (PWR or BWR) conditions.

- CALIPSO - A test train in an in-core sodium potassium loop for material testing under high $(\sim 15)$ dpa and limited thermal gradients $\left(<8^{\circ} \mathrm{C}\right)$

- ADELINE - A test train in an in-pile loop for fuel testing under LWR (BWR or PWR) offnormal conditions (e.g. power ramps) with fission product measurement

- $\quad$ LORELEI - A test capsule for fuel testing under LWR (PWR or BWR) accident (LOCA) conditions to observe phenomena such as clad ballooning or rupture, corrosion, and quench behavior and investigate fission product release.

The above trains are currently in the design and component verification stages. However, all are scheduled to be available when the JHR achieves criticality in 2014.

In addition to the above test trains, CEA has initiated an effort to enhance instrumentation for its users. This effort, which is known as the INSNU (see Section 4.1), was initially launched to improve instrumentation available to all European research reactors. In 2009, the INSNU effort was relocated from Saclay to Cadarache so that it can be better coordinated with the JHR.

It is also worth highlighting the Halden Boiling Water Reactor (HBWR) in this section. Although this reactor is older and its maximum power level $(20 \mathrm{MWt})$ is over an order of magnitude smaller than the ATR, its testing flexibility and the expertise of its staff for instrumenting its tests make this facility an ideal user facility. For decades, organizations within the international community (including the US NRC, vendors such as GE and AREVA, and the US naval reactor 


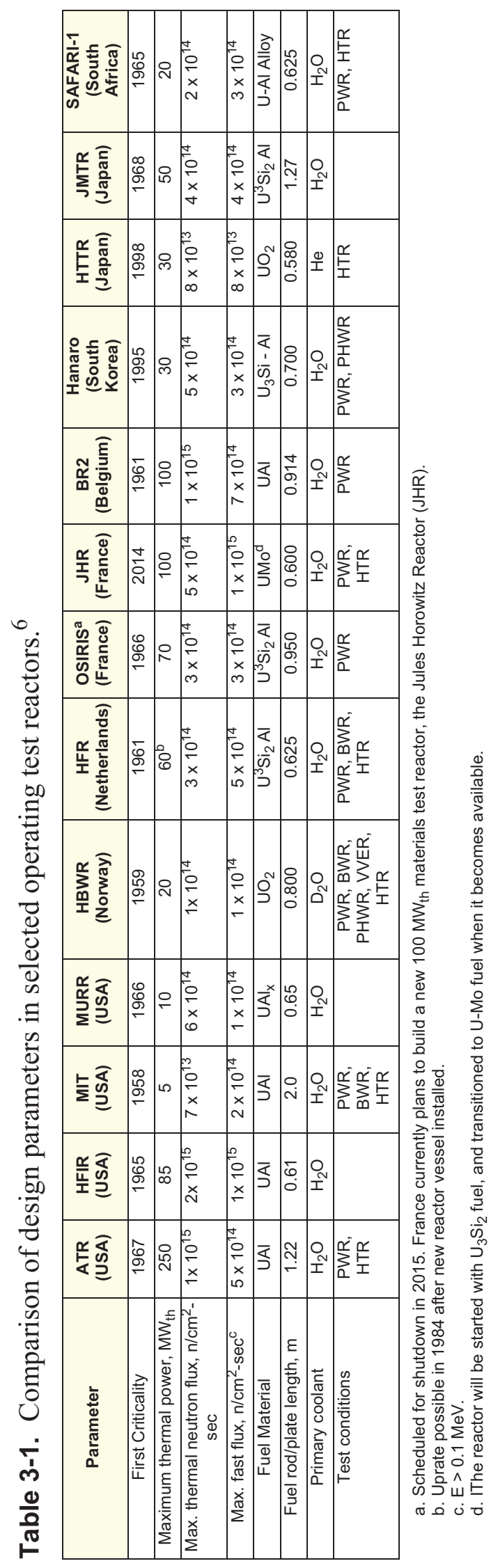




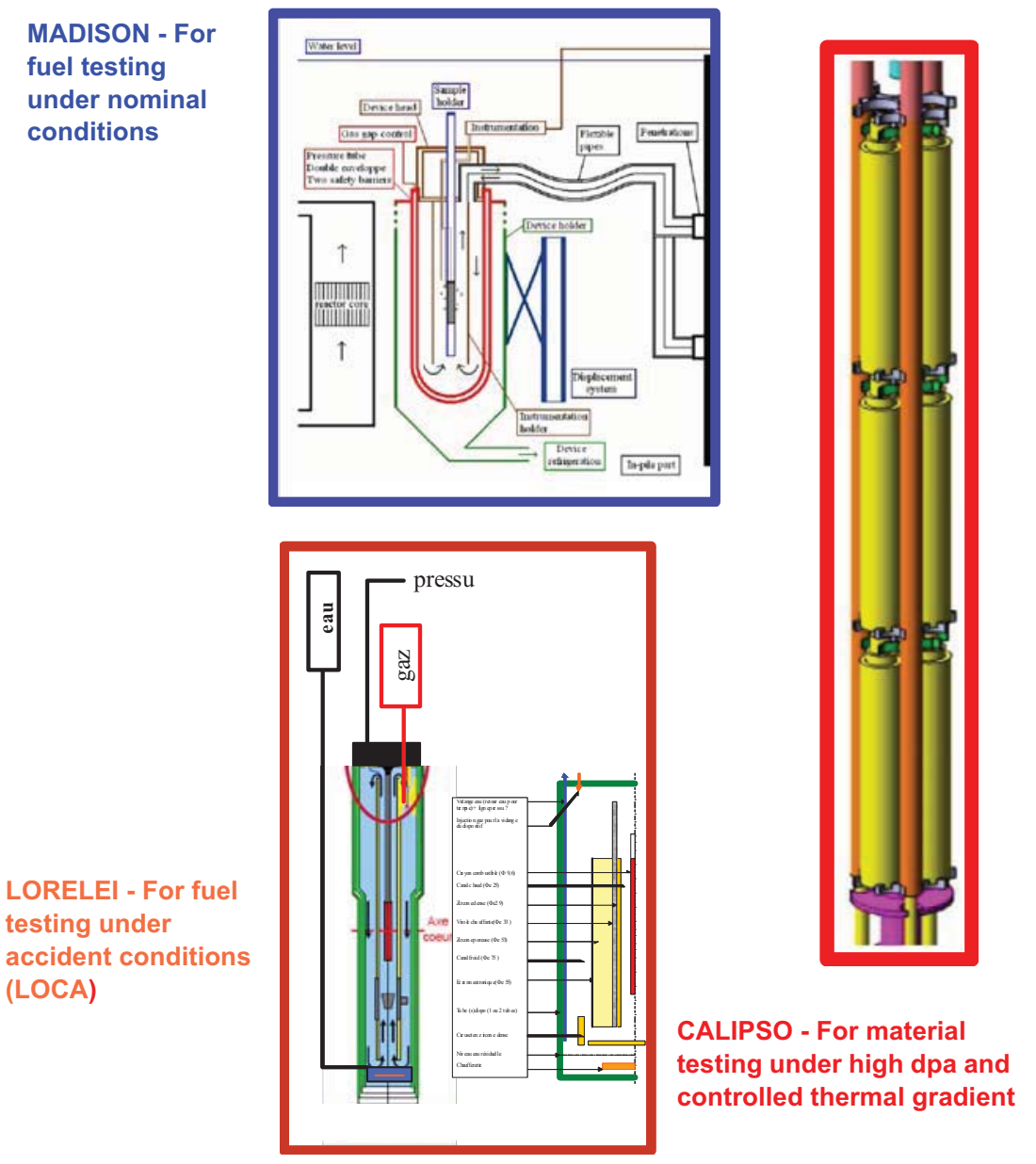

ADELINE - For fuel

testing under off-

normal conditions and

FP online

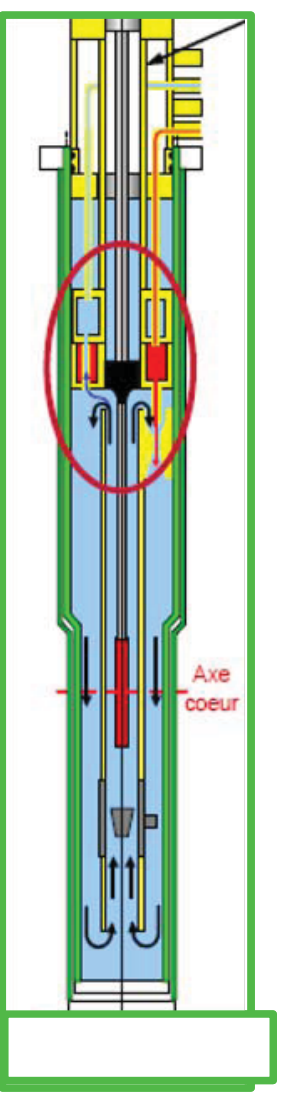

Figure 3-1. Test trains under development for JHR.

program) have utilized this facility for in-pile irradiation needs. Approximately $40 \%$ of HBWR testing is devoted to OECD programs with the remainder sponsored by bilateral agreements between Norway and customers from other countries. ${ }^{9}$ Most of these bilateral agreements allow the HBWR to perform tests for utility customers to address issues related to fuel thermal performance, fuel pellet/clad interactions, fuel fission gas release, reactor vessel embrittlement, structural materials degradation (e.g., corrosion, creep, etc.). As noted in Table 3-1, this reactor has developed loops for simulating BWR, PWR, CANDU, and VVER conditions.

Although other test reactors, such as the HBWR, may currently have superior instrumentation capabilities and more flexible test trains, the ATR can become made competitive by adding additional capabilities required for research programs being performed at other research reactors. Table 3-2 lists typical research and industry programs that materials and test reactors currently support. Many materials and fuels irradiations support research programs for existing LWRs (e.g., PWRs and BWRS) and advanced reactors (e.g, gas-cooled reactors, sodium fast reactors, and fusion reactors). Successful development and deployment of advanced reactors depends to a large 
extent on demonstration of "enabling" technologies. For example, the high temperature irradiation performance of new fuels and structural materials must be demonstrated with instrumented tests in prototypical environments. In addition, materials and test reactors also support a wide range of non-nuclear programs including medical isotope production research, and semiconductor industry production (neutron transmutation doping of semiconductors).

Improved instrumentation for such tests offer the potential to obtain higher fidelity data, reduce irradiation costs, increase isotope production, and improve doping processes. Although research funding to advance instrumentation required to support material and test reactor irradiations was significantly reduced in the 1980s, several organizations (as discussed in Section 4), are now promoting research programs to advance in-pile instrumentation at their materials and test reactors.

Table 3-2. Representative research reactor irradiation programs.

\begin{tabular}{|c|c|c|}
\hline & Evaluations & Programa $^{a}$ \\
\hline \multicolumn{3}{|l|}{ Materials } \\
\hline & Reactor vessel steels & LWR, SFR, MTRs \\
\hline & Metallic reactor internal structure & LWR, Fusion, MTRs \\
\hline & Graphite & HTR \\
\hline & Fuel Cladding & LWR/SFR \\
\hline & Zr/Nb Alloys & HWR \\
\hline & Ceramics & GCR, Fusion \\
\hline & Refractory materials & Fusion \\
\hline & Nuclear Physics Parameters & LWR, ALWR, MTR, SFR, Fusion \\
\hline \multicolumn{3}{|l|}{ Fuels } \\
\hline & Power Ramp/Transients & LWR, ADSs, HWR, SFRs \\
\hline & High Burnup & LWR, HWR \\
\hline & New Design Qualification & LWR, ALWR, MTR, ADS, SFR, GCR \\
\hline & Nuclear Physics Parameters & LWR, ALWR, MTR, SFR, Fusion \\
\hline \multicolumn{3}{|l|}{ Other } \\
\hline & Isotope Production & Radioisotopes (Tracers, and Nuclear Medicine) \\
\hline & Transmutation/Doping & Electronics (semiconductors), Gemstones \\
\hline & Instrumentation Qualification & MTRs, LWRs \\
\hline & Medical Treatment & $\begin{array}{c}\text { Boron Neutron Capture Therapy, Intensity Modulated } \\
\text { Radiotherapy }\end{array}$ \\
\hline & Radiography & LWR, industry component evaluations \\
\hline
\end{tabular}

a. Acronyms: ADS - Accelerator Driven System; GCR - Gas-Cooled Reactor; HWR - Heavy Water Reactor; LWR - Light Water Reactor; MTR - Materials and Test Reactors; and SFR - Sodium Fast Reactor 


\section{INTERNATIONAL DEVELOPMENT EFFORTS}

As noted in Section 1.2, new instrumentation techniques are needed to support in-pile irradiations. Most in-pile instrumentation was developed over 20 years ago, and efforts to advance inpile instrumentation were reduced in the 1980s. In recent years, several organizations have either initiated or enhanced their research instrumentation development programs. This section summarizes key international in-pile instrumentation efforts.

\subsection{CEA}

The "INSNU" program was initiated by the French CEA (Commissariat à l'Energie Atomique) with the aim of developing innovative in-pile instrumentation to meet the needs of emerging nuclear programs, such as GEN IV, fusion, and GNEP. ${ }^{13}$ through 16 The scope of these studies includes:

- radiation measurements (e.g., neutron flux and gamma heating)

- measurements of physical parameters inside the irradiation rigs (e.g., temperature, sample dimensions, and fission gas release)

The orange boxes in Figure 4-1 identify instrumentation areas studied within this CEA program. These areas were selected to address current and prospective needs identified by research reactor operators and irradiation experiment customers.

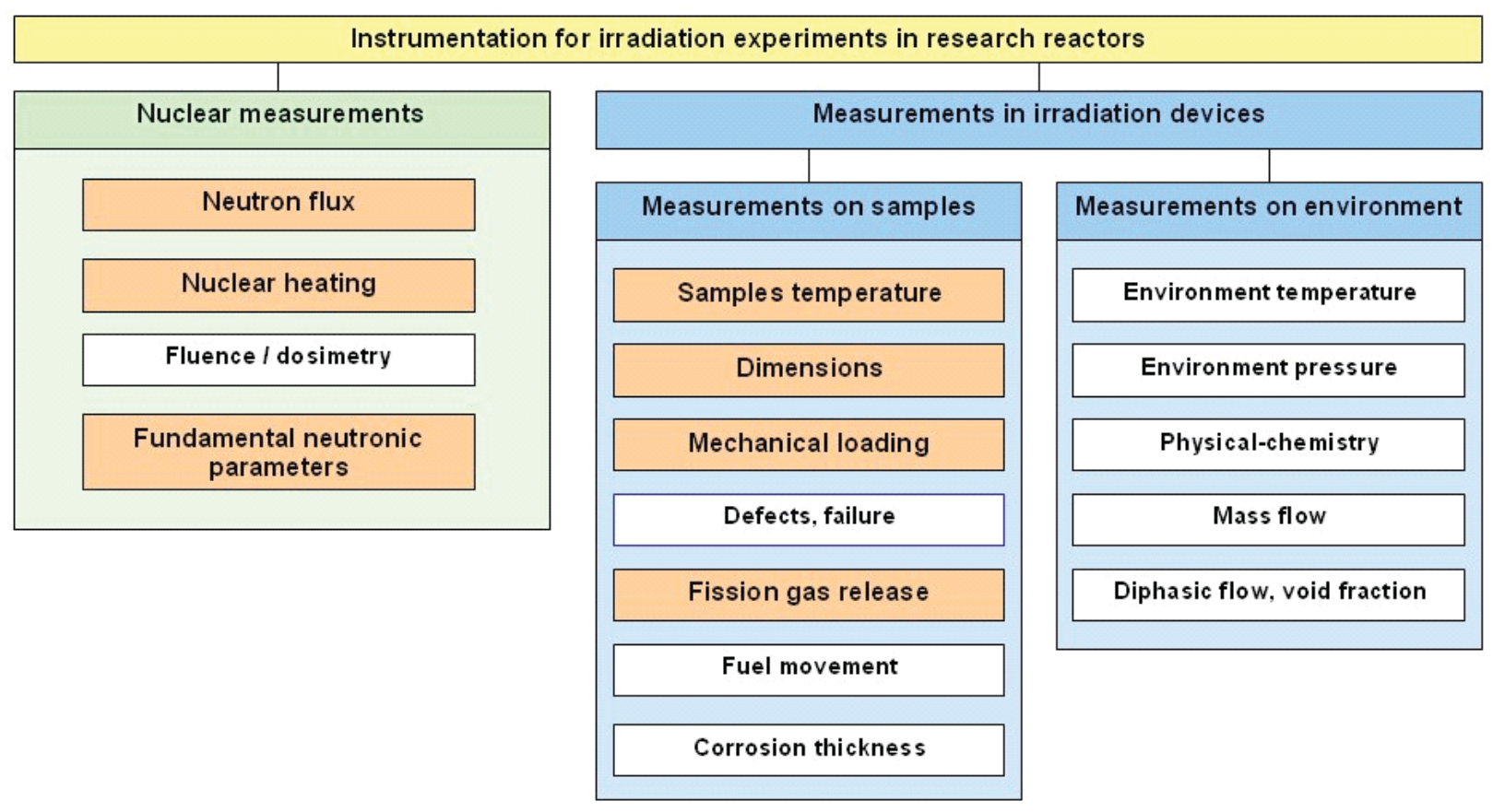

Figure 4-1. In-pile instrumentation needs for future irradiation experiments. 
Originally, INSNU was a combined CEA-Saclay (DEN/DRSN) and SCK·CEN (Belgian Nuclear Research Centre) effort to improve instrumentation in the OSIRIS reactor in Saclay, France, and the BR2 in Mol, Belgium. However, in preparation for the future Jules Horowitz Reactor that will go critical in Cadarache, France in 2014, the CEA instrumentation effort was moved to Cadarache and increased to include a larger number of organizations and sensor development activities (see Table 4-1).

Table 4-1. Current INSNU in-pile instrumentation research

\begin{tabular}{|c|c|c|c|}
\hline Main INSNU programs & Leader & $\begin{array}{c}\text { Main } \\
\text { collaboration }\end{array}$ & \begin{tabular}{|c|}
$\begin{array}{c}\text { Scheduled } \\
\text { end }\end{array}$ \\
\end{tabular} \\
\hline \multicolumn{4}{|l|}{ Temperature } \\
\hline Development of high-temperature Mo-Nb thermocouples & DEN/DRSN & Thermocoax & 2009 \\
\hline Development of in-pile noise thermometry & DEN/DRSN & FZJ+Thermocoax & 2010 \\
\hline Development of in-pile infrared pyrometry & DEN/DPC & & 2013 \\
\hline \multicolumn{4}{|l|}{ Dimensions } \\
\hline Optimization and qualification of IFE (Halden) elongation and diameter gauges & DEN/DRSN & IFE Halden & 2010 \\
\hline Developement of in-pile optical dimensional measurements & LCICEA-SCK & & 2009 \\
\hline \multicolumn{4}{|l|}{ Fission gas release: } \\
\hline Adaptation of the OSIRIS counter-pressure sensor for high-pressure meas. & DEN/DRSN & Thermocoax & 2008 \\
\hline Developement of in-pile acoustic fission gas release measurements & LCI CEA-SCK & $\mathrm{IES}(\mathrm{CNRS})$ & 2010 \\
\hline \multicolumn{4}{|l|}{ Neutron flux: } \\
\hline Qualification of sub-miniature fission chambers & DEN/DER & Photonis & 2006 \\
\hline Developement of a Fast Neutron flux Detection System & LCI CEA-SCK & DRT/DETECS & 2009 \\
\hline \multicolumn{4}{|l|}{ Nuclear heating and gamma measurement: } \\
\hline Development of a calorimetric and neutronic scanning system & DENIDRSN & & 2009 \\
\hline Development of Self-Powered Gamma Detectors & LCI CEA-SCK & Thermocoax & 2009 \\
\hline \multicolumn{4}{|l|}{ Fondamental parameters for neutronics } \\
\hline Uncertainties reduction programs for critical mock-ups & DEN/DER & & 2008 \\
\hline Development of a generic neutron measurement network & DEN/DER & DRT/DETECS & 2009 \\
\hline Improvement of activation dosimetry capabilities & DEN/DER & $\mathrm{PSI}$ & 2010 \\
\hline
\end{tabular}

As discussed in References 13 and 14, INSNU objectives focus upon developing innovative instrumentation for materials and test reactor irradiations that have possible fission and fusion reactor applications. Decisions for instrumentation development are based on users-needs, and development efforts include in-pile qualification. As indicated in Table 4-1, instrumentation development efforts are often a collaborative effort between government research laboratories (CEA, PSI, HRP, etc.) and industry (e.g., Photonis, Thermocoax, etc.). By including industry partners, developers insure its availability from a commercial supplier.

General characteristics of instrumentation developed within INSNU include:

- Reliable (because it is impossible or difficult to perform maintenance on irradiated objects)

- Accurate (sensors must meet testing requirements; ex: $\mu \mathrm{m}$ dimensional measurements and within $5{ }^{\circ} \mathrm{C}$ temperature measurements)

- Miniature (irradiation volumes are limited with narrow dimensions: few mm available)

- High temperature resistant $\left(>300{ }^{\circ} \mathrm{C}\right.$, up to $\left.1600^{\circ} \mathrm{C}\right)$

- Corrosion resistant (in pressurized water, high temperature gas, and liquid metals)

- Neutron / $\gamma$ "resistant" (dose > 1GGy/day and > 10dpa/year in MTRs) 
As noted in References 14 and 16, in-pile instrumentation must be developed that doesn't pose a threat to the safety or economic operation of the test reactor (e.g., "simpler" is smarter). Selected examples of CEA in-pile instrumentation development are discussed within subsections in this section. The reader may find other examples, such as their collaboration with $\mathrm{SCK} \cdot \mathrm{CEN}$ to explore the use of fiber optics in Section 4.2.3 or their collaboration with Forschungzentrum Jülich to demonstrate the viability of Johnson Noise Power Thermometry (JNPT) in References 13 and 14 .

\subsubsection{Subminiature Fission Chambers}

For decades, in-pile neutron flux measurements were obtained using Self Powered Neutron Detectors (SPNDs), and signals were generally correlated with post-irradiation analysis of activation foil dosimeters. The development of CEA's sub-miniature fission chambers for in-pile measurements of high thermal neutron fluxes (up to $4 \times 10^{14} \mathrm{n} / \mathrm{cm}^{2}-\mathrm{s}$ ) represents a significant improvement. These $1.5 \mathrm{~mm}$ external diameter sensors, containing a $\mathrm{U}^{235}$ fissile deposit, were qualified in the BR2 reactor in the CALLISTO loop between 2001 and 2004, although additional studies are needed to verify sensor robustness. These sensors are now manufactured by the PHOTONIS Company under the name "CFUZ53" (see Reference 17).

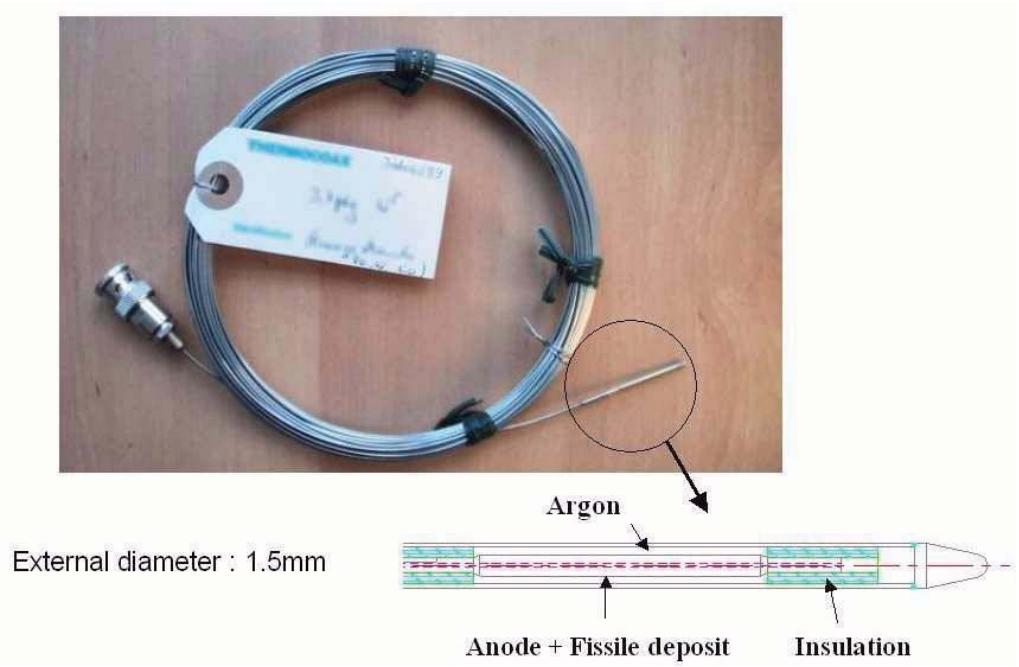

Figure 4-2. CEA-developed sub-miniature fission chamber

In addition, CEA, in collaboration with SCK-CEN, are developing and qualifying an improved sub-miniature fission chamber system, also known as the Fast Neutron Detection System (FNDS) for measuring fast neutron fluxes $(\mathrm{E}>1.0 \mathrm{MeV})$. At this time, no other sensor can provide online measurement of fast neutron flux. The FNDS is based on a patented miniature fission chamber with a special fissile deposit sensitive to fast flux with a low thermal contribution, operated in Campbelling mode for a high gamma rejection. A particular data processing software also calculates online the evolution of the signal given by the system. Major components of the FNDS are shown in Figure 4-3. 


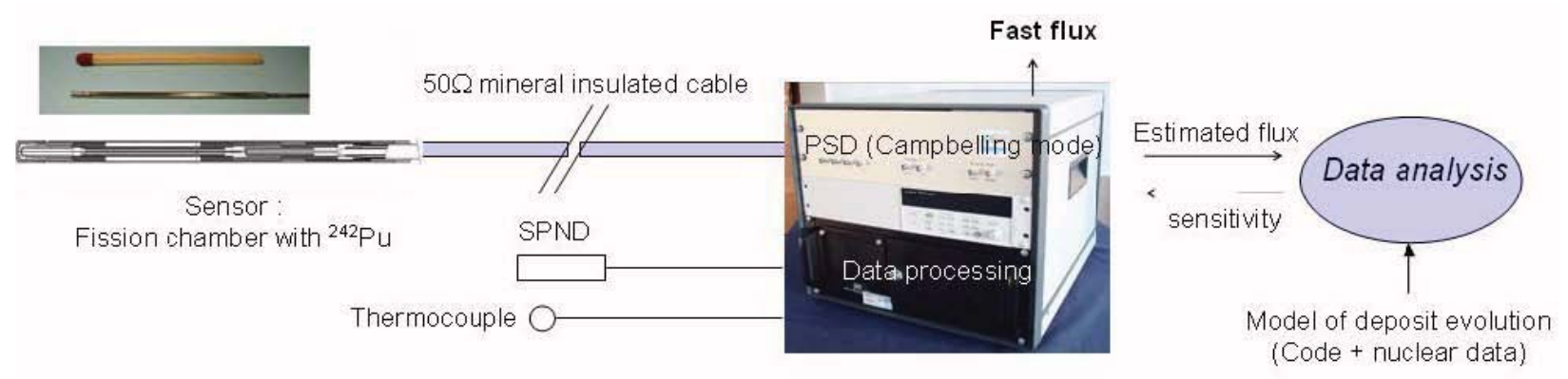

Figure 4-3. Schematic view of the FNDS prototype.

Selection of the fissile deposit in the fast fission chamber was motivated by two major factors:

- The fission cross-section must be much larger for thermal neutrons than for fast neutrons.

- The potential to form other isotopes via radiative capture of (primarily thermal) neutrons. This process, either directly or after some radioactive decays, leads to new isotopes in the deposit that are likely to undergo fission preferentially with thermal neutrons. The sensitivity to thermal neutrons of a chamber based on these isotopes therefore increases gradually. Note that it was decided to not use screen-absorbers that could prevent thermal neutrons from reaching the chamber, because of their large size and of the local perturbation induced on the thermal flux.

Analytical simulations of candidate fissile deposits identified ${ }^{242} \mathrm{Pu}$ as the best choice to measure the fast component of a high neutron flux for cases where there is also a significant thermal contribution over the entire reactor cycle. Its sensitivity to fast neutrons is excellent at the beginning of irradiation and slowly decreases with fluence. Prototypes of fission chambers with ${ }^{242} \mathrm{Pu}$ deposit have been manufactured by CEA in Cadarache and tested in 2005 and 2006 in the BR2 reactor of SCK $\bullet \mathrm{CEN}$. A $3 \mathrm{~mm}$ diameter design with a $50 \Omega$ impedance mineral insulated cable was selected due to its appropriate efficiency and reliability.

The signal given by a fission chamber at high counting rates is the sum of a mean constant current and a fluctuation around this value. Classically, fission chambers are used in "current mode" under high neutron flux where it is not possible to individually count each event in the detector. However it is also possible to use the signal variance. This parameter characterizes the random variations of the signal around its mean value, and is proportional to the incident neutron flux. This method is called Campbelling mode or MSV (Mean Square Voltage). In a fission chamber implemented in a materials test reactor (MTR), all interactions contribute to the signal, even those due to gamma radiation, that can be considered as parasitic for the neutron flux measurement. This difficulty is particularly strong in MTRs because of their very high gamma level. The advantage of the Campbelling mode is that the gamma contribution to the signal is drastically less than in current mode because it plays a part as the square of the charges, which are notably lower for events generated by gamma than for those induced by fission reactions. Thus, this mode is very useful for rejecting the gamma component. Tests performed in the BR2 reactor in 2005 and 2006 have demonstrated that the Campbelling mode is viable for measuring the fast 
neutron flux: the gamma contribution to the signal of a ${ }^{242} \mathrm{Pu}$ fission chamber was reduced from $50 \%$ in current mode to $0.6 \%$ in Campbelling mode.

The FNDS system has been designed for long duration in-pile experiments in MTRs. The initial impurities (mainly of ${ }^{239} \mathrm{Pu}$ and ${ }^{241} \mathrm{Pu}$ ) contained in the ${ }^{242} \mathrm{Pu}$ deposit and the isotopic evolution under irradiation of ${ }^{242} \mathrm{Pu}$ itself lead to a significant and increasing contribution of the thermal component to the signal. Therefore, achieving precise and long-term measurements implies that one should also estimate the thermal component with a dedicated detector, which can be either a ${ }^{235} \mathrm{U}$ fission chamber or an SPND. For this reason, an algorithm that estimates both thermal and fast components of a neutron flux based on the use of two on-line detectors signals and prior knowledge of the shape of the spectrum has been developed and integrated in the FNDS system. This algorithm can estimate the neutron flux in two large energy bands when a spectrum model is provided. Two detectors, one devoted to thermal flux, the other to fast flux, are used in combination; and their evolution under irradiation is evaluated in a joint manner. Initial testing of this algorithm was completed in 2008. These tests showed that it is possible to estimate the flux even in cases where the flux experienced large variations over time.

Two complete prototypes of the FNDS system have been manufactured for testing by the Joint Instrumentation Laboratory in 2008 at the ISIS reactor, a $700 \mathrm{~kW}$ critical mock-up located in CEA Saclay, France. In-pile qualification of the system is scheduled in 2009 in the BR2 reactor, in the FICTIONS-8 experiment. The irradiation device shown in Figure 4-4 was been designed to implement eight ${ }^{242} \mathrm{Pu}$ fission chambers and several other detectors, such as ${ }^{235} \mathrm{U}$ fission chambers, SPND, gamma thermometers, thermocouples and activation dosimeters, in order to provide reference measurements of the nuclear and thermal environment of the experiment.

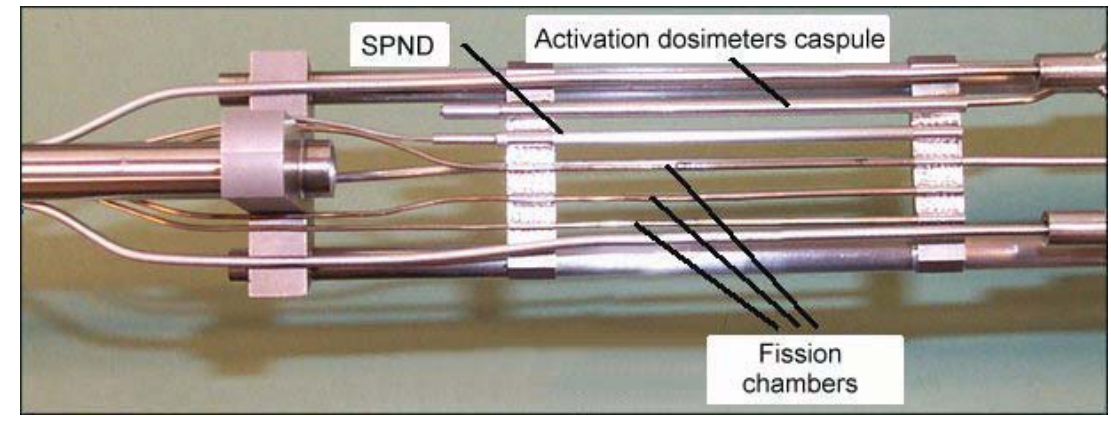

Figure 4-4. Partial view of the FICTIONS device to be irradiated in the BR2 reactor

\subsection{2. $\mathrm{Mo} / \mathrm{Nb}$ Thermocouples}

CEA, in collaboration with the THERMOCOAX Company, has been developing high-temperature in-pile thermocouples. ${ }^{18}$ This CEA/THERMOCOAX effort investigated thermoelements containing molybdenum and niobium because the low neutron absorption cross sections of these elements make them less susceptible to transmutation-induced drift during irradiation. Materials interactions tests conducted by CEA/THERMOCOAX in high temperature furnaces, in the range from 1000 to $1600{ }^{\circ} \mathrm{C}$, indicated that materials less susceptible to interactions with $\mathrm{Mo}$ and $\mathrm{Nb}$ 
thermoelement wires were $\mathrm{HfO}_{2}$ insulation and $\mathrm{Nb}$ or Ta sheaths. Investigations to quantify the thermoelectric response of a loose-assembly $\mathrm{Mo}-\mathrm{Nb}$ thermocouple found that its emf in its intended temperature range $\left(1000\right.$ to $\left.1600{ }^{\circ} \mathrm{C}\right)$ is of the same order as commercially-available high-temperature Type $\mathrm{C}$ or $\mathrm{S}$ thermocouples.

The next step concerned thermal stabilization of these thermocouples. Candidate heat treatments to stabilize grain growth to minimize drift during high temperature use were evaluated using long-duration high-temperature out-of-pile tests. Reference 12 reports that thermocouples were drifting at a rate somewhat lower than $0.02{ }^{\circ} \mathrm{C} / \mathrm{h}$ at $1100{ }^{\circ} \mathrm{C}$. After 5000 hours, this would result in $100^{\circ} \mathrm{C}$ or $10 \%$ drift, which is higher than observed in the INL long duration evaluations at $1200{ }^{\circ} \mathrm{C}$ of a doped $\mathrm{Mo} / \mathrm{Nb}$ alloy thermocouples (see Section 6.1).

Reference 18 reported plans for an in-pile high-temperature qualification in the OSIRIS reactor that would include both standard high-temperature and new Mo-Nb thermocouples in a long-term neutron irradiation experiment called "THERMEX" (see Figure 4-5). During irradiation, the reference temperature will be regularly established by using a pure copper fixed point melting device from which results will be compared with temperatures measured by these Mo-Nb thermocouples. More recent information ${ }^{14}$ suggests that these thermocouples may be irradiated in the HRF reactor in 2010 as part of CEA's gas reactor research program and that THERMOCOAX is now exploring the use of doped Mo/Nb-alloy thermoelement materials. ${ }^{\text {a }}$

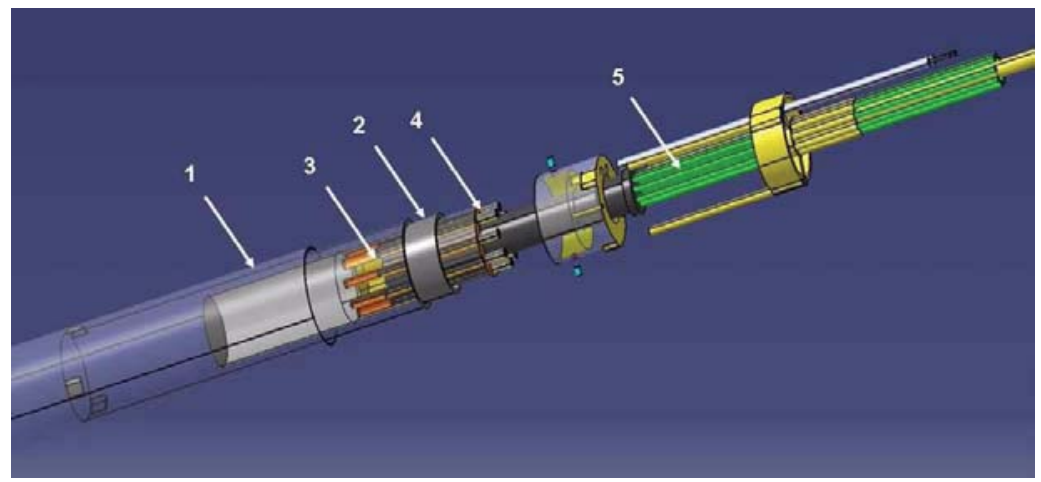

Figure 4-5. THERMEX experiment device: stainless steel capsule (1), graphite barrel (3) filled with pure copper (2), additional electric heating elements (4), thermocouples (5).

\subsubsection{Improved Linear Variable Differential Transducers (LVDTs) and Diameter Gauges}

CEA, in collaboration with the Institute for Energy Technology at the Halden Reactor Project (IFE -HRP), have recently started an effort to improve the performance of Linear Variable Differential Transducers (LVDTs). Since 2005, LVDT technologies fabricated by IFE-Halden have been used in the OSIRIS reactor with accuracies of $+/-4 \mu \mathrm{m}$ and displacements up to $+/-15$ $\mathrm{mm}$ (total range) and +/- $6 \mathrm{~mm}$ (linear range). During 2007, CEA performed a series of out-of-pile

a. It is not clear that the THERMEX qualification will occur. 
tests to characterize and try to improve the performance of these LVDTs and diameter gauges based on LVDT sensors. CEA investigations were focussed upon:

- Quantifying usable LVDT temperature range

- Quantifying maximum LVDT measurement range

- Developing the most appropriate LVDT signal correlation versus measurement ranges

- Developing post-test appropriate LVDT adjustments (Gain - Phase)

Tests were conducted at room temperature and at higher temperatures (up to $380{ }^{\circ} \mathrm{C}$ ) in inert gas, water, and sodium potassium conditions

As part of this effort, CEA proposed several improvements to LVDT designs currently manufactured by IFE-HRP. First, to extend their measurement range, CEA has requested that a polynomial equation be used to characterize the signal of LVDTs procured from IFE - HRP. Second, CEA requested that IFE-HRP develop a 'fifth wire' or "self compensating electronics setup." Figure 4-6 illustrates the wiring used for such a setup (compared to the standard 4-wire setup that only uses the wires labeled 1,2,3, and 4). In this configuration, wire 3 and 4 are Type K " $\mathrm{B}$ " thermocouple wires and Wire 5 is a Type $\mathrm{K}$ " $\mathrm{A}$ " thermocouple wire. In a 4-wire configuration, only the voltage difference between the two secondary coils is measured. Hence, the voltage output is proportional to the core displacement, or

Displacement $=G \cdot\left(V_{C 1}-V_{C 2}\right)$

Where $G$ is the gain, and $V_{C 1}$ and $V_{C 2}$, represent the voltage of coils 1 and 2 , respectively. In the 5-wire setup, the additional wire is connected as a zero reference between the two secondary coils. Hence, the ratio between the two secondary coils is used to estimate the displacement, using Displacement $=G \cdot \frac{\left(V_{C 1}-V_{C 2}\right)}{\left(V_{C 1}+V_{C 2}\right)}$

Theoretically, the influence of global changes in the system will have negligible effect on the system because the resulting signal is a ratio. For example, this setup offers several potential improvements:

- improved linearity

- suppression of temperature sensitivity

- suppression of signal aberrations in its central area

- suppression of Curie temperature effects of nickel (although this requires experimental confirmation)

- suppression of signal shift due to irradiation (although this requires experimental confirmation)

In particular, the following ratio of signals from the secondary are used to quantify elongation rather than the combined secondary signal. As long as the LVDT is at a uniform temperature, the signal should be more accurate (because it is no longer susceptible to Curie temperature effects). 


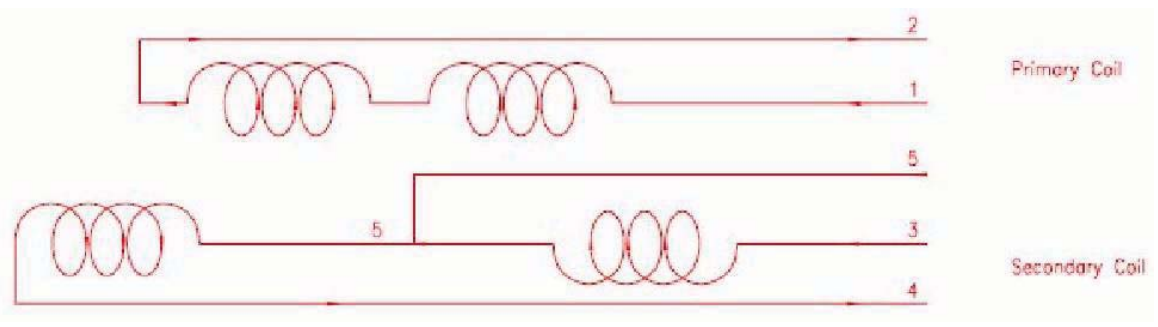

Figure 4-6. Wiring schematic for LVDTs using the five-wire method.

In the MELODIE and MUSCIA tests, it is planned to evaluate the performance of these improved designs in the OSIRIS reactor during 2010. As shown in Figure 4-7, the MELODIE tests will provide real-time elongation and diameter change data from an in-core irradiation of a PWR fuel cladding tube $(90 \mathrm{~mm})$ at $350{ }^{\circ} \mathrm{C}$. The test capsule includes controlled mechanical loading ranging from 60 to $180 \mathrm{MPa}$ (with stress steps) and variable biaxial stress ratio: ranging from 0 (hoop stress) to infinity (axial stress).
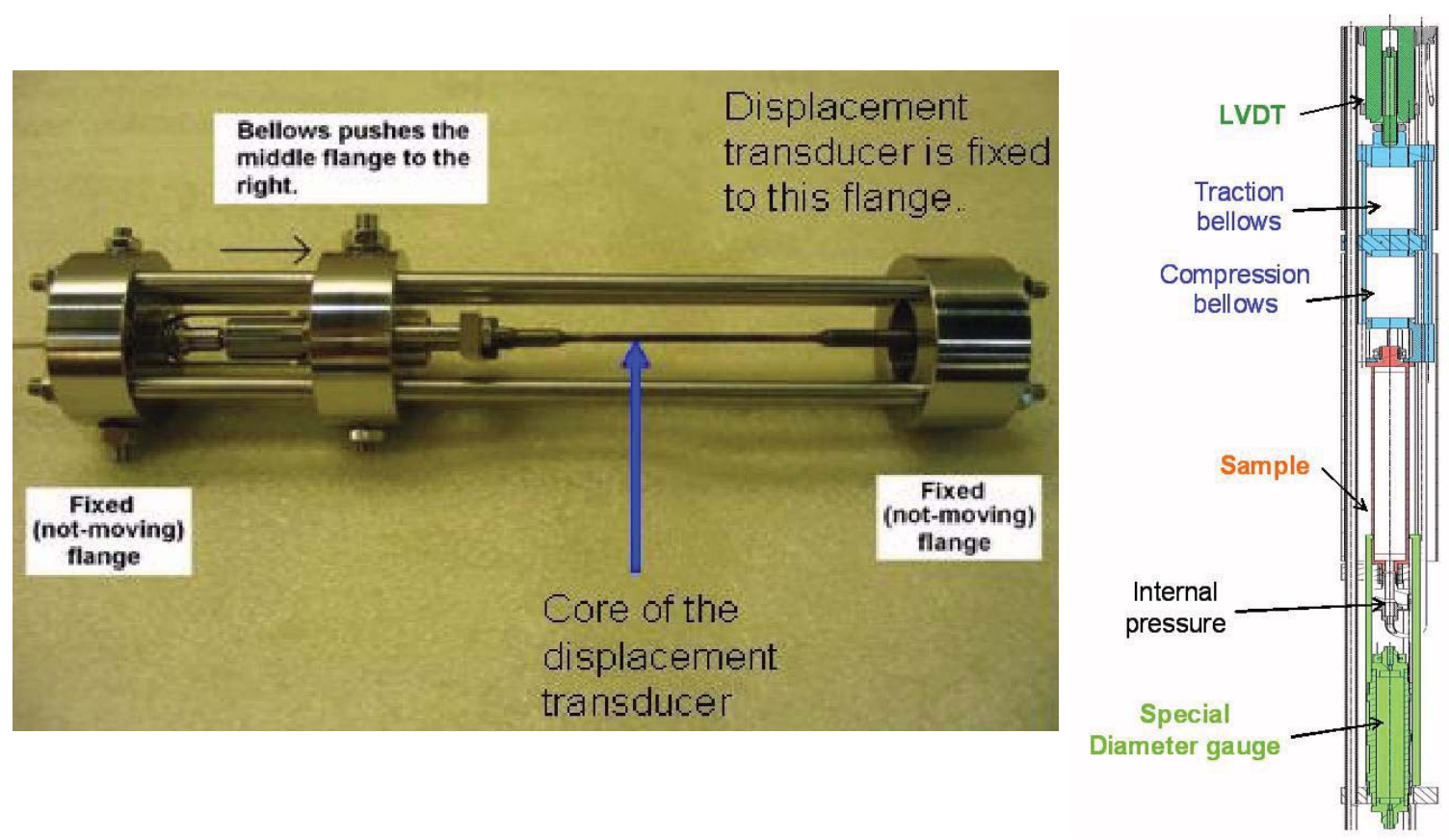

Figure 4-7. Proposed sensor for detecting elongation and diameter changes in OSIRIS testing.

\subsubsection{Fission Gas Release}

In-situ measurement of fission gas release inside nuclear fuel rods is of major interest for irradiation programs in materials testing reactors. This parameter is particularly important in fuel rod irradiations because fission gas release kinetics is an important indicator of nuclear reactions and its measurement is key in fuel performance studies. There is interest in detecting the composition 
and amount of fission gas release. To address this need, CEA is investigating counter-pressure and acoustical measurement techniques.

Figure 4-8 shows the counter-pressure sensor used by CEA to detect the pressure associated with fission gas release from a fuel rod during irradiation. The imbalance between the internal rod pressure and the counter-pressure is accurately detected by two electric contacts, activated by the motion of the bellows. The physical principles associated with the counter-pressure avoids any decalibration due to nuclear radiation. The automatic acquisition and control system drives the counter-pressure operation and checks the integrity of the double bellows as a safety barrier. The sensor was firstly qualified in-pile on a dummy fuel rod with a controlled internal pressure. The measured accuracy is $< \pm 0.5$ bar in the whole pressure range of interest. The counter-pressure sensor has been used successfully in REMORA-1 and REMORA-2 experiments. Design and manufacturing of a special counter-pressure sensor for high-pressure measurements (up to 250 bar) is underway.

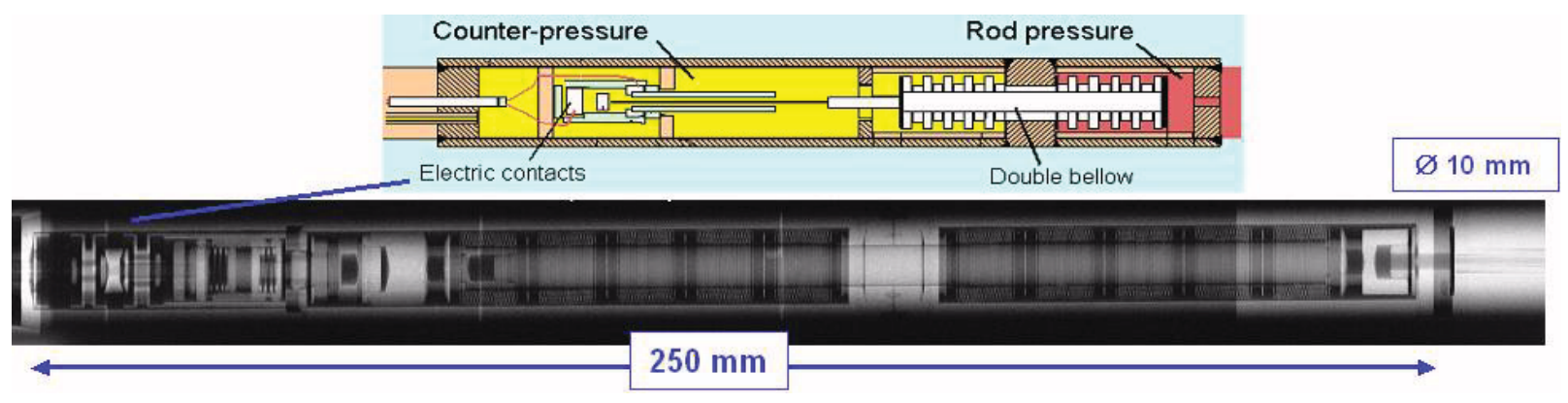

Figure 4-8. CEA counter-pressure sensor for detecting fission gas release amount.

CEA, in collaboration with several organizations within France, such as LAIN (Interfaces and Nanophysics Analysis Laboratory) and the Université Montpellier II, and the Studiecentrum voor Kernenergie • Centre d'Étude de l'énergie Nucléaire (SCK·CEN) in Mol, Belgium, are investigating the potential to measure fission gas release using techniques based on acoustic measurements with high-frequency echography. ${ }^{21}$ through 24 The proposed method implements a piezoelectric sensor measuring the acoustic wave velocity in the gas contained inside the fuel rod. This sensor can generate a high-frequency acoustic pulse in a cylindrical cavity directly connected to the plenum of the fuel rod and then measures the echoes from acoustic waves propagating in the cavity (see Figure 4-9). In these conditions, the acoustic wave velocity is directly dependant on the fraction of fission products in the helium gas. ${ }^{22}$ Furthermore, this technique is relatively easy to implement because it requires no mechanical parts. Hence, its in-pile application appears promising for future irradiation programs.

The first phase of these studies validated the feasibility to measure He-Xe mixture composition in an out-of-pile test. A preliminary design of the fission gas release sensor was manufactured and tested to ensure sufficient propagation of ultrasonic waves inside the gas cavity, solving the problem of the small acoustic impedance of gas compared to a solid one, which induces a strong 

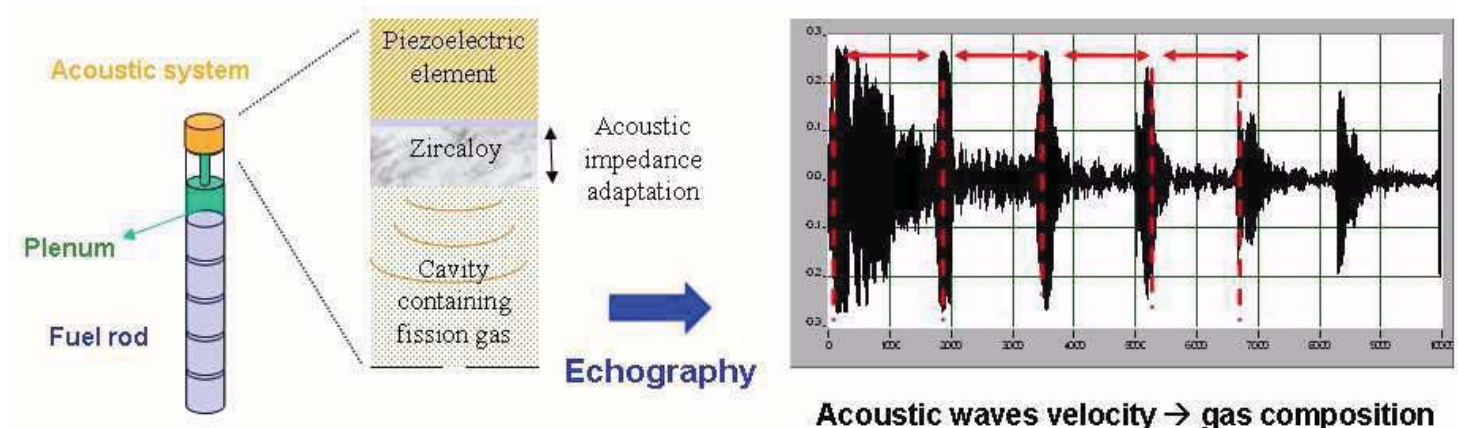

Figure 4-9. Principle of in-pile fission gas release acoustic measurement.

insertion loss. The signal processing system has also been developed in order to properly and automatically extract the He-Xe mixture composition parameter. In parallel, efforts are underway to understand the ability of piezoelectric sensors to withstand irradiation. Sensors were successfully tested in 2004 under pure gamma radiation up to $1.5 \mathrm{MGy}\left(15 \times 10^{6}\right.$ rads $) .^{23,24} \mathrm{In} 2008$, irradiation tests were completed in the BR1 in Mol, Belgium in a mixed neutron-gamma environment $^{23}$ with a total neutron fluence of $1.6 \times 10^{17} \mathrm{n} / \mathrm{cm}^{2}$. These tests provide additional insights about the most appropriate materials and the optimal position of the sensor in future irradiation experiments. Subsequent in-pile qualification tests for this sensor are planned for the OSIRS reactor in 2010. ${ }^{16}$ Furthermore, the first real experiment using this innovative sensor installed on a pre-irradiated Pressurized Water Reactor fuel rod is already planned to begin in 2011 in the OSIRIS reactor. ${ }^{15}$

\subsection{SCK.CEN}

In support of their BR-1 and BR-2 reactors in Belgium and to facilitate irradiations at other nuclear reactors, Studiecentrum voor Kernenergie - Centre d'Étude de l'énergie Nucléaire (SCK·CEN) continues to perform research focussed upon in-pile instrumentation development, evaluations, and fabrication. ${ }^{25}$ Selected projects currently investigated by SCK $\cdot$ CEN are summarized in this section. Some of these instrumentation development efforts are collaborations between SCK·CEN and CEA, such as the SMFCs discussed in Section 4.1.1 and the fission gas release sensors discussed in Section 4.1.4. Another interesting capability now available at the BR2 reactor is in-pile tensile testing with sensors to detect the load applied to the specimen and the elongation of the specimen (see Section 4.2.4). ${ }^{26}$

\subsubsection{Real-time measurement of gamma and neutron fluxes}

In 1999, SCK C CEN manufactured the experimental device, DOLMEN (Device for On-Line MEasurement of the Neutron flux). This instrument contains SPNDs, activation dosimeters and gamma thermometers that can be moved vertically in any BR2 channel. Prior to manufacturing this device, SCK·CEN optimized DOLMEN design information using data from an irradiated 
Rhodium-SPND and two specifically designed - thermometers in various BR2 reactor channels. In addition, SCK $\cdot \mathrm{CEN}$ theoretically studied the sensitivities of each type of SPND versus neutron and gamma spectra. The SCK·CEN-developed computer model SEDEIRA (SElf-powered DEtector of Ionizing RAdiation) showed the importance of the insulator in the SPND and the role played by the neutron spectrum on the detector performance. SCK CEN is developing a new Monte-Carlo model, which will allow analysts to evaluate the signals from in-pile monitoring devices in the BR2 reactor and parasitic effects of neutron and gamma fluxes in the instrumentation chain. The DOLMEN device has been inserted into the BR2 reactor. Objectives of this irradiation include developing an algorithm for estimating the actual neutron flux using the measured electric signal, identifying the sensitivity to each parameter (neutron spectrum, gamma spectrum), qualifying a calibration method, and assessing the best suitable SPND for specific applications.

\subsubsection{Radiation-hardened Micro-electronics for Nuclear Instrumentation}

$\mathrm{SCK} \cdot \mathrm{CEN}$ has also initiated an effort to develop new electronics and communication equipment capable of withstanding in-pile irradiations with radiation levels in excess of several MGy. Goals of this task are to identify commercially available equipment and to ultimately design improved radiation tolerant ( $>$ several MGy) integrated electronic circuits. Using a stepwise approach, SCK·CEN is first designing circuits with discrete components that can withstand radiation and then looking for an equivalent integrated technology. This will enable SCK·CEN to develop innovative instrumentation and communication tools for the next generation of nuclear reactors, where both radiation hardening and miniaturization play a dominant role.

\subsubsection{Fiber Optic Testing}

Materials test reactors could benefit from advantages offered by fiber-optic communication and sensing systems. However, the deployment of such systems in nuclear environments has been limited up to now, mainly due to reliability and safety constraints. Prior investigations (see Reference 20 for a review) have shown that the lifetime of fiber-optic components depends on the fiber composition, the temperature, the total dose, and the operating wavelength. Radiation affects the optical transmission of silica by creating various point defects of different nature that in turn absorb light at specific wavelengths. This Radiation-Induced Absorption (RIA) is particularly strong in the ultraviolet (UV) spectrum, which limits the fiber applicability to a very low dose (typically less than 10-100 Gy). Compared to the UV spectrum, fiber-optic transmission in the visible spectrum is less critical, but transmission can still remain a concern (especially for long fiber paths) due to the formation of an absorption band at $600 \mathrm{~nm}$, which is believed to pertain to the creation of non-bridging hole centers. However, hydrogen treatment applied to the silica fibers can reduce the formation of non bridging oxide hole centers (NBOHCs) and has been proven to improve their radiation resistance in the visible spectrum. Optical absorption of less than 0.5 $\mathrm{dB} / \mathrm{m}$ at $630 \mathrm{~nm}$ has been demonstrated in aluminum-coated fibers irradiated with $\gamma$-rays up to 6 MGy and less than $5 \mathrm{~dB} / \mathrm{m}$ under fission reactor irradiation up to about $20 \mathrm{MGy}$ and neutron fluences of $5 \times 10^{19} \mathrm{n} / \mathrm{cm}^{2}\left(\mathrm{E}_{\mathrm{n}}>0.1 \mathrm{MeV}\right)$. 
At higher doses, optical fiber applications may be possible for wavelengths above $850 \mathrm{~nm}$. Previous in-core reactor experiments at Material Testing Reactors (MTRs) in Europe and Japan demonstrated that RIA can remain limited to few $\mathrm{dB} / \mathrm{m}$ in the 800-1100 $\mathrm{nm}$ even after intense irradiation up to the GGy level and n/cm. Such RIA in the near infrared spectral region opens perspectives for the development of new types of in-core reactor instrumentation based on optical fiber sensors (OFS) technology. OFSs offer attractive and unique sensing capabilities which can be of particular benefit for measurements inside MTRs. The major advantages are the capability for passive remote sensing with the potential for high accuracy and operation at high-temperature $\left(500-1000{ }^{\circ} \mathrm{C}\right)$. In addition OFSs feature capabilities for distributed sensing with extremely limited intrusiveness. Low intrusivity appears to be a key factor in MTRs, not only because of limited space available but also because small sensors will not disturb the temperature and radiation profile on the material under study.

As part of the JRL between CEA and $\mathrm{SCK} \cdot \mathrm{CEN}$, a program was initiated to develop a new OFS prototype with the aim of measuring dimensional changes on nuclear materials irradiated in MTRs. As part of this effort, the COSI experiment was completed in which the single model (SM) and multimode (MM) optical fibers listed in Table 4-2 were irradiated in the OSIRIS reactor for 92 days (corresponding to a thermal fluence of $10^{21} \mathrm{n}_{\mathrm{th}} / \mathrm{cm}^{2}$ and a fast fluence of $10^{20} \mathrm{n}_{\text {fast }} / \mathrm{cm}^{2}$, and a calculated gamma dose rate of $7.2 \times 10^{6} \mathrm{~Gy} / \mathrm{hr}$, with an integrated ionizing dose of 16 GGy). This duration, which corresponds to representative conditions during a typical materials irradiation program, represents over an order of magnitude than other reported tests in the literature.

Table 4-2. Single mode and multimode optical fibers tested in OSIRIS COSI test

\begin{tabular}{|c|c|c|c|c|}
\hline Fibers & Manufacturer & $\begin{array}{c}\text { Manufacturer Designator } \\
\text { (SM or MM) }\end{array}$ & $\begin{array}{l}\text { Core/Cladding } \\
\text { Diameter }\end{array}$ & Coating \\
\hline $\begin{array}{l}\text { FORC1 } \\
\text { FORC2 } \\
\text { FORC3 }\end{array}$ & $\begin{array}{c}\text { Fiber Optic } \\
\text { Research Center } \\
\text { (Moscow) }\end{array}$ & $-/ \mathrm{SM}$ & $\sim 10 \mu \mathrm{m} / 150 \mu \mathrm{m}$ & acrylate \\
\hline $\begin{array}{l}\mathrm{B} 11 \\
\mathrm{~B} 13\end{array}$ & $\begin{array}{l}\text { Blaze Photonics } \\
\text { (Cristal Fiber) }\end{array}$ & HC $1060-02 / \mathrm{SM}$ & $9.7 \mu \mathrm{m}($ hole $) / 125 \mu \mathrm{m}$ & acrylate \\
\hline $\begin{array}{l}\text { STU1 } \\
\text { STU1 }\end{array}$ & Polymicro & FIP100.110.125 STU//MM & $\sim 100 \mu \mathrm{m} / 110 \mu \mathrm{m}$ & polyimide \\
\hline $\begin{array}{l}\text { FIL1 } \\
\text { FIL2 }\end{array}$ & Polymicro & FIP100.110.150/MM & $\sim 100 \mu \mathrm{m} / 150 \mu \mathrm{m}$ & aluminum \\
\hline $\begin{array}{l}\text { FVL1 } \\
\text { FVL2 }\end{array}$ & Polymicro & FIP100.110.150/MM & $\sim 100 \mu \mathrm{m} / 150 \mu \mathrm{m}$ & aluminum \\
\hline
\end{tabular}

As shown in Figure 4-10, the fibers were mounted onto an aluminum plate and placed in a $2 \mathrm{~mm}$ internal diameter stainless steel tube. The fibers made a loop with a bend radius of either 23 or $32 \mathrm{~mm}$. The fluence was measured with a SPND. Although placed in the periphery of the core, the central part of these $40 \mathrm{~m}$ fibers was close to the reactor core. Results from this test indicate that there are SM and MM optical fibers with acceptable losses for testing in materials and test reactors. As shown by representative results in Figure 4-11, the most favorable spectral region lies in the 800-1200 $\mathrm{nm}$ range . 


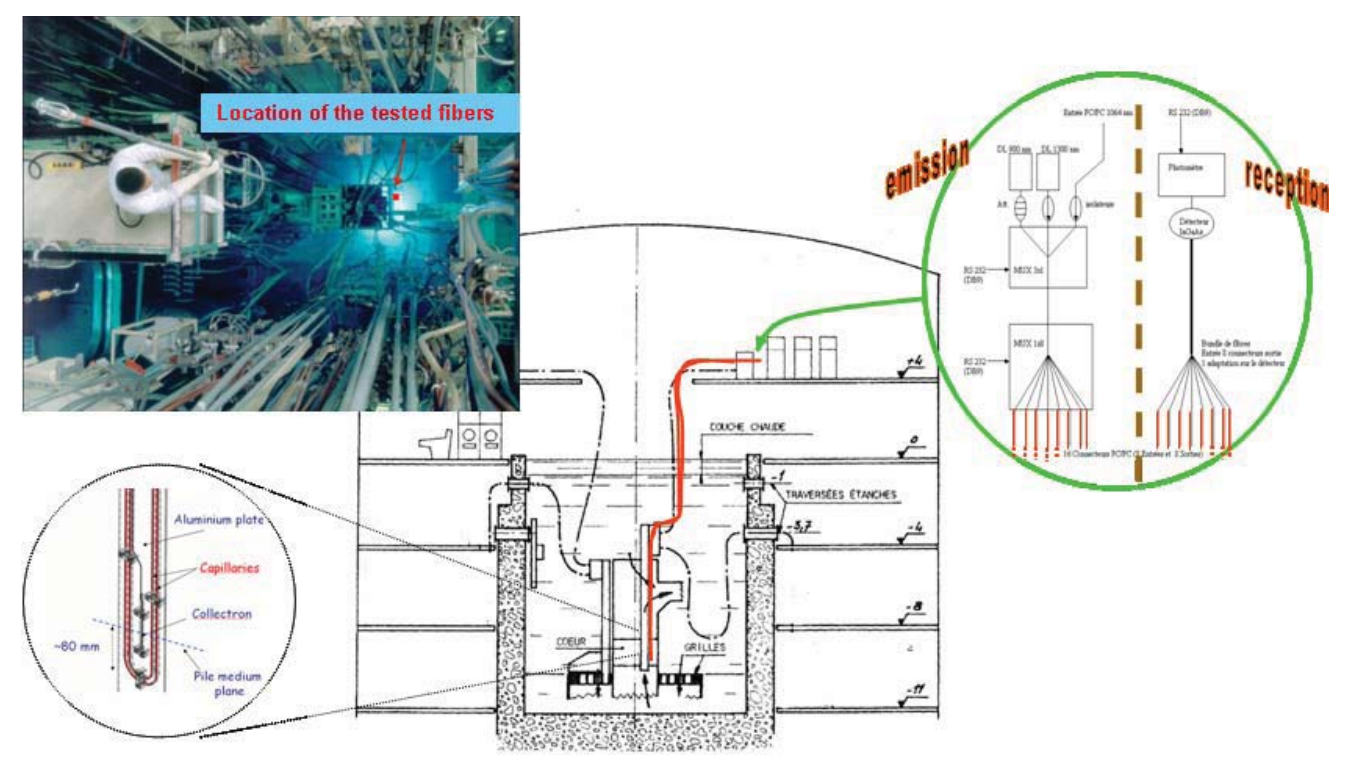

Figure 4-10. COSI test rig setup.

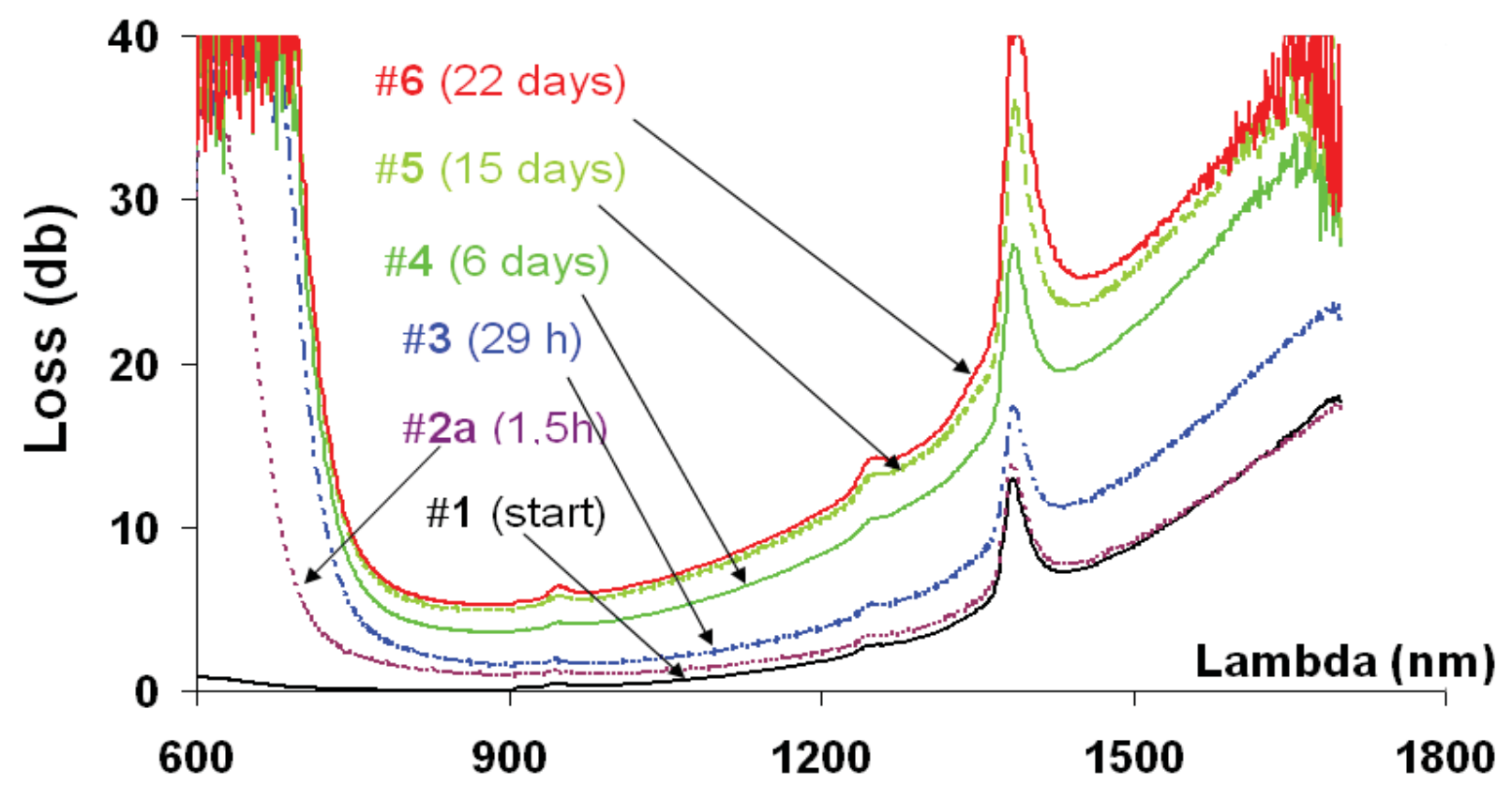

Figure 4-11. Representative results from COSI-Change in loss for the STU2 fiber (22 days corresponds to $3 \times 10^{20} \mathrm{n}_{\mathrm{th}} / \mathrm{cm}^{2}$ and $3 \times 10^{19} \mathrm{n}_{\text {fast }} / \mathrm{cm}^{2}$ )

To address concern about degradation of fiber optic mechanical properties, $\mathrm{SCK} \cdot \mathrm{CEN}$ tested four standard telecom acrylate-coated Ge-doped single-mode fibres from three different manufacturers and one acrylate-coated Ge-doped multi-mode fibre. Fibre samples of $50 \mathrm{~m}$ were loosely coiled with a diameter of $60 \mathrm{~mm}$ and exposed to a dose rate of $27 \mathrm{kGy} / \mathrm{h}$ up to a total dose of $15 \mathrm{MGy}$ at an ambient temperature of approximately $55^{\circ} \mathrm{C}$. Several mechanical tests were per- 
formed before and after irradiation, including the two-point bend test. These destructive two-point bend tests allow quantification of the fibres' strength (50\% failure stress) and the dynamic fatigue factor. Weibull analysis revealed a strength reduction of about 50\% at these MGy dose levels. SEM (scanning electronic microscope) images of fibre samples, which had their coatings removed after irradiation, suggest that 'roughening of the outer glass surface' may cause this degradation. These results indicate that the long-term mechanical strength of optical fibres could be seriously affected when exposed to MGy dose levels.

Figure 4-12 shows a fiber-optic based sensor jointly developed by CEA and SCK $\cdot \mathrm{CEN}$ for detecting elongation of material samples during irradiation. Irradiation testing to qualify this sensor is scheduled to begin in January 2009 in the BR-2 reactor.
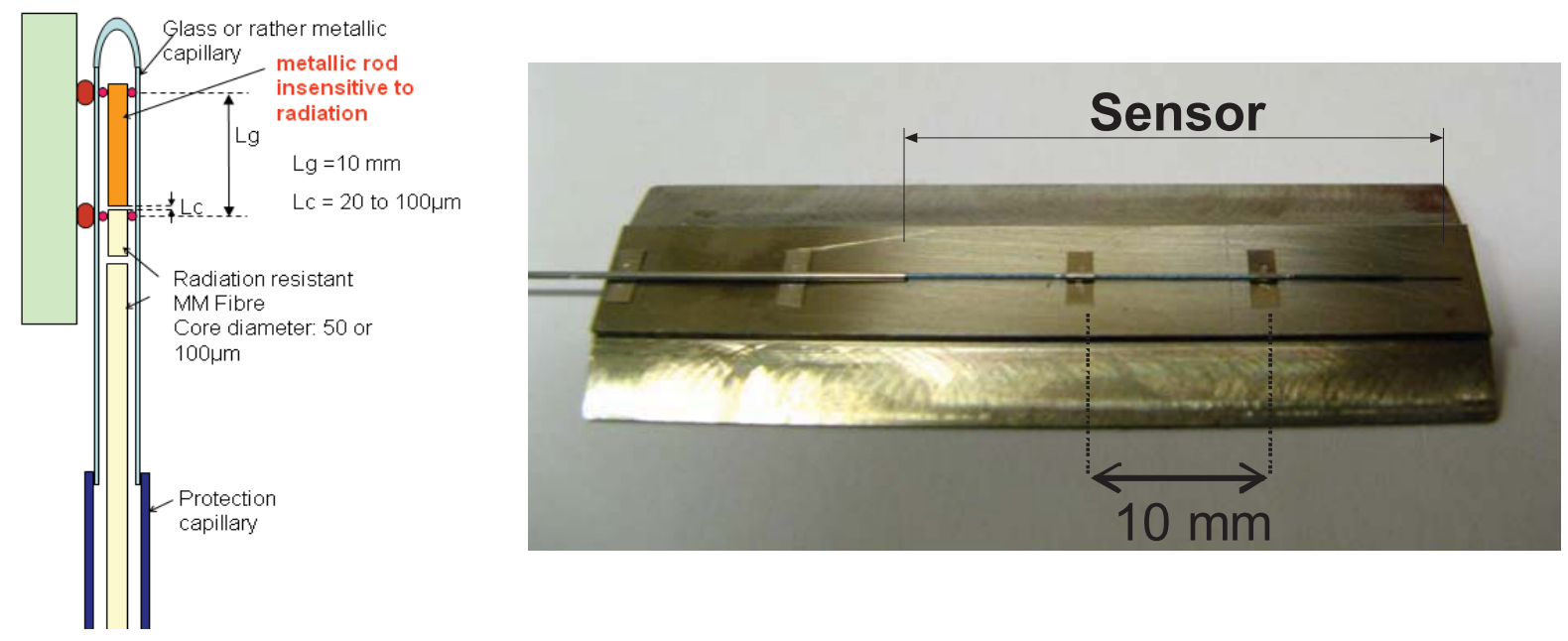

Figure 4-12. Optical fiber based elongation detection sensor developed by CEA and SCK-CEN.

\subsubsection{In-Pile Tensile Testing}

As part of a European Fusion Development Agreement (EFDA), the BR-2 has been used to demonstrate the performance of an in-pile tensile test module developed by the VTT Technical Research Center of Finland. As discussed in Reference 26, it is recognized that it is unlikely that the primary damage experience by a specimen will be affected by the applied stress during irradiation. However, it is believed that the subsequent process of dislocation formation, that is responsible for radiation hardening, yield drop, and plastic flow localization, will be substantially altered by the applied stress. It is speculated that the fatigue lifetime during in-situ cyclic loading experiments may be significantly different from the ones obtained during fatigue experiments on specimens in the post-irradiated condition. Hence, an in-situ material testing system has been developed by VTT and used to perform fracture mechanic, corrosion fatigue, tensile, and electrochemical measurements in the BR-2. 
As shown in Figure 4-13, this test system is based on the use of a pneumatic loading unit, which loads a test specimen using gas to pressurize metallic bellows, and a LVDT from IFE-HRP (see Section 4.3.1) to measure the resulting displacement produced in the tensile specimen. The outside diameter of the module is $25 \mathrm{~mm}$, and the total length of the module with the LVDT is $150 \mathrm{~mm}$. Figure 4-14 shows the actual test rig with this module developed by Mol for irradiations in the BR-2 reactor. During irradiation, the test assembly remained submerged in stagnant demineralized water. For approximately 300 hours, the specimens were exposed to a neutron flux of $3 \times 10^{13} \mathrm{n} / \mathrm{cm}^{2} \mathrm{~s}(\mathrm{E}>1 \mathrm{MeV})$ corresponding to a displacement damage rate of $\sim 6 \times 10^{-8} \mathrm{dpa} / \mathrm{s}$. The temperature of the test module increased rapidly (up to $90^{\circ} \mathrm{C}$ within 15 minutes) due to gamma heating power of $4.4 \mathrm{~W} / \mathrm{g}$. Then, the desired strain was imposed on the specimen.

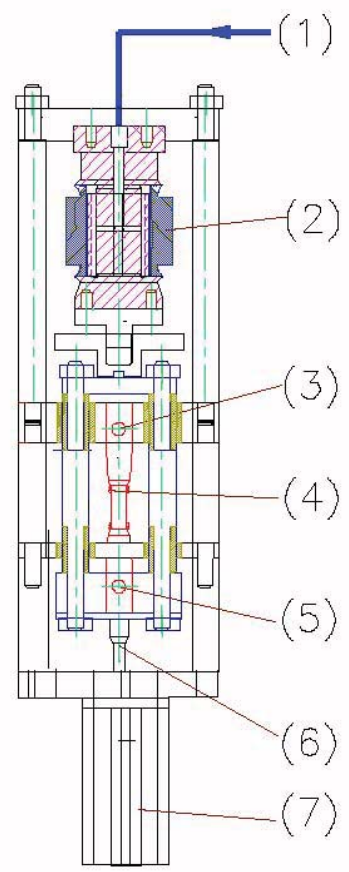

Figure 4-13. Schematic of tensile test module: (1) gas line, (2) pneumatic loading unit, (3) firm specimen fixing point, (4) specimen, (5) movable specimen fixing point, (6) LVDT plunger and (7) LVDT holder.

The load generated by the pneumatic loading unit with the metallic bellows is calculated from the pressure difference experienced by the bellows. The stiffness and effective cross section of the bellows impacts the load produced by the specimen. However, the 'stiffness' of the pneumatic loading unit differs from the stiffness of the bellows. Hence, VTT developed a calibration unit (see Figure 4-15) to correlate the applied gas pressure in the bellows with the actual load acting on the tensile specimen. A two step calibration procedure was implemented. In the first step, the characteristic stiffness of the bellow together with friction forces of the moving parts of the module were determined. In the second step, the load induced on the tensile specimen by the applied gas was measured directly by a load cell. 

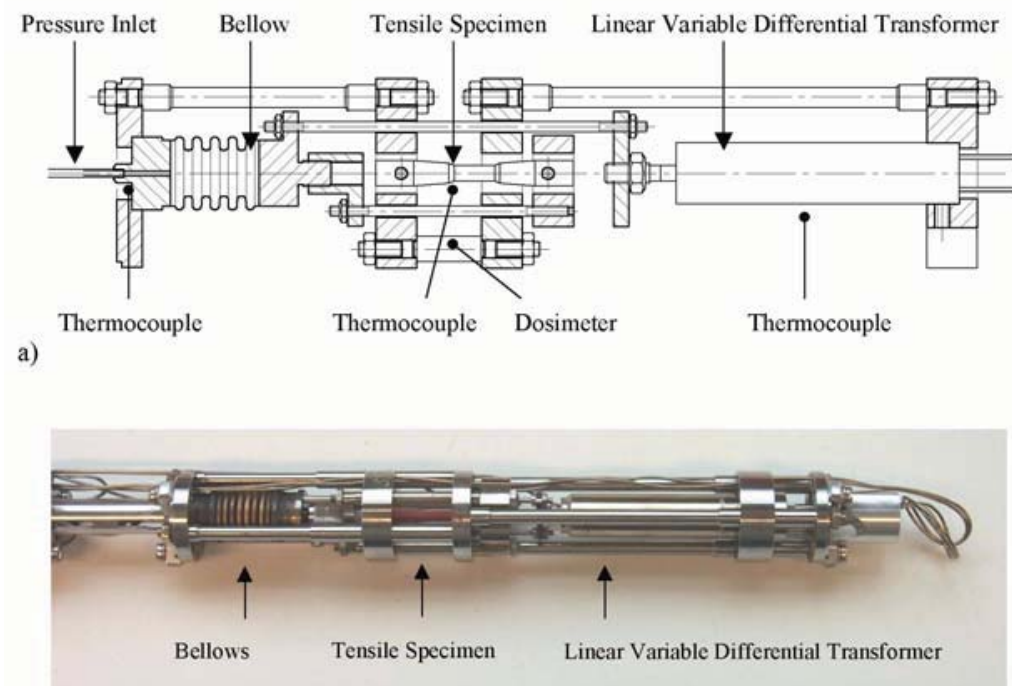

b)

Figure 4-14. Tensile test rig for BR-2 irradiations: (a) simplified layout and operational features including necessary instrumentation; and (b) final assembly of test module prior to installation in the test rig.

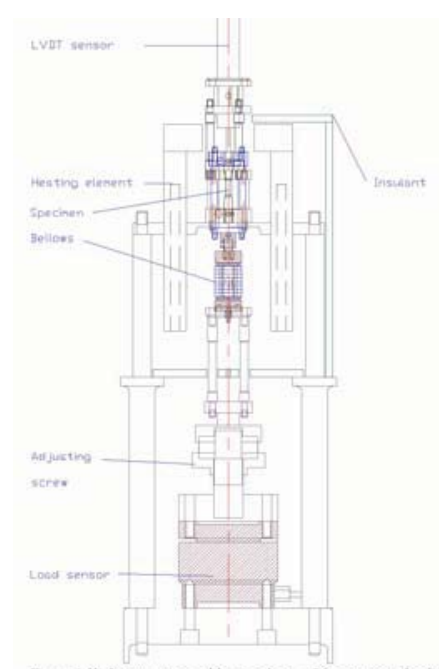

Figure 4-15. High temperature calibration device of the pneumatic loading unit.

\subsection{IFE-HRP}

The Organization for Economic Cooperation and Development (OECD)-sponsored Halden Reactor Project (HRP), which is operated by the Norwegian Institutt for Energiteknikk (IFE), has more than thirty years of experience in performing complicated in-core measurements and experiments in the Halden Boiling Water Reactor (HBWR); and a wide range of specialized sensors, equipment and techniques have been developed for this purpose. 
As listed in Table 4-3, a wide range of in-core instrumentation has been developed, fabricated, and used by the IFE-HRP for measuring key fuel and material performance parameters such as fuel temperature, fuel swelling / densification, fission gas release, cladding creep, corrosion/crud buildup, and crack-growth rates. ${ }^{27}$ through 34 Instruments are also available for monitoring the irradiation environment (e.g. SPNDs and miniaturized gamma thermometers) and thermal-hydraulic and water chemistry conditions (e.g. flow meters, ECP-electrodes and conductivity cells). HRP-developed sensors can be attached to non-irradiated fuel rods and material samples or to pre-irradiated fuel rods and material samples by using remote operated manipulators and specially-designed re-instrumentation equipment. Ongoing IFE-HRP instrumentation development focuses on high temperature conditions, new methods for crack detection and corrosion of fuel cladding materials, and online corrosion detection by means of Electrochemical Impedance Spectroscopy (EIS).

Table 4-3. Instrumentation available at Halden

\begin{tabular}{|l|l|}
\hline \multicolumn{1}{|c|}{ Instrument } & \multicolumn{1}{c|}{ Parameters } \\
\hline Turbine flow meter & $\begin{array}{l}\text { inlet /outlet flow (single or two phase); with channel power information, outlet } \\
\text { void fraction }\end{array}$ \\
\hline Thermocouples (Type K and C) & temperature and thermal conductivity \\
\hline Gamma thermometer & gamma flux, fuel assembly power indication \\
\hline Self-powered neutron detectors & neutron flux, fuel heatup rate and burnup, power \\
\hline Void gauge & dynamic void measurements in a fuel channel \\
\hline $\begin{array}{l}\text { LVDTs (cladding extensometers, fuel } \\
\text { diameter gauges, position indicators) }\end{array}$ & $\begin{array}{l}\text { fuel rod mechanical deformation (e.g. creep and strain), fuel and cladding } \\
\text { length changes, profiles for changes in cladding diameter, temperature } \\
\text { (deduced from expansion of known material in an expansion rod), crack } \\
\text { initiation, and pressure (deduced from movement of plate attached to LVDT) }\end{array}$ \\
\hline Pressure gauges & fuel rod fission gas pressure \\
\hline Eddy current cladding defect sensor & cladding defects, crack growth \\
\hline Electrical impedance spectroscopy & corrosion growth \\
\hline Level gauges & moderator level \\
\hline $\begin{array}{l}\text { Electrical chemical potential } \\
\text { measurements (platinum or palladium } \\
\text { electrodes) }\end{array}$ & oxygen concentration, hydrogen concentration (e.g., corrosion potential) \\
\hline Gap meter (squeezing technique) & internal fuel rod gaps \\
\hline
\end{tabular}

a. Note HBWR-specific corrections are required to compensate for transmutation that occurs in Type $\mathrm{C}$ high temperature thermocouples during irradiation. However, similar temperatures and fluxes and temperature gradients and flux distributions must exist during irradiation in order to apply such correction factors, and the thermocouple lifetimes are generally limited to 1 year at high temperatures. Furthermore, informal HRP discussions indicate that there are batch-to-batch variations in the Type $C$ thermocouples that they receive. b. Thermal conductivity estimates require assumptions about fuel densification, and gap conductance (if it isn't assumed to close). ${ }^{31}$

The HRP relies heavily on specialized in-core instrumentation in order to perform fuel and material irradiation programs in the HBWR. In recent years, IFE-HRP has become a supplier of inpile instrumentation for other test reactors (e.g., OSIRS, BR-2, and HANARO). This subsection provides additional information about selected IFE-HRP instrumentation development activities. 


\subsubsection{Linear Variable Differential Transformers (LVDTs)}

Many HRP-developed sensors rely upon Linear Variable Differential Transformers (LVDTs) as a base instrument. The principle design of an LVDT is shown in Figure 4-16. The LVDT consists of one primary coil and two secondary coils. In the center of the coil system, there is a magnetic core. The primary coil is activated by a $400 \mathrm{~Hz}$ constant current generator, and the position of the magnetic core in relation to the secondary coils affects the balance of the signal from the secondary coils. Thus, the position of the magnetic core can be measured with an accuracy of $\pm 1 \mu \mathrm{m}$. Since the HRP started with in-core measurements, more than 2200 LVDTs of different types have been installed in different test rigs in the HBWR. A failure rate of less than 10\% after 5 year of operation is expected for their LVDTs operating in BWR, PWR or CANDU conditions.

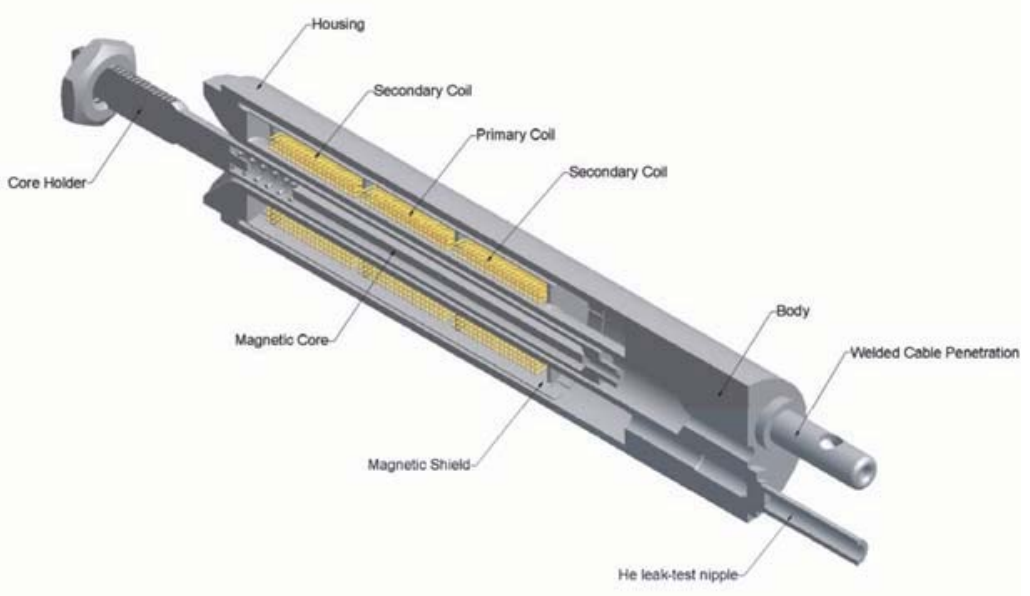

Figure 4-16. Principle design of a Linear Voltage Differential Transformer.

Using LVDTs as a base instrument, specialized HRP-developed sensors have been developed that allow on-line monitoring of various parameters, such as fuel stack elongation, cladding elongation, fuel center temperature, fuel diameter, and fuel rod pressure. For example, build-up of cladding oxide layer and detection of the point of dry-out can be derived from the above measurements. One example of note is an HRP-developed diameter gauge (see Section 4.3.5) that enables on-line measurement of cladding diameter changes due to pellet cladding interaction and creep. This, and other sensors used and developed at the HBWR are described in this section.

Recently, IFE- HRP has explored several improvements for LVDTs. As discussed in Section 4.1.3, IFE-HRP staff has collaborated with CEA to improve the accuracy of LVDTs when they are subjected to the Curie temperature. As noted in Section 6.3, the IFE-HRP is collaborating with INL to investigate the use of alternate coil wires and design modifications to improve the performance of LVDTs and diameter gauges at higher temperatures. 


\subsubsection{Fuel centerline temperature measurements}

For monitoring fuel centerline temperatures, the IFE-HRP uses fuel thermocouples and/or expansion thermometers. The fuel centerline temperature measurements provide important information on the thermal performance of the fuel and if desired, the fuel thermal conductivity. By monitoring the fuel thermal conductivity over a longer period of time, the fuel thermal conductivity degradation as a function of burn-up is studied. An example of $\mathrm{UO}_{2}$ thermal conductivity data derived from fuel centerline temperature measurements is illustrated in Figure 4-17. Informal discussions ${ }^{30}$ indicate that such tests have been done with specially-designed fuel rods with a small as-fabricated fuel-to-clad gap that minimizes the influence of gap conductance change (densification/swelling, fission gas release) on the fuel center temperature during the irradiation. Another feature often used is to have a small pellet diameter in order to increase the burnup accumulation rate. In addition, in-pile power calibration is required for such tests.

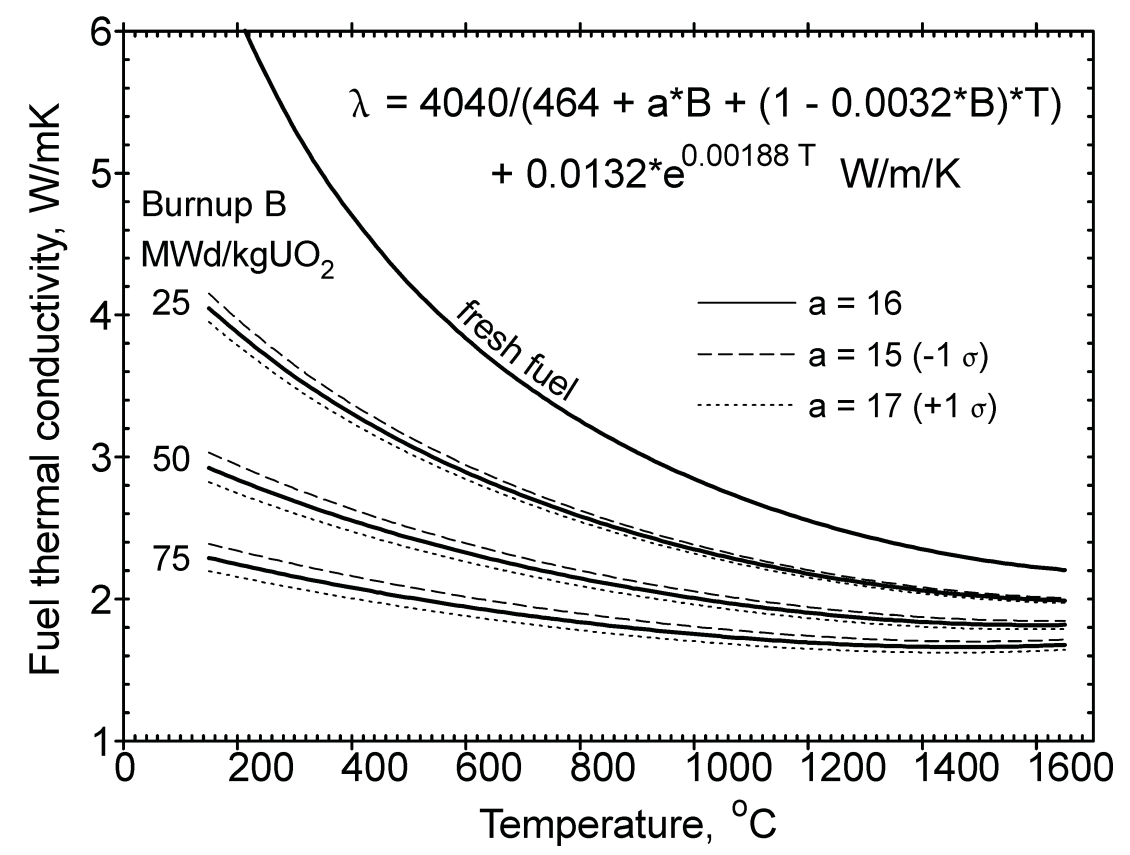

Figure 4-17. Fuel thermal conductivity derived from fuel centerline temperature measurements.

HRP fuel centerline thermocouples normally operate for several years in-core without failure, but the lifetime of the "Type C" tungsten-rhenium used in the HBWR thermocouples has been found to decrease with increasing fuel centerline temperatures. If the fuel centerline temperature exceeds 1400 to $1500{ }^{\circ} \mathrm{C}$, the expected lifetime of the Type $\mathrm{C}$ thermocouples, which must be used with an HRP-specific correction factor to offset transmutation, is typically less than one year (although no fluence values were cited, the peak thermal flux at the HBRWR is $1 \times 10^{14} \mathrm{n} / \mathrm{cm}^{2} \mathrm{~s}$ ). Furthermore, informal discussions with HRP staff indicate that 'batch-to-batch' variations have been observed in Type $\mathrm{C}$ thermocouples procured from various vendors.

The HRP expansion thermometer (see Figure 4-18) consists of a tungsten rod that is inserted through a hole drilled in a fuel stack. The thermal expansion of the tungsten rod is measured using 
an LVDT. The fuel centerline temperature is then derived from the measured expansion of the tungsten rod. The expected lifetime of an expansion thermometer is longer than for a thermocouple, but the accuracy of an expansion thermometer is not as good as the accuracy of a thermocouple. There is also the potential for mechanical interactions between the fuel and the tungsten rod that can affect expansion thermometer performance.

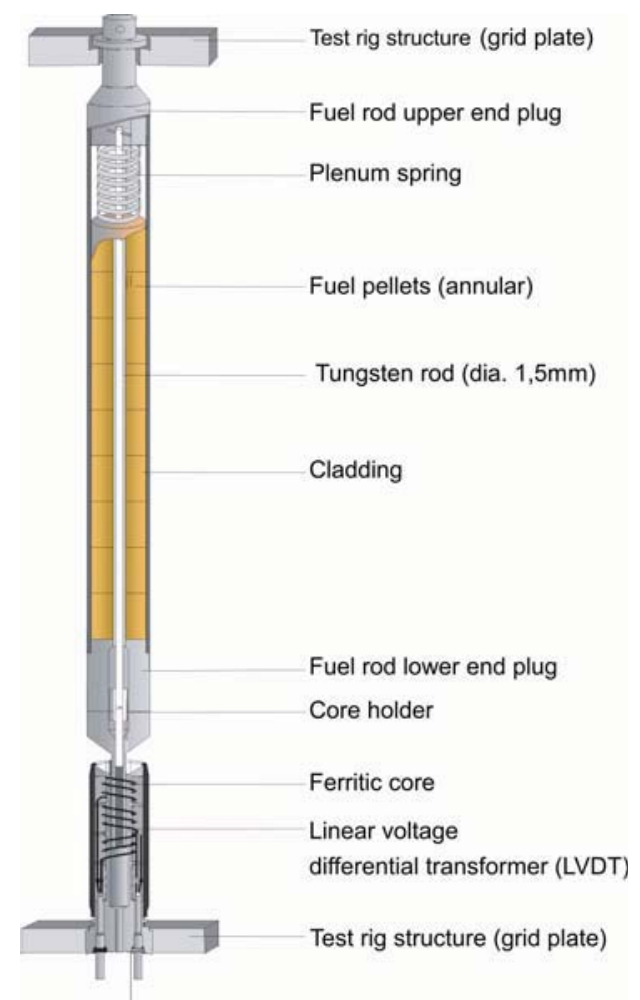

Figure 4-18. Thermal expansion thermometer.

\subsubsection{Fuel densification / swelling measurements}

The mechanical stability of nuclear fuels is an important performance parameter. For in-pile monitoring fuel stack-length changes, the HRP has also developed instruments based on LVDTs. In order to measure fuel densification and swelling, the magnetic core of the LVDT is attached to a spring-loaded plate in contact with a fuel pellet in one end of the fuel stack (see Figure 4-19). The magnetic core then follows the expansion and contraction of the fuel stack and provides data on the fuel's mechanical behavior.

\subsubsection{Fuel rod pressure measurements}

Fission gas release mechanisms and the fuel rod internal pressure are key issues for extending the burn-up of fuel in power reactors. To study the fission gas release phenomena under transient conditions, the HRP developed an in-core pressure sensor which is also based on LVDT technology. The pressure sensor (Figure 4-20) consists of a miniaturized bellows assembly, made from 


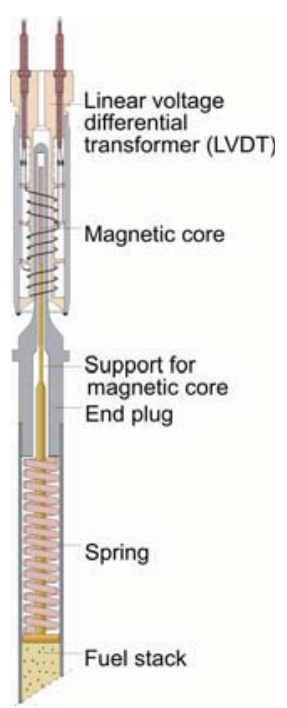

Figure 4-19. Fuel stack elongation detector.

stainless steel or Inconel, inserted into the plenum of the fuel rod. One end of the bellows is fixed to the fuel rod end plug, while the other end is allowed to move freely. A magnetic core assembly is attached to the free moving end of the bellows assembly. If the pressure in the fuel rod plenum is increasing, the bellows assembly will contract (due to the increased outer pressure), and the magnetic core will move accordingly. An LVDT is used for monitoring the position of the magnetic core; and thus, the fuel rod internal pressure can be measured.

Figure 4-20. Pressure gauge

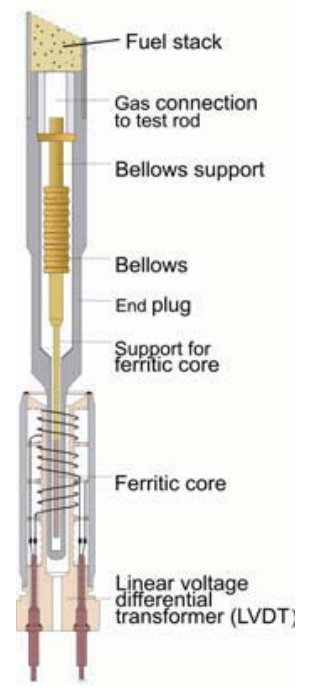

Measurement ranges up to 150 bar (15 $\mathrm{MPa}$ or $2180 \mathrm{psig}$ ) are possible. To reduce material creep at high temperature and radiation intensity, the bellows are pre-pressurized (inside) and conditioned for several days at high pressure and temperature. The pressure transducer can be systematically re-calibrated during reactor outages using procedures developed at HRP (that HRP will provide to other facilities employing one of their sensors). The bellows differential pressure 
will, in addition to release of fission gases, be dependent upon fuel densification/swelling characteristics, changes in gas temperature and fuel/cladding thermal expansion during operation. Densification will lower the fuel rod internal pressure, while swelling and gas temperature effects and fuel differential expansion will increase fuel rod internal pressure.

\subsubsection{Fuel rod diameter measurements}

The HRP uses fuel rod diameter measurements to obtain data on cladding creep, pellet-cladding mechanical interaction, fuel creep / relaxation and fuel rod crud deposits. Several of these items are not only related to the basic fuel behavior, but are also influenced by the environment surrounding the fuel rod. For example, fuel diameter changes are detected as a function of water chemistry and temperature, and the impact of crud deposition on reactor power can be detected using SPNDs. As shown in Figure 4-21, representative test sensors provide real-time in-pile detection of fuel diameter changes, temperature, and neutron exposure and loop coolant temperature, flow, and chemistry (e.g., concentration, $\mathrm{pH}$, etc.).

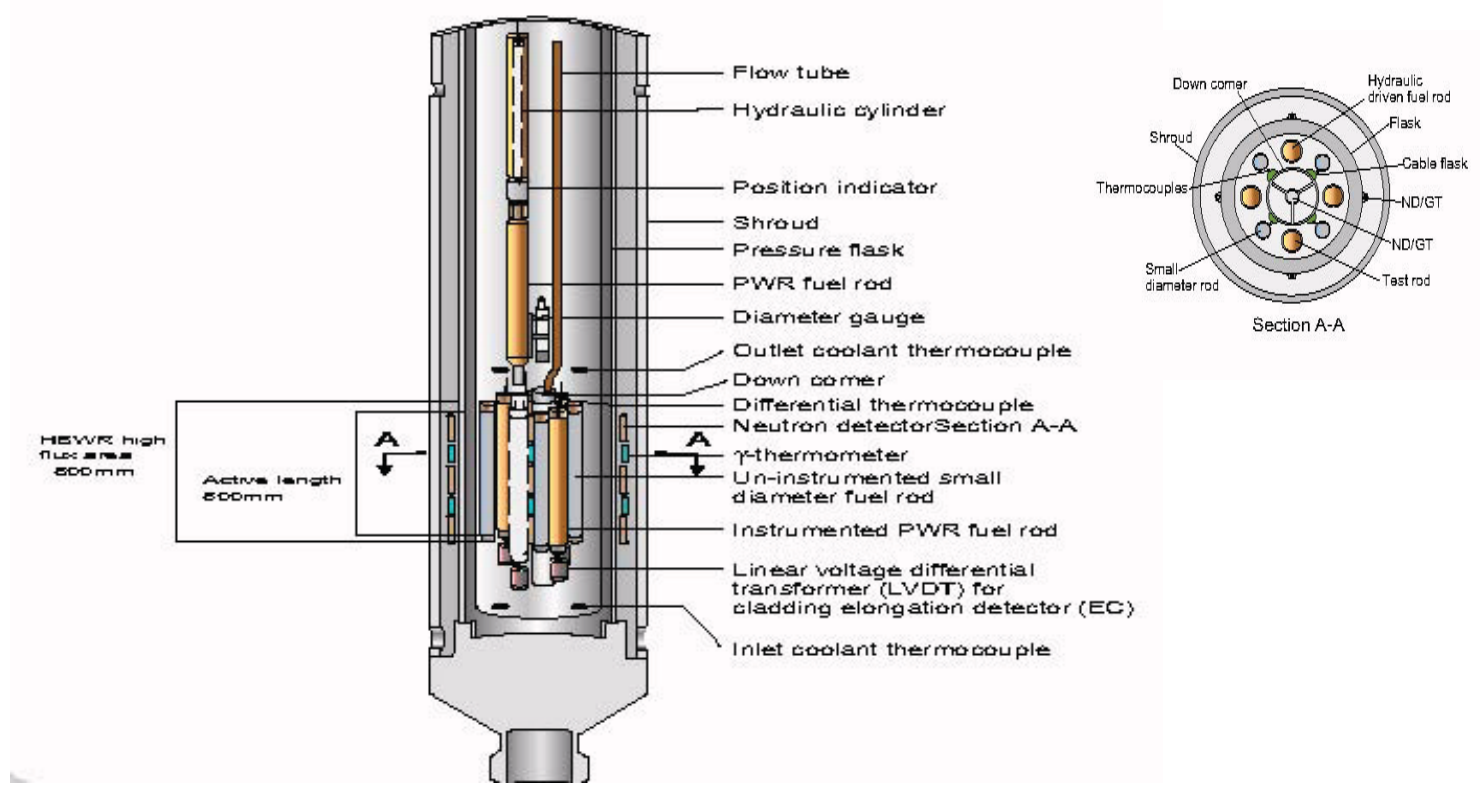

Figure 4-21. Representative HRP fuel pellet cladding interaction or crud deposition test rig.

IFE-HRP relies on LVDT-based technology in this diameter gauge. As shown in Figure 422, the diameter gauge contains a differential transformer with two feelers on opposite sides of the fuel rod. The magnetic flux path is almost entirely enclosed in ferromagnetic material except for a few very narrow gaps. The coils are wound on a ferromagnetic core and the ferromagnetic armature is suspended in cross springs parallel to the coil system in such a way that when the armature moves, one magnet gap will increase while the opposite one decreases. The diameter gauge travels along the fuel rod by using an in-core hydraulic drive and positioning system. It is possible to perform diameter measurements on a continuous basis (e.g. during power transients for measuring pellet-cladding interaction) or on a less frequent basis (e.g. once every month for monitoring crud build-up). The accuracy of the diameter gauge is $\pm 2 \mu \mathrm{m}$, and a calibration is 
performed in conjunction with each diameter trace by using known calibration steps on both fuel rod end plugs. The diameter gauge can operate at up to 165 bar and $325{ }^{\circ} \mathrm{C}$, However, there is the potential to increase this temperature limit with alternate LVDT components and fabrication processes.

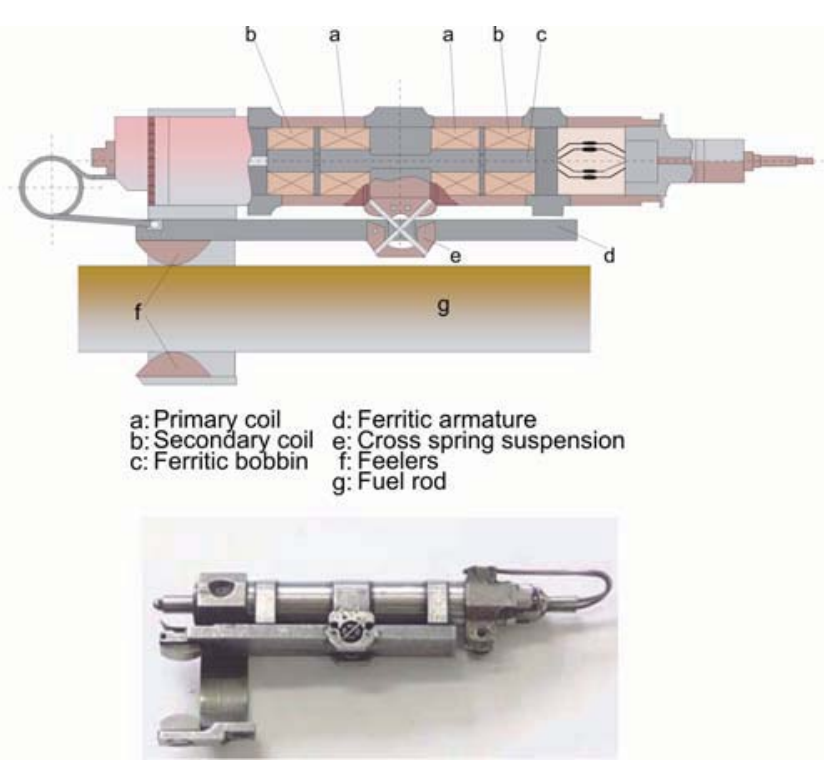

Figure 4-22. Diameter gauge used at HRP.

Figure 4-23 shows results from diameter measurements on a typical PWR fuel rod irradiated in the HBWR as part of a PWR crud evaluation program. The irradiation is performed in a PWR loop system that allows variations in water chemistry parameters during irradiation. Diameter gauge run no. 7275 was performed immediately after startup of the experiment to provide initial fuel rod diameter data. Diameter gauge run no. 7739 was performed after approximately 230 days at full power and shows cladding creep-down typical for PWR fuel rods. Diameter run. no. 7754 was performed after an additional 25 days after changing the water chemistry in the loop system. The water chemistry change included an increase in the iron and nickel content. The diameter trace shows that crud deposits formed on the upper part of the fuel rod. The possibility of observing the formation of crud by monitoring the fuel rod diameter on-line along with changes in neutron flux and fuel temperature provides the HRP insights into developing a remedy for crud and related phenomena as "Axial Offset Anomaly". 32

\subsubsection{Crack-growth measurements}

In order to monitor crack-growth rates in core structural component materials, the HRP utilizes miniaturized Compact Tension (CT) specimens and the "direct current potential drop method" for measuring crack propagation. The direct current potential drop method (see Figure 424) is based on sending an electrical current through the specimen and measuring the potential (voltage) at several locations on the CT-specimen. The measured potentials depend on the propagation of the crack. Thus, the crack-length can be determined from the measured potential drops. Reference 33 reports results in which this approach was successfully applied to detect changes in 


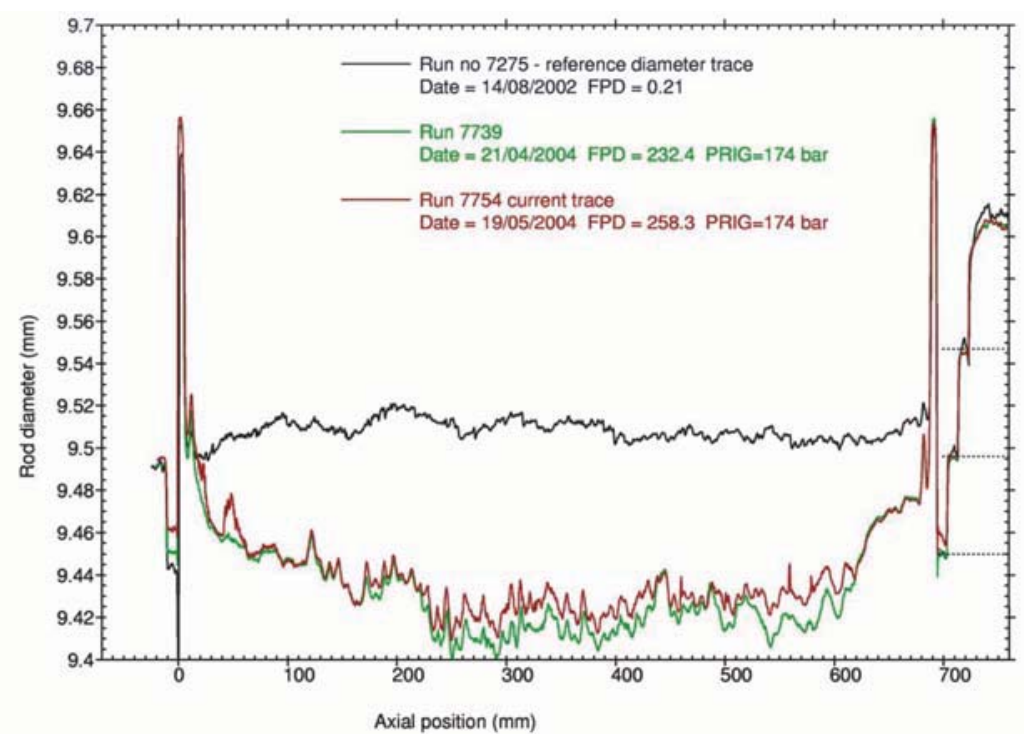

Figure 4-23. Fuel rod diameter traces showing cladding creep down and crud deposition.

crack growth rate due to variations in coolant $\mathrm{pH}$ for various metals. HRP has applied this technology to detect the impact of coolant parameters ( $\mathrm{pH}$, impurities, boron concentration, etc.) on fuel cladding corrosion. In addition, HRP can perform such measurements on pre-irradiated fuel removed from commercial reactors.

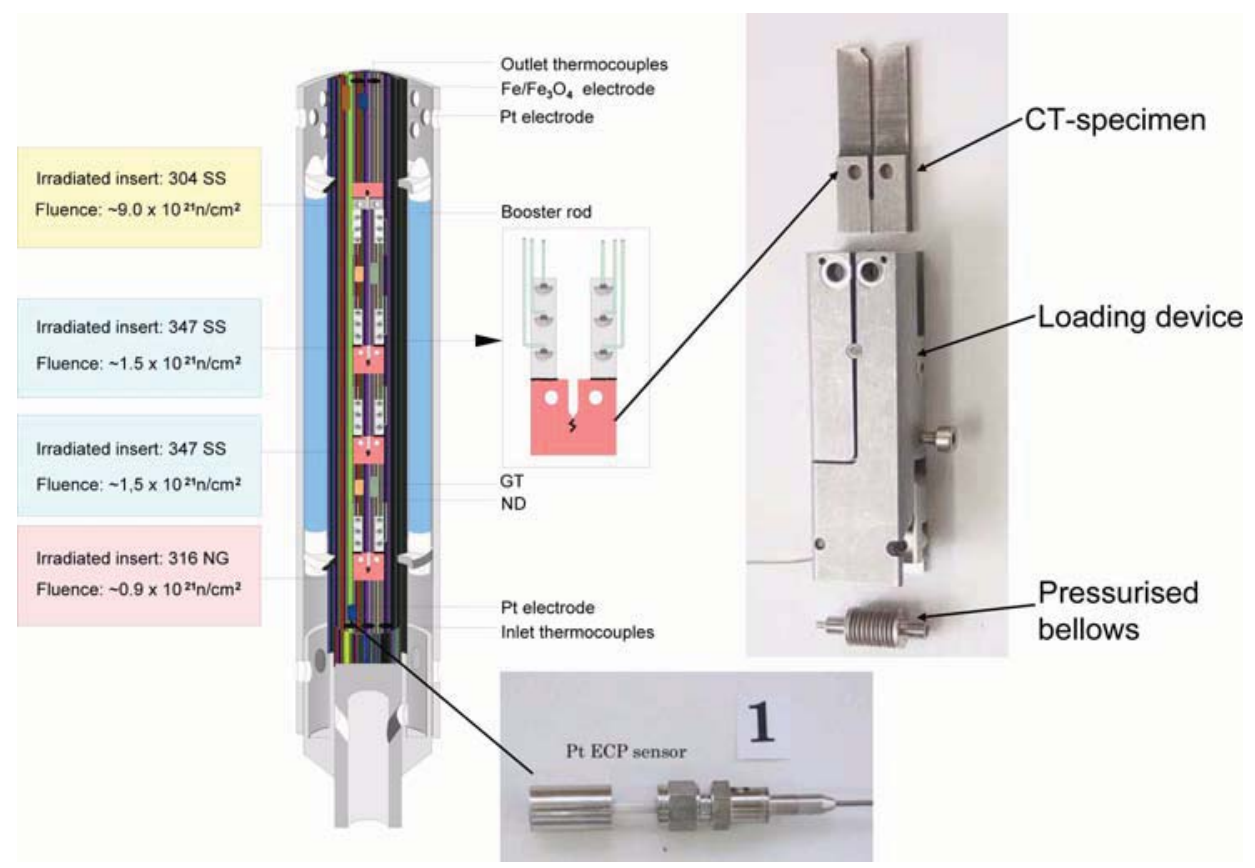

Figure 4-24. Crack growth test rig 


\subsubsection{Summary}

Although the HBWR has a much lower power rating and is considerably older than the ATR, the instrumentation capabilities developed by HRP staff have significantly extended its irradiation capabilities. In addition, the HRP has leveraged this expertise to supply instrumentation for commercial, naval, and other materials test reactors.

The HRP relies heavily on specialized in-core instrumentation in order to perform fuel and material irradiation programs in the HBWR. Although not discussed in this section, the HRP also has the ability to attach in-core instrumentation to pre-irradiated fuel rods and material samples from power reactors. Typically, HRP applies instrumentation to detect fission gas release and thermal conductivity degradation to pre-irradiated fuel rods. Irradiated structural material samples have been instrumented to detect crack growth. The IFE-HRP continues to refine its existing inpile instrumentation and develop new instruments.Ongoing IFE-HRP instrumentation development focuses on high temperature conditions, new methods for crack detection and corrosion of fuel cladding materials.

\subsection{JAEA}

The Japan Atomic Eneryg Agency (JAEA) [formerly the Japan Atomic Energy Research Institute (JAERI)] provides several types of instrumentation to support tests in the Japan Materials Test Reactor (JMTR). ${ }^{35}$ Commercial-available sensors procured from Japanese vendors allow JMTR customers to detect temperatures (via Type N, K, and C thermocouples and In, Sn, Pb, Ag, and $\mathrm{Zn}$ melt wires), length and diameters (using LVDT-based sensors made by Japanese vendors), fission gas release, and neutron flux (using $1.8 \mathrm{~mm}$ diameter fission chambers, SPNDs containing $\mathrm{Rh}, \mathrm{Co}$, or Pt-40\%Rh, or flux wires--Fe for fast flux and Al-Co, V-Co, or Ti-Co for thermal neutrons), and crack growth (using bellows to load a precracked sample with direct current potential drop techniques). Reference 35 also indicates that JAEA can reinstrument previously irradiated fuel rods. JAEA continues to conduct research to enhance specialized instrumentation to support high temperature irradiations conducted in their High Temperature Test Reactor (HTTR) prototype gas reactor and Japan Materials Test Reactor (JMTR). As discussed in References 35 through 39 , research is focussing on new technologies for in-pile measurements of temperature, creep, neutron flux, and gamma-ray intensity distributions.

\subsubsection{Creep and Deformation}

Reference 37 describes JAEA efforts to develop irradiation equipment for in-pile creep and deformation of specimens subjected to loads of up to $10 \mathrm{kN}$ at temperatures up to $600{ }^{\circ} \mathrm{C}$. The invessel parts of this unit (see Figure 4-25) is installed in the reactor pressure vessel through an HTTR standpipe. This in-vessel part is $8.9 \mathrm{~m}$ long with the lower portion consisting of three tubular parts, two irradiation units and a guide tube, that are each $2.6 \mathrm{~m}$ long and $0.113 \mathrm{~m}$ in diameter. Although the specimens are primarily heated from HTTR core heat, a smaller electric $300 \mathrm{~W}$ 
heater is included for supplementary temperature control. The neutron flux that specimens experience is monitored using SPNDs containing rhodium as the emitter. Small fluence wires are also included for post-irradiation fast and thermal fluence measurements. Temperature is monitored using Type $\mathrm{K}$ thermocouples, and specimen elongation is monitored by LVDTs containing "fine mineral insulated cable" coil material. Reference 37 notes that JAEA developed these LVDTS specially for these tests, but doesn't provide any additional information about what metals are used in the coil material and if this material is subject to any Curie temperature effect (such as the materials used in the HRP coils). Furthermore, Reference 37 doesn't cite any additional references where additional information on JAEA LVDT design and performance evaluations can be found.

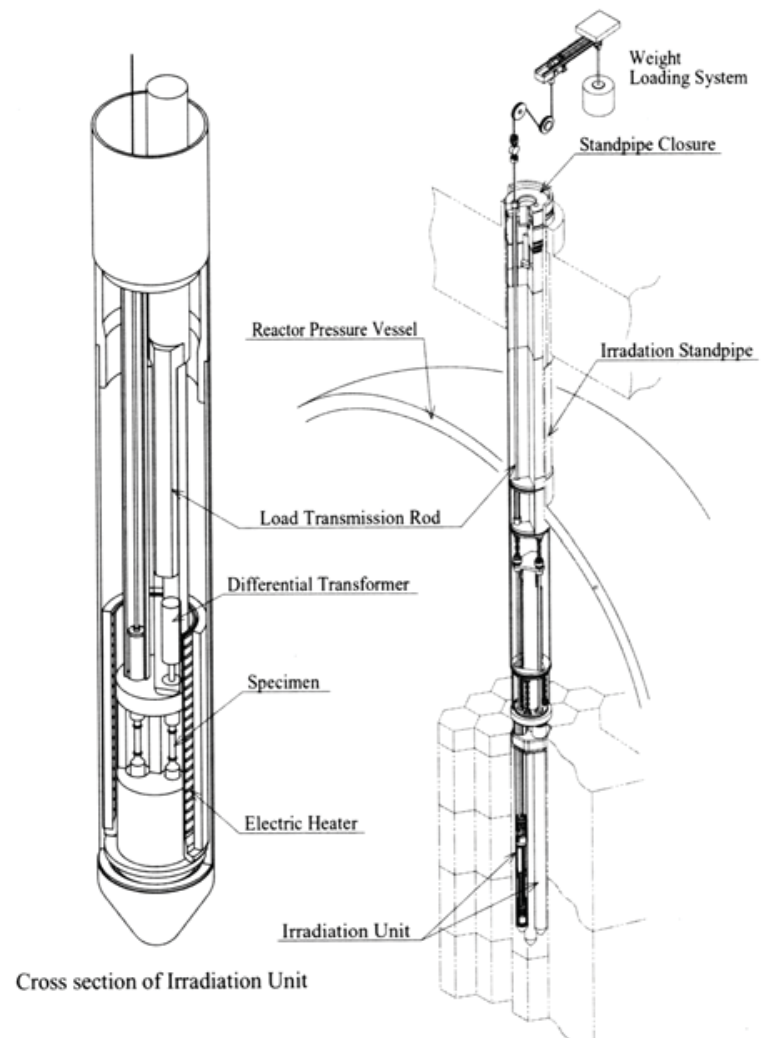

Figure 4-25. I-I type irradiation unit with weight loading equipment

\subsubsection{Optical Diagnostic Techniques}

JAEA has been active in research to use optical diagnostic techniques to measure temperatures, reactor power, and other operating parameters. Reference 38 reports research results indicating that newly-developed fluorine doped (F-doped) optical fibres can withstand radiation damage better than silicon core fibres. Results for an F-doped optical fiber indicate that the radiation-induced optical absorption at about $600 \mathrm{~nm}$ was less than $0.2 \mathrm{~dB} / \mathrm{m}$ for an electronic excitation exposure dose of 1.9E6 Gy (1.9e13 rads). 


\subsubsection{Neutron Flux and Gamma-Ray Intensity Detection}

For real-time measurement of thermal neutron flux and gamma-ray intensity distributions, JAEA is exploring two methods: a scintillator optical fiber with a scanning driver and a self-powered detector with the driver. Tests were completed using the driver system to insert each type of detector into irradiation holes of the TRIGA II reactor at the Institute for Atomic Energy at Rikkyo University. Results indicate that scanning a one meter long core using an optical fiber with a scintillator (ruby) attached to the tip yields neutron flux distributions similar to that obtained with foil activation methods (see Figure 4-26). If the scintillator powder is mixed with ${ }^{6} \mathrm{LiF}$ powder, it can be used for gamma-ray measurement. However, the foil activation method require 4 to 5 hours whereas the fibre method only requires 10 minutes.

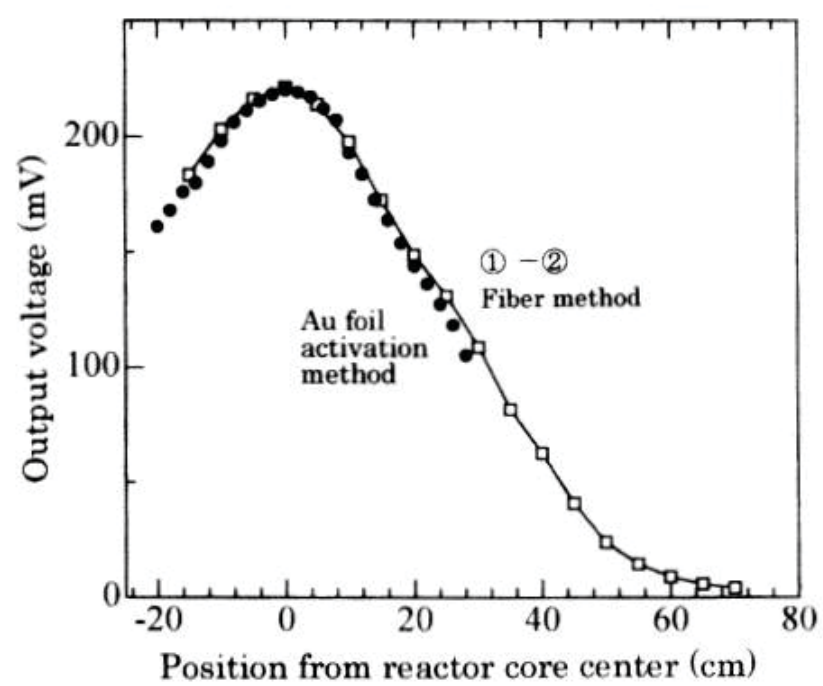

Figure 4-26. Signals obtained with optical fiber detector and Au foil activation methods.

Because light emission of the ruby scintillator decreases at high temperatures, this method is limited to temperatures of around $100{ }^{\circ} \mathrm{C}$. Although JAEA is continuing to explore the potential of other scintillators, Reference 39 also reports results from tests using the driver system with self-powered detectors containing quartz insulators were found to function for temperatures up to $500{ }^{\circ} \mathrm{C}$. Detectors with alumina tubes were only found to function up to $400{ }^{\circ} \mathrm{C}$.

\subsection{NRG}

The High Flux Reactor (HFR) at Petten, which is owned by the European Communities and operated by the Netherlands Energy Research Foundation (ECN), has been conducting fuel irradiations using instrumented test rigs for over 40 years. The Nuclear Research and consultancy Group (NRG) was established as a Partnership Firm in 1998 through the merger of ECN's (70\% share) and KEMA's (30\% share) business activities in the nuclear fields. HFR test capsules have been successfully used to investigate power cycles and ramping behavior on PWR and BWR fuel 
rods. ${ }^{40}$ Although the HTR originally focussed on LWR fuel irradiations, significant testing of HTR and SFR fuels have also been conducted in this facility. Typical instrumentation in such capsules allows measurement of fuel stack displacement, fuel rod length, fuel rod internal pressure, neutron flux, gamma flux, and fuel rod central temperatures (up to $1350{ }^{\circ} \mathrm{C}$ ). Discussions with Petten staff indicates that instruments are primarily obtained from commercial vendors or IFEHRP. ${ }^{41,42}$ Typical instruments employed in specialized ECN test rigs (and the vendors from whom they are typically obtained) are listed in Table 4-4. Reference 43 describes a testing facility installed in Petten for continuous in-pile crack testing of samples up to $730{ }^{\circ} \mathrm{C}$. In recent years, NRG has been involved in several internationally-sponsored tests for advanced reactor fuels. ${ }^{44} \mathrm{In}$ particular, this reference discusses recently completed and ongoing campaigns to evaluate gas reactor fuel elements (the HFR-EU1bis and HFR-EU1 tests), gas reactor fuel coating materials (the PYCAASSO I and II tests), liquid metal fast reactor and accelerator driven system fuel tests (CONFIRM, FUJI), transmutation fuel tests (HELIOS irradiations), and advanced fuel cycle (e.g., U-Pu and Th-U cycle tests (THORIUM testing).

Table 4-4. Sensors typically deployed in HFR test rigs

\begin{tabular}{|c|c|c|c|c|}
\hline Parameter & Sensor & Description & Manufacturer & Limitations \\
\hline \multirow[t]{2}{*}{ Neutron Fluence } & $\begin{array}{c}\text { Neutron } \\
\text { metrology sets }\end{array}$ & $\begin{array}{l}\text { SS tubes containing quartz } \\
\text { minitubes with flux wires } \\
(\mathrm{Nb}, \mathrm{Ti}, \mathrm{Fe}, \mathrm{NiCo})\end{array}$ & NRG & $\begin{array}{l}\text { Maintain below } 800-1000{ }^{\circ} \mathrm{C} \text { (to } \\
\text { prevent damage to quartz } \\
\text { minitubes containing wires). }\end{array}$ \\
\hline & $\begin{array}{l}\text { Self Power } \\
\text { Neutron } \\
\text { Detectors }\end{array}$ & $\begin{array}{l}\text { Contains tube with } \\
\text { emitter,that transmutes and } \\
\text { decays, emitting electrons } \\
\text { that produce electrical } \\
\text { current. Response time } \\
\text { depends on emitter } \\
\text { material (Co and } \mathrm{Pt} \sim, 0.05 \\
\text { sec; } \mathrm{V}, \mathrm{Rh}, \text { and } \mathrm{Ag} \sim 51 \\
\text { sec. to } 5.4 \text { min.) }\end{array}$ & $\begin{array}{l}\text { Thermocoax, } \\
\text { Halden }\end{array}$ & $\begin{array}{l}\text { Properties of SPND change due } \\
\text { to emitter transmutation. } \\
\text { Lifetime limited by emitter (V } \\
\text { and } \mathrm{Co} \sim 20 \text { year lifetime; } \mathrm{Rh} \sim \\
\left.3 \text { year lifetime in } 10^{9} \mathrm{nt} / \mathrm{cm}^{2} \mathrm{~s}\right)\end{array}$ \\
\hline Temperature & Thermocouples & Type $\mathrm{K}$ and Type $\mathrm{N}$ & Thermocoax & $1000^{\circ} \mathrm{C}$ \\
\hline \multirow[t]{2}{*}{ Pressure } & $\begin{array}{l}\text { Silicon Chip } \\
\text { Transducer } \\
\text { (XTL-190M) }\end{array}$ & $\begin{array}{l}\text { Tube containing silicon } \\
\text { chip influenced by } \\
\text { pressure. }\end{array}$ & Kulite & $\begin{array}{l}\text { Below } 210 \text { bar (measurement } \\
\text { range depends on requested } \\
\text { pressure --- } 9 \text { ranges available } \\
\text { between } 0 \text { and } 140 \text { bar). }\end{array}$ \\
\hline & $\begin{array}{l}\text { LVDT pressure } \\
\text { transducer }\end{array}$ & $\begin{array}{l}\text { SS tube containing sealed } \\
\text { bellow, magnetic core, and } \\
\text { LVDT. } \\
\text { Dimensions: } 13 \mathrm{~mm} \\
\text { (diameter) x } 130 \mathrm{~mm} \\
\text { (length) }\end{array}$ & IFE-HRP & $\begin{array}{l}\text { Successfully used in gamma } \\
\text { field. Probably usable in neutron } \\
\text { field (but not tested). }\end{array}$ \\
\hline
\end{tabular}




\subsection{KAERI}

The Korea Atomic Energy Research Institute (KAERI) utilizes specialized instrumentation in test capsules supporting materials and fuel irradiations in their High flux

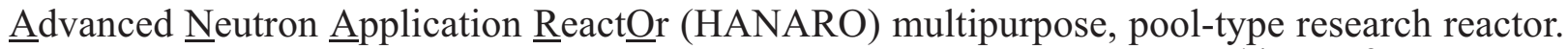
HANARO was designed to provide a peak thermal and fast flux of $5 \times 10^{14} \mathrm{n} / \mathrm{cm}^{2} \cdot \sec (\mathrm{E}<$ $0.625 \mathrm{eV})$ and $2.1 \times 10^{14} \mathrm{n} / \mathrm{cm}^{2} \cdot \mathrm{sec}(\mathrm{E}>1.0 \mathrm{MeV})$ at a $30 \mathrm{MW}$ thermal power, respectively. Since HANARO began operation in 1995, a significant number of experimental facilities has been developed and installed in its 32 vertical holes and 7 horizontal beam ports to support fuels and material irradiations. 45 and 46

Test equipment for irradiating nuclear fuels and materials in HANARO are classified into two categories, capsules (non-instrumented and instrumented) and FTL (Fuel Test Loop). Instrumented capsules for materials irradiations may include thermocouples, fluence monitors, and heaters. Fuel tests may include thermocouples (Types K and C), pressure transducers and elongation detectors to measure fuel temperature, internal pressure of the fuel rod, and fuel deformation, respectively, and SPNDs to detect neutron flux. In addition, KAERI has developed specialized capsules for creep and fatigue testing. These capsules often include thermocouples, fluence monitors, and heaters. KAERI typically procures commercially-available sensors from Thermocoax (thermocouples and SPNDs), Studsvik (SPNDs) and IFE-HRP (LVDTs). Recently, KAERI has initiated efforts to obtain enhanced instrumentation for testing of LWR and advanced reactor fuels and materials, including instrumentation being developed in other countries. ${ }^{46}$

\subsection{NECSA}

The SAFARI-1 test reactor, which is operated by the South Africa Nuclear Energy Corporation, has in recent years been primarily utilized for the production of isotopes that are needed by the international industrial and medical sectors. However, preparations are underway to implement test rigs to allow reactor materials and fuel irradiations. It is planned to include the following instrumentation in these irradiation test rigs: 47

- SPNDs to continuously monitor the thermal flux

- Thermocouples imbedded in irradiation devices

- Flux monitors (e.g., flux foils and/or wires) to measure fluence at selected locations

- Calorimeters to measure total heat deposited in various materials.

It is planned to procure most of this instrumentation from commercial vendors. However, the high temperatures planned for future GCR fuel irradiations have led NECSA to request INLdeveloped HTIR-TCs (see Section 6.1). A wide range of measurements has been planned for the Pebble Bed Modular Reactor (PBMR) Demonstration Power Plant (DPP) that will be built in South Africa. As indicated in Reference 48, the Core Structure Instrumentation (CSI) system will measure the neutron flux and temperature distribution in the reactor's graphite reflector. The mechanical stresses, loads, and temperatures on the core barrel will also be monitored. Most of 
this instrumentation is commercially available instrumentation, such as source range monitors, SPNDs, strain gauges, LVDTs, and Type N thermocouples. In some cases, however, newer technologies are under consideration. For example, PBMR is considering the use of fiber optics to detect temperature and strain.

\subsection{ORNL}

The High Flux Isotope Reactor (HFIR), which is located at and operated by Oak Ridge National Laboratory (ORNL), is an 85-MW isotope production and test reactor that is berylliumreflected, light-water-cooled and -moderated, with highly enriched uranium-235 as the fuel. HFIR provides one of the highest steady-state neutron fluxes available in any of the world's reactors, and neutron currents from its four horizontal beam tubes are among the highest available.

The original primary purpose of HFIR was the production of transuranium isotopes. However, many experiment-irradiation facilities were included in its original design; and several others have been added. Experiment-irradiation facilities available include (1) four horizontal beam tubes, which originate in the beryllium reflector; (2) the hydraulic tube facility, located in the very high flux region of the flux trap, which allows for insertion and removal of irradiation samples while the reactor is operating; (3) thirty target positions in the flux trap, which normally contain transuranium production rods but which can be used for the irradiation of other experiments (two are instrumented target positions provided by a recent modification); (4) six peripheral target positions located at the outer edge of the flux trap; (5) numerous vertical irradiation facilities of various sizes located throughout the beryllium reflector; (6) two pneumatic tube facilities in the beryllium reflector, which allow for insertion and removal of irradiation samples while the reactor is operating for activation analysis; and (7) four slant access facilities, called "engineering facilities," located adjacent to the outer edge of the beryllium reflector. In addition, spent fuel assemblies are used for gamma irradiation in the gamma irradiation facility in the reactor pool.

Today, HFIR is principally used to provide a stable neutron source for fundamental scientific experiments associated with neutron scattering. A 5 inch deep flux trap located at the center of the HFIR fuel element provides a thermal neutron flux of $2 \times 10^{15} \mathrm{n} / \mathrm{cm}^{2}$-sec for instrumented lead capsules and loop tests; reflector positions are available for exposing samples in static capsules, loop, and isotope production tests to fluxes of $1 \times 10^{15} \mathrm{n} / \mathrm{cm}^{2}$-sec. Access to some experimental positions is via a pneumatic tube to allow rapid insertion and removal during reactor operation. One unique sensor currently deployed at HFIR, SiC temperature monitors for detecting peak temperature in static capsule tests, is discussed in Section 4.8.1.

\subsubsection{Silicon Carbide Temperature Monitors for Peak Temperature Detection}

Since the early 1960s, the observation that irradiation-induced swelling of silicon carbide ( $\mathrm{SiC}$ ) begins to anneal out at temperatures exceeding its irradiation temperature has been used as a 
post-irradiation temperature monitor. ${ }^{49}$ Various approaches (e.g., changes in length, density, thermal conductivity, and electrical resistivity) have been used to infer irradiation temperature from this observed phenomena. Snead et al. ${ }^{50}$ recommends using changes in resistivity because of improved accuracy, ease of measurement, and reduced costs. Work presented by Snead in Reference 50 was conducted on chemically vapor deposited (CVD) SiC. This material is fully dense (3.203 g/cc) and stoichiometric. Comparisons between $\mathrm{SiC}$ measurements and thermocouples indicate that accuracies of approximately $20^{\circ} \mathrm{C}$ are possible for dose ranges of 1 to 8 dpa and temperatures from 200 to at least $800^{\circ} \mathrm{C}$. Absolute limits for this approach are $150{ }^{\circ} \mathrm{C}$ (an amorphorous threshold) and $875^{\circ} \mathrm{C}$ (due to recrystallization). Note that Reference 51 cites that measurements should be taken in a controlled environment (within $0.4{ }^{\circ} \mathrm{C}$ ) with annealing periods of approximately 30 minutes to obtain these accuracies.

Figure 4-27 (from Reference 50) shows data obtained from this technique. The curves shown in this figure represent data obtained from a series of samples, all irradiated in the ORNL HFIR core at similar dose rates of $\sim 8 \times 10^{14} \mathrm{n} / \mathrm{cm}^{2}$-s $(E>0.1 \mathrm{MeV})$. The total dose for the curves is not identical. The curve for an irradiation temperature of $\sim 350{ }^{\circ} \mathrm{C}$ is at the lowest dose $(\sim 0.1 \mathrm{dpa}$, assuming $1 \mathrm{dpa}=1 \times 10^{21} \mathrm{n} / \mathrm{cm}^{2} ; \mathrm{E}>0.1 \mathrm{MeV}$ ) while the remainder are from $\sim 1-8 \mathrm{dpa}$. It is speculated that the apparent saturation in normalized resistivity for the 0.1 dpa sample represents the point at which the simplest of the defects in the irradiated $\mathrm{SiC}$ have annealed away and represents conductivity at the new dopant level for the irradiated SiC.

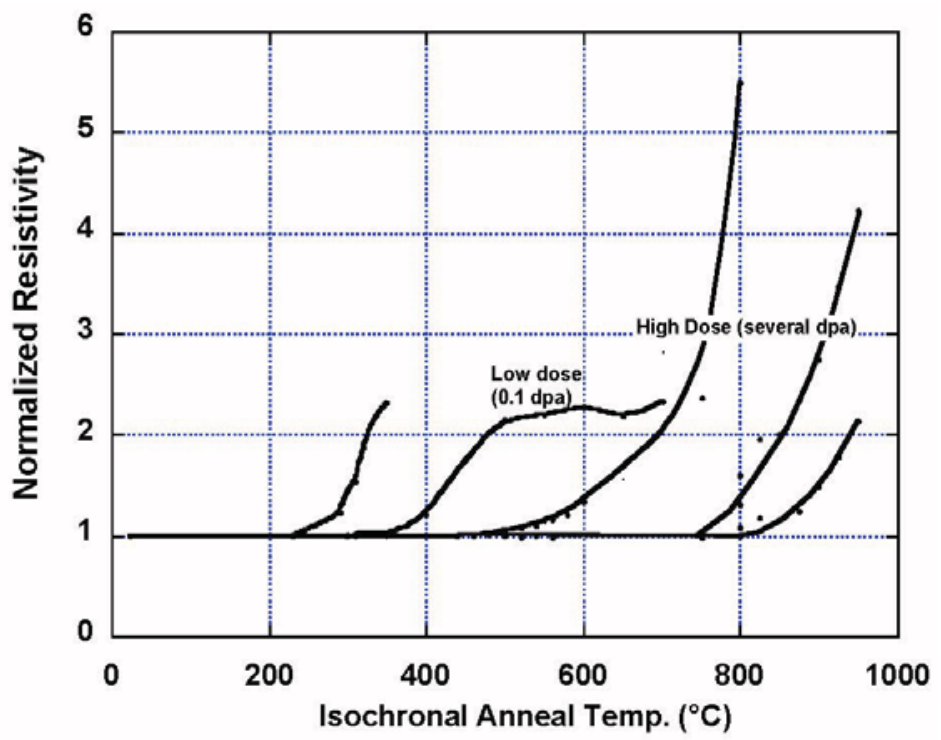

Figure 4-27. Electrical resistivity technique applied over a range of irradiation temperatures.

It should be noted that there are several limitations associated with the use of $\mathrm{SiC}$ temperature detectors. As discussed in Reference 52, temperatures are inferred by post-irradiation detection of changes in the stable defect population within $\mathrm{SiC}$ monitors that were incurred during 
irradiation. Some examples where errors could be inferred from SiC monitors cited in Reference 52 include:

- Irradiation temperatures rising during the latter part of irradiation. For damages greater than $>0.1 \mathrm{dpa}$ ), the increasing temperature will anneal out defects that occur at the lower irradiation temperature, while creating stable defects at the higher temperature. When isochronal annealing is performed, lower temperature defects (to some or great extent) will have already been removed, and the recovery curve will be smeared to somewhat higher temperatures. If the temperature increase during irradiation is not great, or the time at higher temperature not high, then the original departure from linearity will still give the earlier irradiation temperature.

- Irradiation temperatures decreasing during irradiation. This decrease will lead to defects being created and frozen-in at the higher-temperature, while continuing to create lower temperature defects. The isochronal anneal will then give you an indication of the lowest irradiation temperature (in this case at the end of the irradiation period) and the recovery curve will be smeared because you will continue to anneal higher and higher temperature stable defect.

- Upward or downward temperature spikes during irradiation. This case has the potential to lead to partially created or annealed defects, depending on the change and duration of the temperature increase and the damage to the $\mathrm{SiC}$ monitor during irradiation.

However, if irradiation tests are conducted at or near the same temperature when the reactor is at power, none of these situations are of concerns. 


\section{PATH FORWARD FOR ENHANCED ATR INSTRUMENTATION}

INL has a long history of developing highly specialized instrumentation to meet demands of customers conducting unique tests in INL facilities. Such instrumentation was used in INL test reactors and in facilities from the Power Burst Facility (PBF) and Loss of Fluid Test (LOFT) research programs. Unfortunately, INL instrumentation development and research funding declined significantly in the 1980s, when large test facility programs ended. Until recently, ATR irradiations relied primarily on commercial vendors for instrumentation.

As documented in Section 4, several test reactor programs in Europe and Asia, such as the HFR (Petten) and HBWR (Halden) appear to have better maintained their instrumentation development and evaluation research capability. Others, such as CEA, are rapidly trying to regain this expertise. As part of the ATR NSUF, it was recognized that a similar focussed effort was needed at INL if the ATR is to become competitive as a world class irradiation facility. Hence, a research and development plan was developed in 2007 so that ATR users have access to enhanced realtime in-pile instrumentation, comparable to (and, in some cases, superior to) that available at other materials and test reactors, by 2015. As documented in this section, the plan identifies and prioritizes instrumentation research considering customer and reactor staff needs along with technology readiness. Section 6 reports on INL progress in accomplishing objectives outlined in the research plan presented in this section.

\subsection{Motivation/Justification for Investment}

There are several reasons that an instrumentation research and development program is right for the ATR, the ATR NSUF, and INL:

- Key Component for ATR NSUF Success. If the ATR NSUF is to become a world-class irradiation facility, adequate instrumentation must be available to its users. Clearly, the ATR has advantages over many other materials and test reactors that are older with smaller irradiation test locations and lower flux levels. Yet, the instrumentation capabilities developed by research staff at other test reactors allow their customers to obtain real-time data from tests that cannot be obtained from tests conducted in the ATR.

- Expertise for prioritizing instrumentation program tasks. Specialized instrumentation was once a core capability of this laboratory. Engineering staff that support ATR irradiations at INL have a long history of designing specialized capsules and test fixtures. If INL obtains input from staff that support ATR irradiations for DOE-NE and naval reactor programs that will be funding most near-term materials and fuels tests, this instrumentation development program can help meet near-term customer needs and help the ATR attract other customers.

- Expertise and facilities for developing and deploying unique instrumentation. Much of the investment has already been made to obtain the right equipment and trained staff. INL's High Temperature Test Laboratory (HTTL) is a state-of-the-art facility with unique equipment for evaluating and fabricating (where needed) this instrumentation. INL has a unique test reactor for demonstrating and using new instrumentation for in-pile measurements.

- Market for research program task collaboration and products. Clearly, the primary market 
for products from this research program are ATR users. However, INL-developed instrumentation have the potential to attract customers from other materials test reactors (e.g., ECN and NESCA as noted in Section 4). In addition, there is the potential for instrumentation developed and deployed from this research to be used in commercial nuclear power plants and for non-nuclear applications. Potential funding sources for an ATR NSUF instrumentation program and its products are summarized in Table 5-1. This table also lists potential collaborators for various instrumentation program elements.

Table 5-1. Funding sources and potential collaborators for INL instrumentation elements.

\begin{tabular}{|c|c|c|}
\hline Program Elements & Funding Sources & Collaborators \\
\hline $\begin{array}{l}\text { Instrumentation Program } \\
\text { Sensor Development }\end{array}$ & $\begin{array}{l}\text { ATR Scientific User Facility } \\
\text { DOE-NE Sponsored LWR R\&D } \\
\text { DOE-NE Sponsored Advanced Fuel Cycle R\&D } \\
\text { Nuclear Regulatory Commission } \\
\text { INL LDRD }\end{array}$ & $\begin{array}{l}\text { IFE-HRP } \\
\text { CEA } \\
\text { SCK·CEN } \\
\text { NRG } \\
\text { KAERI } \\
\text { JAERI } \\
\text { International Funding Agencies } \\
\text { (OECD, IAEA, JRC) }\end{array}$ \\
\hline $\begin{array}{l}\text { Developed Sensors- } \\
\text { Nuclear Customers }\end{array}$ & $\begin{array}{l}\text { Other Materials Test Reactors (South Africa } \\
\text { SAFARI-1, NRG/JRC - Petten, KAERI-HANARO, } \\
\text { ORNL-HFIR, SNL-ACRR, etc.) } \\
\text { Commercial Nuclear Reactors } \\
\text { DOE-NE (NGNP, GNEP, LWR R\&D, etc.) } \\
\text { NNSA (NR) } \\
\text { NASA }\end{array}$ & $\begin{array}{l}\text { Other Materials Test Reactors } \\
\text { (China, South Africa, Australia, } \\
\text { France, Norway, Netherlands, US- } \\
\text { SNL \& ORNL) } \\
\text { Commercial Industry (fiber optic, } \\
\text { thermocouple, and pushrod } \\
\text { dilatometer / LVDT vendors via } \\
\text { STTR or venture capital) to } \\
\text { transfer technology. }\end{array}$ \\
\hline $\begin{array}{l}\text { Developed Sensors- } \\
\text { Non-Nuclear Customers }\end{array}$ & $\begin{array}{l}\text { Department of Defense, Aircraft Industry, } \\
\text { Coal Industry }\end{array}$ & $\begin{array}{l}\text { High Temperature Refractory } \\
\text { Metal Processing, Aircraft Industry }\end{array}$ \\
\hline
\end{tabular}

\subsection{Currently Available ATR Instrumentation}

Table 5-2 identifies instrumentation currently used in various ATR experiments. As noted above, most ATR instrumentation is obtained from commercial vendors. The column labeled "Currently Available" under "Possible Instrumentation Advancement" lists instrumentation that is used at other test reactors that could be adapted for ATR applications. As indicated in this table, several technologies are being used at other test reactors that could enhance ATR instrumentation capabilities. Note that adapting such instrumentation from other test reactors often requires laboratory demonstrations because of ATR-specific irradiation conditions and test capsule geometries. For example, smaller devices may be required that can withstand higher temperatures and fluences. The column labeled "Developmental" under "Proposed Instrumentation Advancement" lists developmental or non-nuclear technologies that could be used in ATR irradiation tests. Technologies listed in this column are considered to be less "ready" for implementation. 
Table 5-2. Current and developmental instrumentation for ATR irradiations.

\begin{tabular}{|c|c|c|c|c|}
\hline \multirow[t]{2}{*}{ Location } & \multirow[t]{2}{*}{ Parameter } & \multirow[t]{2}{*}{ Technology at ATR } & \multicolumn{2}{|c|}{$\begin{array}{l}\text { Possible Instrumentation Advancement } \\
\text { (Section where discussed) }\end{array}$} \\
\hline & & & Currently Available & Developmental \\
\hline \multirow[t]{3}{*}{$\begin{array}{l}\text { Static } \\
\text { Capsule } \\
\text { Experiment }\end{array}$} & $\begin{array}{l}\text { Peak } \\
\text { Temperature }\end{array}$ & $\begin{array}{l}\text {-Melt wires } \\
\text {-Paint spots }\end{array}$ & $\begin{array}{l}\text {-SiC Temperature Monitors } \\
\text { (ORNL / INL - Section 4.8.1 and } \\
\text { Section 6.1) }\end{array}$ & -Wireless technologies \\
\hline & $\begin{array}{l}\text { Fluence ( } \\
\text { neutron) }\end{array}$ & $\begin{array}{l}\text {-Flux wires (Fe, } \mathrm{Ni} \text {, } \\
\text { and } \mathrm{Nb} \text { ) }\end{array}$ & $\begin{array}{l}\text {-Activating foil dosimeters - } \\
\text { (CEA - Section 4.1) }\end{array}$ & -Wireless technologies \\
\hline & Dimensional & & & -Wireless technologies \\
\hline \multirow[t]{7}{*}{$\begin{array}{l}\text { Instrumented } \\
\text { Lead Experi- } \\
\text { ment }\end{array}$} & Temperature & $\begin{array}{l}\text {-Thermocouples (Type } \\
\text { N, K, C, and HTIR- } \\
\text { TCs) }\end{array}$ & $\begin{array}{l}\text {-SiC temperature monitors } \\
\text { (Section 4.8.1) }\end{array}$ & $\begin{array}{l}\text { - Fiber Optics (SCK·CEN Sec- } \\
\text { tion 4.2.3, JAERI - Section } \\
\text { 4.4.2, and INL-Section 6.1) } \\
\text { - Ultrasonic Thermometers } \\
\text { (INL -Section 6.1) }\end{array}$ \\
\hline & $\begin{array}{l}\text { Thermal } \\
\text { Conductivity }\end{array}$ & $\begin{array}{l}\text {-Out-of-pile } \\
\text { examinations. }\end{array}$ & $\begin{array}{l}\text { - Degradation detection using } \\
\text { signal from two thermocouples } \\
(\text { HRP- 4.3.2) }\end{array}$ & $\begin{array}{l}\text {-Hot wire techniques (INL - } \\
\text { Section 6.2) }\end{array}$ \\
\hline & $\begin{array}{l}\text { Fluence } \\
\text { (neutron) }\end{array}$ & $\begin{array}{l}\text {-Flux wires (Fe, } \mathrm{Ni}, \\
\text { and } \mathrm{Nb} \text { ) }\end{array}$ & $\begin{array}{l}\text {-Activating foil dosimeters (CEA } \\
\text { - Section 4.1) }\end{array}$ & \\
\hline & Flux (neutron) & & $\begin{array}{l}\text {-Self-Powered Neutron Detec- } \\
\text { tors (HRP - Section 4.3) } \\
\text {-Subminiature fission cham- } \\
\text { bers (CEA - Section 4.1.1) }\end{array}$ & $\begin{array}{l}\text {-Moveable SPNDs } \\
\text { (SCK·CEN - Section 4.2.1) }\end{array}$ \\
\hline & $\begin{array}{l}\text { Gamma } \\
\text { Heating }\end{array}$ & & $\begin{array}{l}\text {-Calorimeters (CEA - Section } \\
4.1 \text { ) } \\
\text {-Gamma thermometers (HRP - } \\
\text { Section 4.3) }\end{array}$ & \\
\hline & $\begin{array}{l}\text { Dimensional } \\
\text { (stressed and } \\
\text { unstressed } \\
\text { samples) }\end{array}$ & $\begin{array}{l}\text {-Out-of-pile } \\
\text { examinations using } \\
\text { strain gauges and/or } \\
\text { inspection }\end{array}$ & $\begin{array}{l}\text {-LVDT-based sample elonga- } \\
\text { tion/ fuel stack elongation / } \\
\text { creep and tensile test rigs (HRP } \\
\text { - Section } 4.3 \text {, JAERI -Section } \\
\text { 4.4.1, KAERI - 4.6, } 4.2 .4 \text { ) } \\
\text {-Diameter gauge (HRP - Sec- } \\
\text { tion 4.3.5) } \\
\text {-Hyper frequency resonant cavi- } \\
\text { ties (CEA - Section 4.1) }\end{array}$ & $\begin{array}{l}\text {-Ultrasonic Transducers } \\
\text { (Section 6.3) }\end{array}$ \\
\hline & $\begin{array}{l}\text { Fission Gas } \\
\text { (Amount, } \\
\text { Composition) }\end{array}$ & $\begin{array}{l}\text {-Gas Chromatography } \\
\text {-Pressure sensors } \\
\text {-"Near real-time sam- } \\
\text { pling with detectors } \\
\text {-Chemistry samples }\end{array}$ & $\begin{array}{l}\text {-LVDT-based pressure gauge } \\
\text { (HRP -Section 4.3.4) }\end{array}$ & $\begin{array}{l}\text {-Acoustic measurements with } \\
\text { high-frequency echography } \\
\text { (CEA - Section 4.1.4) }\end{array}$ \\
\hline
\end{tabular}


Table 5-2. Current and developmental instrumentation for ATR irradiations.

\begin{tabular}{|c|c|c|c|c|}
\hline \multirow[t]{2}{*}{ Location } & \multirow{2}{*}{ Parameter } & \multirow{2}{*}{ Technology at ATR } & \multicolumn{2}{|c|}{$\begin{array}{l}\text { Possible Instrumentation Advancement } \\
\text { (Section where discussed) }\end{array}$} \\
\hline & & & Currently Available & Developmental \\
\hline \multirow[t]{12}{*}{$\begin{array}{l}\text { Pressurized } \\
\text { Water Loop }\end{array}$} & Temperature & $\begin{array}{l}\text {-Thermocouples (Type } \\
\text { N, K, C, and HTIR- } \\
\text { TCs })^{\mathrm{C}}\end{array}$ & & $\begin{array}{l}\text { - Fiber Optics (SCK·CEN Sec- } \\
\text { tion 4.2.3, JAERI - Section } \\
4.4 .2 \text {, and INL-Section 6.1) } \\
\text { - Ultrasonic Thermometers } \\
\text { (INL -Section 6.1) }\end{array}$ \\
\hline & $\begin{array}{l}\text { Thermal } \\
\text { Conductivity }\end{array}$ & $\begin{array}{l}\text {-Out-of-pile } \\
\text { examinations. }\end{array}$ & $\begin{array}{l}\text { - Degradation detection using } \\
\text { signal from two thermocouples } \\
\text { (HRP- 4.3.2) }^{\mathrm{d}}\end{array}$ & $\begin{array}{l}\text {-Hot wire techniques (INL - } \\
\text { Section 6.2) }\end{array}$ \\
\hline & Loop Pressure & $\begin{array}{l}\text {-Differential pressure } \\
\text { transmitters } \\
\text {-Pressure gauges with } \\
\text { impulse lines }\end{array}$ & & \\
\hline & Flowrate & $\begin{array}{l}\text {-Flow venturis } \\
\text {-Orifice plates }\end{array}$ & & \\
\hline & $\begin{array}{l}\text { Water } \\
\text { Chemistry }\end{array}$ & $\begin{array}{l}\text {-Off-line sampling } \\
\text { /analysis }\end{array}$ & $\begin{array}{l}\text {-Electrical chemical potential } \\
\text { probes (HRP - Section 4.3) }\end{array}$ & \\
\hline & $\begin{array}{l}\text { Fission Gas } \\
\text { (Amount, } \\
\text { Composition) }\end{array}$ & $\begin{array}{l}\text {-Gas Chromatography } \\
\text {-Pressure sensors } \\
\text {-Gamma detectors } \\
\text {-Chemistry samples }\end{array}$ & $\begin{array}{l}\text {-LVDT-based pressure gauge } \\
\text { (HRP -Section 4.3.4) }\end{array}$ & $\begin{array}{l}\text {-Acoustic measurements with } \\
\text { high-frequency echography } \\
\text { (CEA - Section 4.1.4) }\end{array}$ \\
\hline & \begin{tabular}{|l} 
Fluence \\
(neutron)
\end{tabular} & $\begin{array}{l}\text {-Flux wires (Fe, } \mathrm{Ni}, \\
\text { and } \mathrm{Nb})\end{array}$ & $\begin{array}{l}\text {-Activating foil dosimeters (CEA } \\
\text { - Section 4.1) }\end{array}$ & \\
\hline & Flux (neutron) & & $\begin{array}{l}\text {-Self-Powered Neutron Detec- } \\
\text { tors (HRP - Section 4.3) } \\
\text {-Subminiature fission } \\
\text { chambers (CEA - Section 4.1.1) }\end{array}$ & $\begin{array}{l}\text {-Moveable SPNDs } \\
\text { (SCK·CEN - Section 4.2.1) }\end{array}$ \\
\hline & $\begin{array}{l}\text { Gamma } \\
\text { Heating }\end{array}$ & & $\begin{array}{l}\text {-Calorimeters (CEA - Section } \\
4.1 \text { ) } \\
\text {-Gamma thermometers (HRP - } \\
\text { Section 4.3) }\end{array}$ & \\
\hline & $\begin{array}{l}\text { Dimensional } \\
\text { (stressed and } \\
\text { unstressed } \\
\text { samples) }\end{array}$ & $\begin{array}{l}\text {-Out-of-pile } \\
\text { examinations using } \\
\text { strain gauges and/or } \\
\text { inspection }\end{array}$ & $\begin{array}{l}\text {-LVDT-based sample elonga- } \\
\text { tion/ creep and tensile test rigs } \\
\text { (HRP - Section 4.3, JAERI - } \\
\text { Section 4.4, KAERI - 4.6, 4.2.4) } \\
\text {-Diameter gauge (HRP - } \\
\text { Section 4.3.5) } \\
\text {-Hyper frequency resonant } \\
\text { cavities (CEA - Section 4.1) }\end{array}$ & $\begin{array}{l}\text {-Ultrasonic Transducers (Sec- } \\
\text { tion 6.3) }\end{array}$ \\
\hline & $\begin{array}{l}\text { Crud deposition } \\
\text { and effects }\end{array}$ & $\begin{array}{l}\text {-Out-of-pile } \\
\text { examinations }\end{array}$ & $\begin{array}{l}\text {-Diameter gauge (HRP - Sec- } \\
\text { tion 4.3.5) with: } \\
\text {-SPNDs to detect impact on } \\
\text { neutron flux (HRP - Section 4.3) } \\
\text {-Thermocouples to detect } \\
\text { impact on power (HRP - Section } \\
\text { 4.3.2) }\end{array}$ & \\
\hline & $\begin{array}{l}\text { Crack initiation } \\
\text { and growth }\end{array}$ & & $\begin{array}{l}\text { - Direct current potential drop } \\
\text { method with CT specimens } \\
\text { (HRP -Section 4.3.6) }\end{array}$ & -Ultrasonic Transducers \\
\hline
\end{tabular}

a. Type $\mathrm{C}$ thermocouple use requires a "correction factor" for decalibration during irradiation.

b. Thermal conductivity estimates require assumptions related to fuel degradation and gap conductance.

c. Type $C$ thermocouple use requires a "correction factor" for decalibration during irradiation.

d. Thermal conductivity estimates require assumptions related to fuel degradation and gap conductance. 


\subsection{Current Prioritization for Instrumentation Development}

Figure 5-1 presents a schedule for developing and demonstrating instrumentation needed to advance ATR NSUF testing capabilities. There are three major activities identified: "Nearer-Term Instrumentation Development", "Developmental Technologies", and "Irradiation Capsule / Test Train Deployment". Qualitative judgments with respect to ATR capabilities compared to other test reactors are shown at the bottom of this figure. As indicated, it is hoped to have comparable instrumentation by FY12 and "world class" (e.g., comparable, and in some cases, superior) irradiation capabilities by FY15.

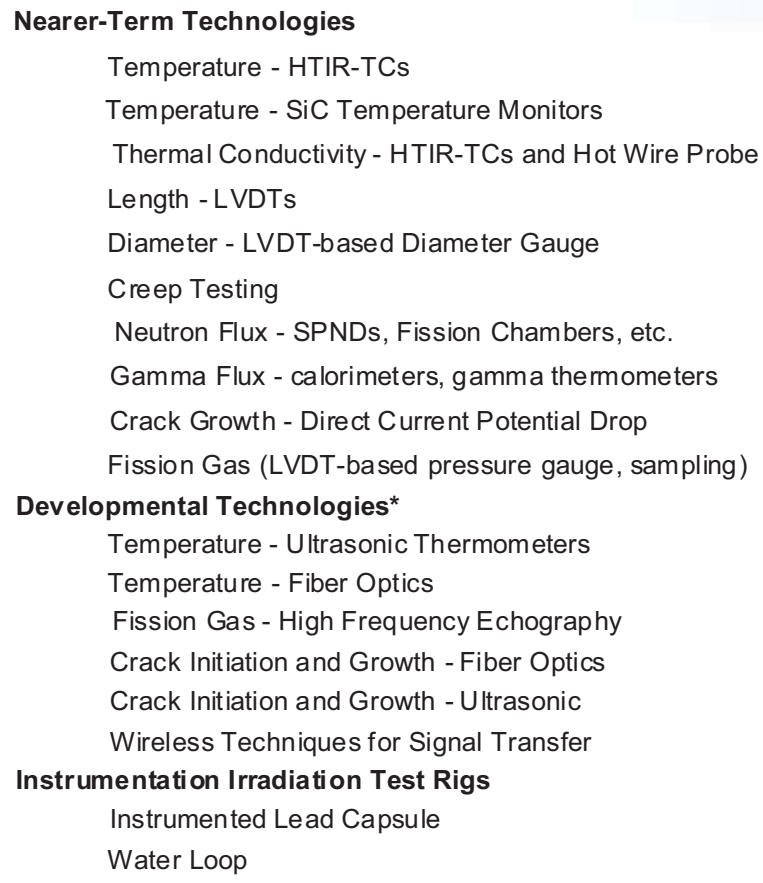

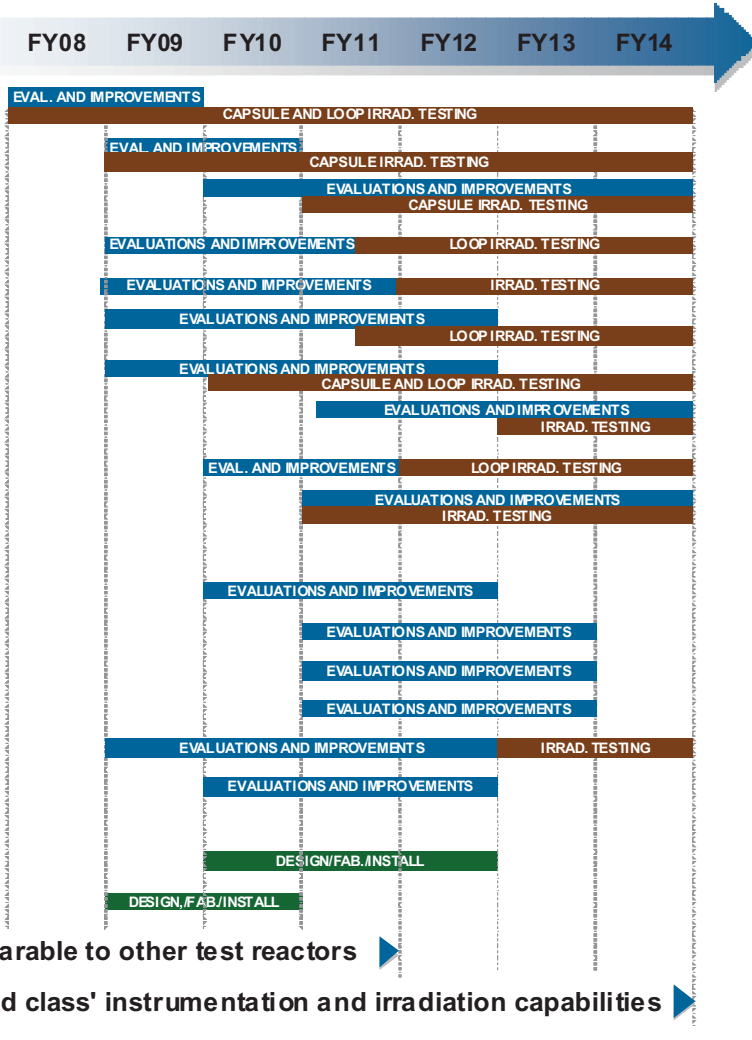

*Irradiation te sting for some technologies to be determined based on evaluation results and user priorities.

Figure 5-1. Current schedule for ATR NSUF advanced instrumentation research and development.

Note that the ATR NSUF-funded instrumentation development effort began in FY 2009. Prior to that time, new ATR instrumentation was primarily developed using a limited amount of internal Laboratory Directed Research and Development (LDRD) funding. Sensors were developed that address needs identified by current and potential customers. Then, programmatic funding covered the costs required for qualifying the instrumentation for ATR irradiations. Although such an approach did allow a limited amount of instrumentation to be developed, previous amounts of LDRD funding devoted to this effort were inadequate for the ATR NSUF to have instrumentation 
comparable to that in other test reactors by 2015. Evaluations indicate that a sustained effort of at least $\$ 1.5 \mathrm{M}$ per year is needed to support this effort. With this level of funding, all 'Nearer Term' technologies can be adapted and demonstrated for ATR applications (at least demonstrated to the point that direct programmatic funding can be obtained for additional instrument qualifications). Note that the this requested level of funding will also provide for selected research of 'Developmental Technologies.' However, the selected priority for "Developmental Technologies" research will be based on customer and reactor staff prioritization recommendations at the time that funding becomes available. ATR NSUF funding will cover costs required to develop and deploy test trains to demonstrate instrumentation performance in inert gas and PWR loop conditions.

Table 5-3 summarizes in-pile instrumentation that are not currently available to ATR users. Instrumentation is grouped according to two major categories "Nearer-Term" and "Developmental Technologies." "Near term" instrumentation identified in Table 5-3 includes sensors currently used at other test reactors. As shown in Table 5-3, users at several other test reactors benefit from several sensors that are not currently available to ATR users. However, transferring in-pile sensor technology is not always straightforward. In many cases, geometry and temperature requirements are more limiting because of the higher fluxes and temperatures at which samples are irradiated at the ATR. In addition, IFE-HRP staff have developed unique expertise for applying their sensors to HBWR test conditions. Consequently, some INL evaluation / testing is needed, which may lead to some design modifications.

Table 5-3 also provides a summary assessment of the status, a ranking of sensor technology readiness (e.g., the remaining development cost required for in-pile sentimentalization qualification), customer and reactor staff input on instrumentation development prioritization. Note that research efforts are focussing on higher priority, "near term" sensor technologies not yet available to ATR users.

Section 6 summarizes the status of all sensor technology development efforts underway at INL. Additional details about ATR NSUF instrumentation enhancement research and development may also be found in References 53 through 62. 
Table 5-3. Candidate sensors to Enhance ATR User Irradiations ${ }^{\text {a }}$

\begin{tabular}{|c|c|c|c|c|}
\hline Parameter & Sensor & Current Status & $\begin{array}{l}\text { Technology } \\
\text { Readiness }^{\mathrm{b}}\end{array}$ & $\begin{array}{l}\text { User } \\
\text { Priorityc }\end{array}$ \\
\hline \multicolumn{5}{|c|}{ Near Term / Minimal R\&D required for modifications for ATR Applications } \\
\hline \multirow[t]{2}{*}{ Temperature } & HTIR-TCS & $\begin{array}{l}\text { Currently deployed at ATR in AGR-1 } \\
\text { test. Available to ATR users. }\end{array}$ & 1 & 1 \\
\hline & SiC Temperature Monitors & $\begin{array}{l}\text { Irradiated at ATR and HFIR. INL ability } \\
\text { to detect temperature under } \\
\text { development. }\end{array}$ & 1 & 1 \\
\hline $\begin{array}{l}\text { Thermal conductivity } \\
\text { changes }\end{array}$ & Thermocouples & $\begin{array}{l}\text { Currently used at HBWR (years ago, } \\
\text { used in EBR-I and MTR). Evaluations } \\
\text { for ATR applications underway. }\end{array}$ & 1 & 1 \\
\hline Length changes & LVDT & $\begin{array}{l}\text { IFE-HRP LVDTs deployed at many test } \\
\text { reactors. Evaluations for ATR } \\
\text { applications underway. }\end{array}$ & 1 & 1 \\
\hline \multirow[t]{2}{*}{$\begin{array}{l}\text { Creep } \\
\text { elongation/failure }\end{array}$} & $\begin{array}{l}\text { LVDT for sample elongation } \\
\text { with calibrated load on } \\
\text { bellows }\end{array}$ & $\begin{array}{l}\text { Currently used at HBWR; design } \\
\text { developed for ATR applications; } \\
\text { evaluations to start in FY10. }\end{array}$ & 1 & 1 \\
\hline & $\begin{array}{l}\text { Variable creep load and } \\
\text { sample elongation }\end{array}$ & $\begin{array}{l}\text { Developed by VTT and evaluated at } \\
\text { BR-2. }\end{array}$ & 2 & 1 \\
\hline \begin{tabular}{|l|} 
Diameter changes \\
(Crud deposition and \\
Corrosion)
\end{tabular} & $\begin{array}{l}\text { Diameter gauge (based on } \\
\text { LVDT technology) }\end{array}$ & $\begin{array}{l}\text { Currently fabricated and deployed by } \\
\text { IFE-HRP. Evaluations for ATR } \\
\text { applications underway. }\end{array}$ & 1 & 1 \\
\hline $\begin{array}{l}\text { Capsule/fuel pin } \\
\text { failure }\end{array}$ & Xe gas tagging & $\begin{array}{l}\text { Used in EBRI-II. ATR-specific design } \\
\text { developed. }\end{array}$ & 1 & 1 \\
\hline Crack growth & $\begin{array}{l}\text { Direct current potential drop w } \\
\text { CT specimens }\end{array}$ & $\begin{array}{l}\text { Currently used by HRP. ATR-specific } \\
\text { design developed by MIT for evaluation }\end{array}$ & 1 & 2 \\
\hline \multirow[t]{2}{*}{ Neutron fluence } & $\begin{array}{l}\text { Subminiature fission cham- } \\
\text { bers }\end{array}$ & $\begin{array}{l}\text { Currently used at OSIRIS and BR-2 } \\
\text { reactors. }\end{array}$ & 1 & 2 \\
\hline & $\begin{array}{l}\text { Self-Powered Neutron } \\
\text { Detectors }\end{array}$ & $\begin{array}{l}\text { Currently used at HBWR, HFR, and } \\
\text { OSIRS }\end{array}$ & 1 & 2 \\
\hline \multirow[t]{2}{*}{ Gamma Heating } & Calorimeters & Currently used at OSIRIS & 1 & 2 \\
\hline & Gamma thermometers & Currently used at HBWR & 1 & 2 \\
\hline $\begin{array}{l}\text { Fission Gas (Amount } \\
\text { and Composition) }\end{array}$ & LVDT-based pressure gauge & Currently used at HBWR & 1 & 3 \\
\hline Water chemistry & ECP probe & Currently used at HBWR & 1 & 3 \\
\hline \multicolumn{5}{|c|}{ Developmental Technologies/ R\&D required to demonstrate feasibility } \\
\hline $\begin{array}{l}\text { Temperature and } \\
\text { crack propagation }\end{array}$ & Fiber optics & $\begin{array}{l}\text { Being investigated by several research } \\
\text { organizations; Luna Incorporated and } \\
\text { INL awarded STTR proposal to } \\
\text { investigate viability of ATR irradiation }\end{array}$ & 2 & 2 \\
\hline Fluence & Moveable SPNDs & Being investigated by CEA & 2 & 2 \\
\hline Thermal Conductivity & Hot wire techniques & $\begin{array}{l}\text { Initial designs proposed by INL; } \\
\text { feasibility evaluations underway. }\end{array}$ & 2 & 2 \\
\hline $\begin{array}{l}\text { Elongation (for }>500 \\
\left.{ }^{\circ} \mathrm{C}\right)\end{array}$ & Combined pushrod/LVDT & $\begin{array}{l}\text { Initial design proposed and feasibility } \\
\text { demonstrates completed by INL; } \\
\text { additional demonstrations needed. }\end{array}$ & 2 & 2 \\
\hline $\begin{array}{l}\text { Dimensional and } \\
\text { phase changes }\end{array}$ & CMUTs & Proposed for INL for investigation & 2 & 2 \\
\hline $\begin{array}{l}\text { Fission Gas } \\
\text { (Amount, } \\
\text { Composition) }\end{array}$ & $\begin{array}{l}\text { Acoustic measurements with } \\
\text { high-frequency echography }\end{array}$ & Being investigated by CEA & 2 & 3 \\
\hline
\end{tabular}

a. Initial assessment, to be updated based on review comments.

b. Technology readiness: 1- Currently used at other materials and test reactors, minimal R\&D required to adapt to ATR conditions, 2 - Currently used for non-reactor applications, some R\&D required to ensure feasibility, 3 - Limited applications to date, significant R\&D required to demonstrate feasibility.

c. User priority: 1 - High; 2- Useful, not required for near term (no immediate application and/or other techniques available). 
INL/EXT-08-13985 


\section{DEVELOPMENT - IDAHO NATIONAL LABORATORY}

Several INL efforts are underway to enhance in-pile instrumentation for ATR users. As indicated in Table 6-1, efforts are underway to obtain instrumentation for measuring a wide range of parameters and conditions. This section summarizes the status of on-going and planned sensor development and evaluation efforts at INL.

Table 6-1. Current and planned ATR NSUF sensor development and evaluation efforts

\begin{tabular}{|c|c|c|}
\hline Parameter & Sensor & Status \\
\hline \multirow[t]{4}{*}{ Temperature } & $\begin{array}{l}\text { High Temperature Irradia- } \\
\text { tion Resistant Thermo- } \\
\text { couples (HTIR-TCs) }\end{array}$ & $\begin{array}{l}\text { Initial out-of-pile testing completed. In-pile testing (in the AGR-1 gas } \\
\text { reactor fuel irradiation test) and sensor enhancement evaluations } \\
\text { underway }\end{array}$ \\
\hline & $\begin{array}{l}\text { Silicon Carbide Tempera- } \\
\text { ture Monitors }\end{array}$ & $\begin{array}{l}\text { Initial in-pile irradiations underway. Development and evaluation of } \\
\text { post-irradiation measurement capability underway. }\end{array}$ \\
\hline & Fiber-Optics $^{a}$ & $\begin{array}{l}\text { Initial testing completed by vendor. Additional out-of-pile and in-pile } \\
\text { testing investigated as part of several STTR/SBIR projects. Because } \\
\text { of cost considerations, Phase II R\&D will be pursued at a university } \\
\text { reactor. }\end{array}$ \\
\hline & Ultrasonic Thermometers & $\begin{array}{l}\text { Successfully developed and deployed to support high temperature } \\
\text { fuel testing several decades ago. Enabling technology information } \\
\text { should be documented and improved upon with improved signal } \\
\text { processing now available. }\end{array}$ \\
\hline \multirow[t]{2}{*}{$\begin{array}{l}\text { Thermal } \\
\text { Conductivity }\end{array}$} & Dual thermocouples & $\begin{array}{l}\text { Initial laboratory testing underway. Anticipate that inclusion of HTIR- } \\
\text { TCs could allow detection at higher temperatures than current meth- } \\
\text { ods used by IFE-HRP. }\end{array}$ \\
\hline & Hot-wire method & $\begin{array}{l}\text { Initial laboratory testing underway. Anticipated that inclusion of } \\
\text { HTIR-TCs could allow detection at higher temperatures. }\end{array}$ \\
\hline \multirow{2}{*}{$\begin{array}{l}\text { Elongation, Crud } \\
\text { deposition, Corro- } \\
\text { sion, }\end{array}$} & LVDTs $^{a}$ & Out-of-pile testing underway. \\
\hline & $\begin{array}{l}\text { Ultrasonic Transducers } \\
\text { (UTs) }\end{array}$ & $\begin{array}{l}\text { Scoping tests completed and prototype conceptual design devel- } \\
\text { oped; additional prototype out-of-pile testing needed. }\end{array}$ \\
\hline $\begin{array}{l}\text { In-pile Creep } \\
\text { Test Rig }\end{array}$ & $\begin{array}{l}\text { LVDT-based rig with bel- } \\
\text { lows }\end{array}$ & Design developed. Prototype being manufactured. \\
\hline Crack propagation & $\begin{array}{l}\text { Direct current potential } \\
\text { drop method with CT }^{\text {specimens }^{\text {a }}}\end{array}$ & Preliminary design (based on HRP method) developed by MIT. \\
\hline
\end{tabular}

a. Fiber optics also offer the potential to measure geometry changes and crack propagation.

\subsection{Temperature Sensors}

Temperature is a key parameter of interest during fuel and material irradiations. Because of its importance, INL efforts have included several new methods for detecting temperature during irradiation. Using specialized equipment at INL's HTTL, efforts have focused on implementing two new sensors: (a) unique new thermocouples that resist decalibration due to high temperatures and neutron transmutation in instrumented lead and loop tests; and (b) silicon carbide temperature 
monitors for static capsule tests. INL has also been involved in preliminary investigations exploring the use of fiber optics as a non-contact temperature sensor.

\subsubsection{High Temperature Irradiation Resistant Thermocouples (HTIR-TCs)}

Commercially-available thermocouples drift due to degradation at high temperatures (above $1100{ }^{\circ} \mathrm{C}$ ) or due to transmutation of thermocouple components with high neutron absorption cross sections. Thermocouples are needed that can withstand both high temperature and high radiation environments. To address this need, INL developed a High Temperature Irradiation Resistant ThermoCouple (HTIR-TC) design that contains commercially-available doped molybdenum paired with a niobium alloy. Battelle Energy Alliance (BEA), the operating contractor for INL, has filed a patent application for this technology; and INL now offers these sensors, with diameters ranging from 1.0 to $3.2 \mathrm{~mm}$, to customers for nuclear and non-nuclear applications. HTIRTC component materials were selected based on data obtained from materials interaction tests, ductility investigations, and resolution evaluations. ${ }^{55}$ through 57 To stabilize grain growth, HTIRTCs are heat treated prior to calibration. Calibration data indicate that HTIR-TCs typically have accuracies ranging from 0.1 to $0.4 \%$. To demonstrate HTIR-TC long duration performance, thermocouples have been heated at elevated temperatures (from $1200{ }^{\circ} \mathrm{C}$ to $1800{ }^{\circ} \mathrm{C}$ ) for up to 6 months. The $1200^{\circ} \mathrm{C}$ test included nineteen commercially-available Type $\mathrm{N}$ thermocouples, three commercially-available Type $\mathrm{K}$ thermocouples, and nine INL-developed swaged HTIR-TCs. As indicated in Figure 6-1, some Type $\mathrm{K}$ and $\mathrm{N}$ thermocouples drifted by over $100{ }^{\circ} \mathrm{C}$ or $8 \%$. Much smaller drifts (typically less than $20{ }^{\circ} \mathrm{C}$ or $2 \%$ ) were observed in the INL-developed HTIR-TCs. As shown in Reference 58, similar drifts $(2 \%)$ were observed in HTIR-TCs in a long duration (4000 hour) test completed at $1400{ }^{\circ} \mathrm{C}$.

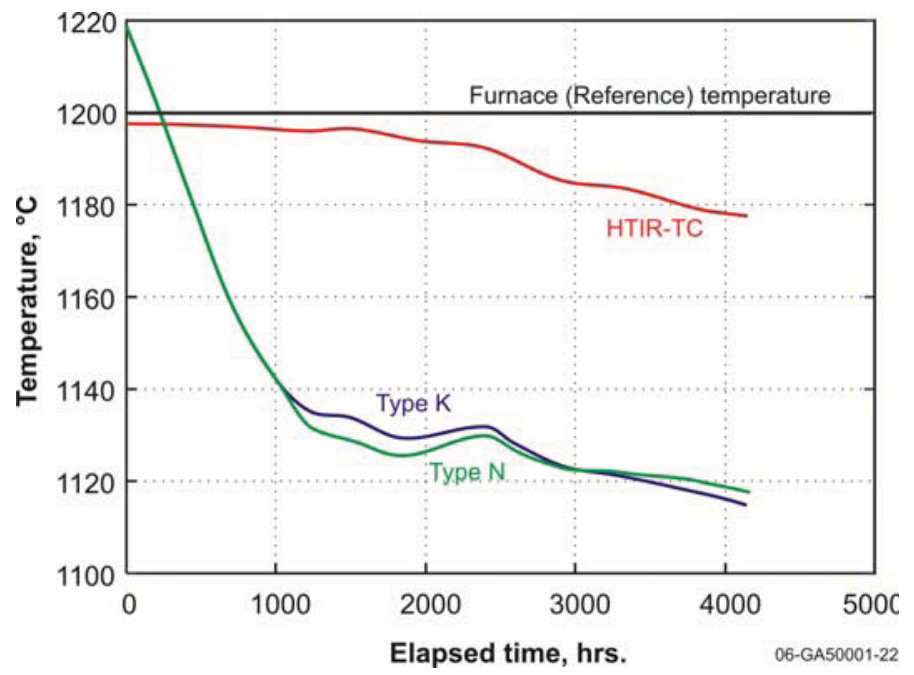

Figure 6-1. Representative thermocouple response in $1200^{\circ} \mathrm{C}$ test.

HTIR-TCs were installed in a multi-capsule experiment that is currently being irradiated in INL's ATR. This multi-capsule experiment, AGR-1, is designed to irradiate gas reactor fuel com- 
pacts at temperatures up to approximately $1200{ }^{\circ} \mathrm{C}$. The test, which started in February 2007, is still underway. Figure 6-2 shows signals from one of the test capsules containing two INL-developed HTIR-TCs and one Type $\mathrm{N}$ thermocouple. The Type $\mathrm{N}$ thermocouple was purposely located at a cooler region within this test capsule. Signal variations are due to ATR power fluctuations and outages. At the beginning of this irradiation, the HTIR-TC located near the Type N thermocouple gave a signal consistent with the signal from the Type $\mathrm{N}$ thermocouple. In addition, the HTIRTC located at a hotter region within the capsule is yielding a consistent signal, but at a higher temperature. However, in October 2008, the Type N thermocouple failed and its signal ceased.
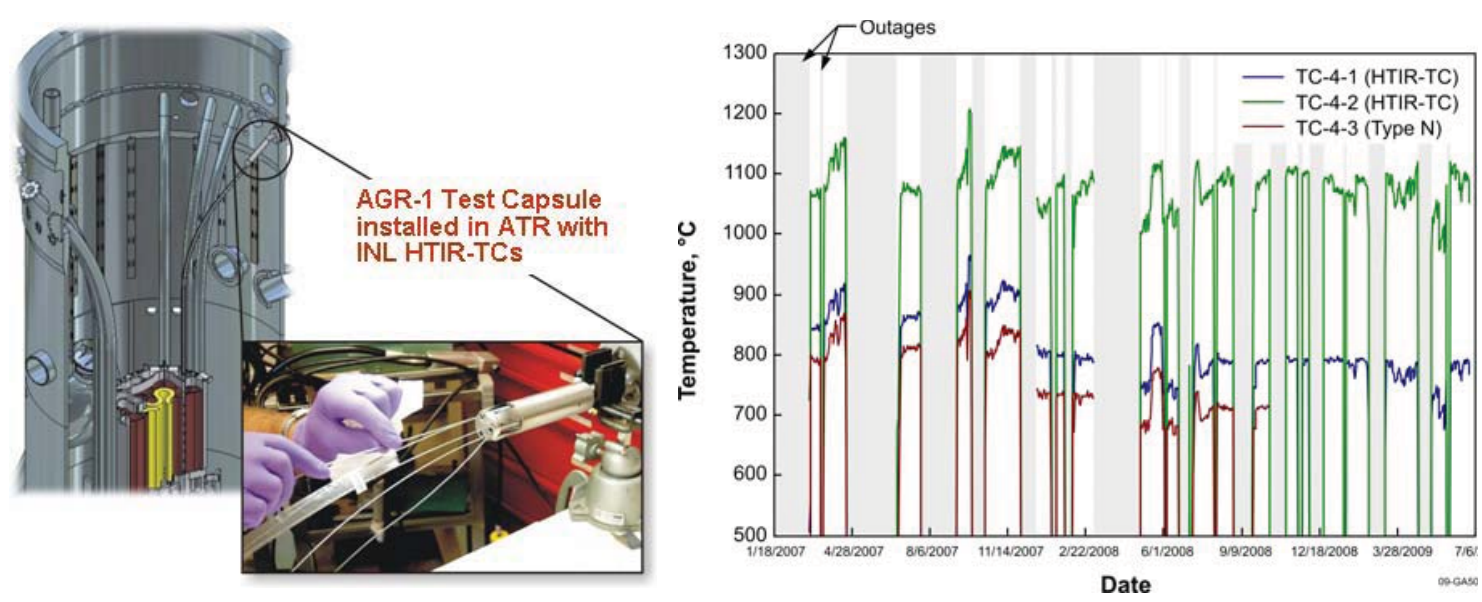

Figure 6-2. HTIR-TCs installed in AGR-1 capsule and representative HTIR-TC and Type N data.

INL has also fabricated HTIR-TCs for other customers. During FY2009, three HTIR-TCs and associated peripherals (e.g., soft extension cables, ice point cell probes, etc.) were fabricated for MITR irradiations. Discussions have been initiated with representatives from the Joint Research Centre (JRC) of the European Commission and the South Africa Nuclear Energy Corporation (NECSA) about the potential for INL to provide HTIR-TCs for upcoming irradiations planned for gas reactor fuel in the High Flux Reactor and the SAFARI-1 research reactor, respectively.

INL has also continued to investigate options that could reduce fabrication costs and enhance the reliability of INL-developed HTIR-TCs for higher temperature in-pile testing, allowing their use in applications up to $1800{ }^{\circ} \mathrm{C}$. Investigations identified several improvements in HTIR-TC fabrication processes that reduced costs and improved thermocouple reliability, such as automated, consistent fabrication techniques, alternate components in compensating soft extension cable, and improved heat treatments. As documented in References [59] through [62], more recent efforts investigate alternate HTIR-TCs designs that offer the potential to improve HTIRTC operation at higher temperatures.

Initially-deployed HTIR-TCs rely on swaging fabrication techniques because of their simplicity and durability. As shown in Figure 6-3a, a swaged TC is fabricated by loading pre-formed, crushable insulator beads onto thermoelement wires and placing the insulated thermoelements in a sheath (tube) that is then swaged (compacted) to form a single, cohesive component. If desired, 
the thermocouple may be joined to hard extension cable using a splice sleeve as shown in Figure 6-3a. Recently, INL has explored drawn and loose assembly HTIR-TC designs.

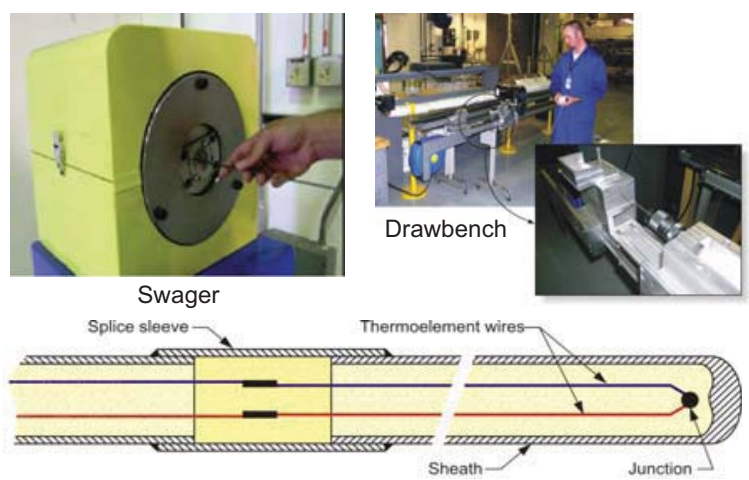

a. Swaged and Drawn HTIR-TCs
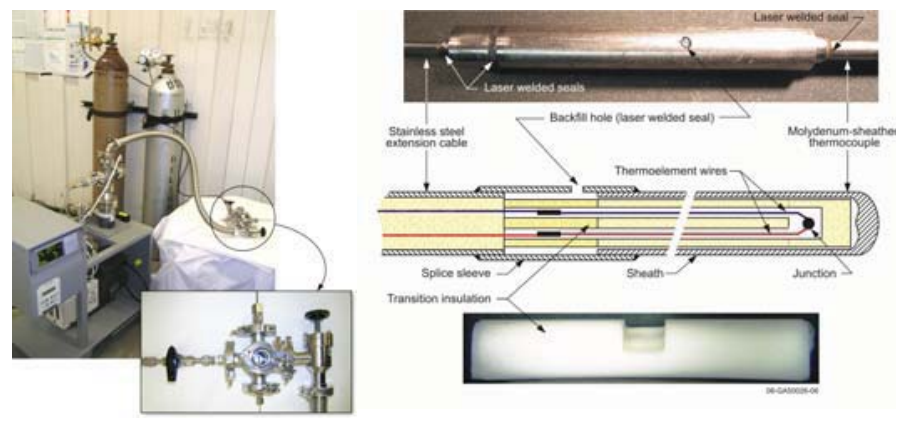

b. Loose-assembly HTIR-TCs

Figure 6-3. Various thermocouple fabrication processes.

Drawn thermocouples are prepared similarly to swaged thermocouples in that crushable insulator beads are loaded onto thermoelement wires that are placed in a sheath. However, the drawn assembly is passed through a stationary die in a drawbench (see Figure 6-3a) to form a thermocouple. In a loose assembly thermocouple (see Figure 6-3b), preformed hard-fired insulators are loaded onto thermoelement wires. After being placed in a sheath, a splice sleeve is used to join the thermocouple assembly to the hard extension cable.

Loose assembly HTIR-TC fabrication requirements included developing specialized splice sleeve and insulators for joining the loose assembly thermocouple to the hard extension cable (see Figure 6-3b). Three sealing welds are also needed (connecting the two halves of the splice sleeve, between the extension cable sheath and the splice sleeve, and between the splice sleeve and the TC sheath). To preclude any oxidation of thermocouple components, the assembly is vacuum purged and backfilled with inert gas through this splice sleeve and specialized fixturing. In this specialized fixturing, the assembly is vacuumed down to at least $10^{-5}$ torr and backfilled with helium through a tiny hole in the splice sleeve. The backfill hole in the splice sleeve is welded closed through the view port of the fixturing using a laser welder.

Drawn and loose assembly thermocouple designs each offer the potential for improved high temperature performance over swaged thermocouples. Compared to swaging, the drawing process 
does not twist HTIR-TC thermoelement wires. INL evaluations also indicate that drawing leads to less distortion of thermoelement wires. In a loose assembly HTIR-TC, higher temperatures may be possible because thermoelement thinning and irregular deformation associated with swaging and drawing are avoided. Furthermore, these designs can better accommodate differential thermal expansion of thermocouple components without inducing thermoelement stress.

A long duration (1000 hour) test was recently completed to compare the performance of swaged, drawn, and loose assembly HTIR-TCs at $1500^{\circ} \mathrm{C}$. This test was performed in the HTTL high temperature vacuum furnace. Multiple swaged, drawn, and loose assembly thermocouples were included in this test. Results from the $1500{ }^{\circ} \mathrm{C}$ test are shown in Figure 6-4. The signals from the swaged and drawn HTIR-TCs decreased by $2.3 \%$, primarily during the first 600 hours of the test. The loose assembly thermocouple displayed greater stability and resolution than either the swaged or drawn thermocouples. Although the swaged HTIR-TC response is consistent with the decalibration observed in prior 1200 and $1400{ }^{\circ} \mathrm{C} 4000$ hour tests, the fact that most of the drift occurred during initial portions of this test suggests that longer duration heat treatments may be needed to stabilize the distortion associated with swaging or drawing processes in larger diameter thermoelement wires (prior HTTL efforts to optimize heat treatment processes had focused on thermocouples smaller diameter wires).

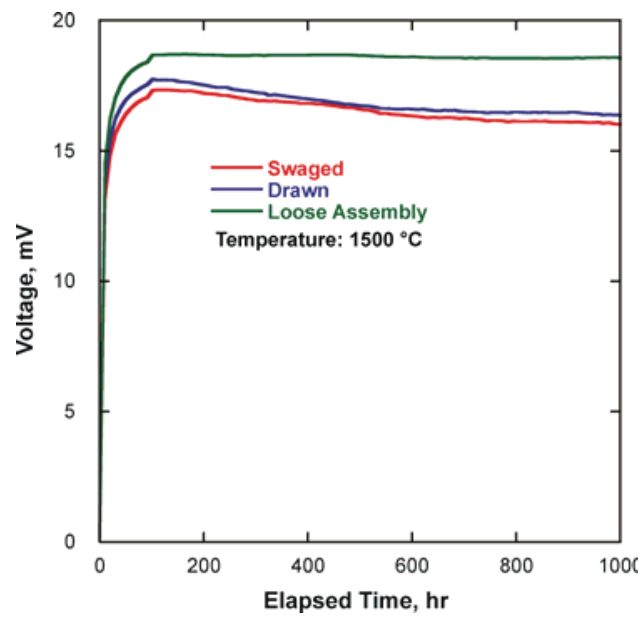

Figure 6-4. Thermocouple performance after 1000 hours at $1500{ }^{\circ} \mathrm{C}$

Selected thermocouples from this test have also been tested at $1800{ }^{\circ} \mathrm{C}$ without any additional heat treatment. Results, shown in Figure 6-5, suggest that HTIR-TCs are also capable of functioning at these temperatures. Although a furnace malfunction led to this test being terminated prematurely at 170 hours, the loose assembly and drawn HTIR-TCs exhibited less than $1 \%$ drift and the swaged HTIR-TC exhibited approximately $8 \%$ drift. Note that fabrication processes for HTIRTCs expected to operate at $1800{ }^{\circ} \mathrm{C}$ would include heat treatment above this temperature. Although better stability would be expected from all three HTIR-TC designs if they had been heat treated for operation at $1800{ }^{\circ} \mathrm{C}$, HTIR-TC performance in this test suggests that they are viable sensors at this temperature. 


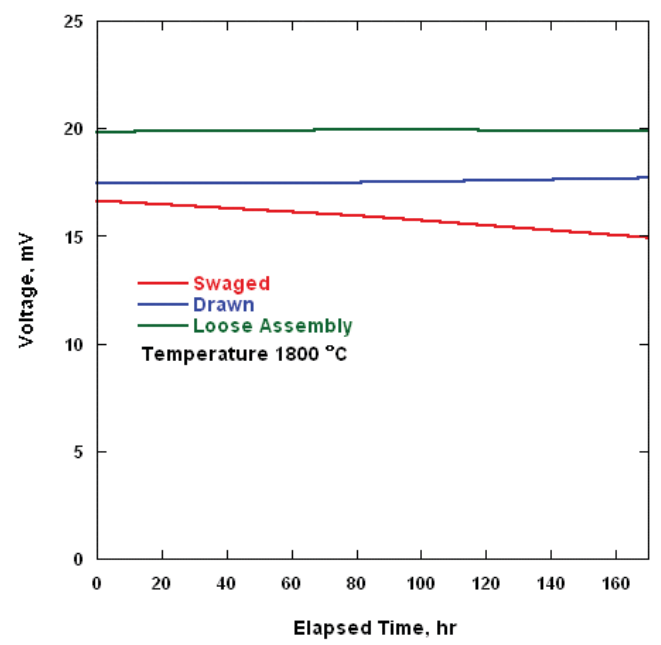

Figure 6-5. Thermocouple performance at $1800{ }^{\circ} \mathrm{C}$

\subsubsection{Silicon Carbide Temperature Monitors}

As noted in Table 6-1, silicon carbide (SiC) temperature monitors are now available for use as temperature sensors in ATR static capsules. Melt wires or paint spots, which are typically for temperature sensors in static capsules, are limited in that they can only detect whether a single temperature was exceeded or not. SiC monitors are advantageous because a single monitor can be used to detect for a range of temperatures that may have occurred during irradiation.

For decades, post-irradiation temperature monitors have been based on the phenomenon that irradiation-induced defects of $\mathrm{SiC}$ begin to anneal out at temperatures exceeding its irradiation temperature. Researchers relied on changes in length, density, thermal conductivity, and electrical resistivity to infer irradiation temperature from $\mathrm{SiC}$ monitors. As discussed in Section 4.8, ORNL used changes in resistivity to detect peak irradiation temperatures between 200 and $800{ }^{\circ} \mathrm{C}$ with accuracies of approximately $20^{\circ} \mathrm{C}$. INL has recently developed a capability similar to that reported by ORNL for detecting peak irradiation temperature. Specialized equipment at INL's HTTL (see Figure 6-6) has been configured so that it can be used to measure resistivity of $\mathrm{SiC}$ samples after heating at various temperatures. $\mathrm{SiC}$ electrical resistivity is measured after heating in a furnace located within a stainless steel enclosure at the HTTL. SiC monitors are heated in a furnace that is placed under a hood located within the stainless steel enclosure. Temperature accuracy in this furnace is verified using thermocouples that have been calibrated using National Institute of Standards and Testing (NIST)-traceable sources. The ventilation system is activated during heating so that any vapors released during heating are vented through this ventilation system. After heating, cooled samples are placed into a constant temperature environmental test chamber to insure electrical resistivity measurements are taken within $0.2{ }^{\circ} \mathrm{C}$ of a predetermined temperature, $30^{\circ} \mathrm{C}$. Reference 50 indicates that resistance measurements must be taken at nearly the same temperature or it will adversely affect the accuracy of SiC temperature monitors. A high accuracy (9 digit) multimeter is used to obtain resistance measurements. This multimeter is placed outside the stainless steel enclosure. 


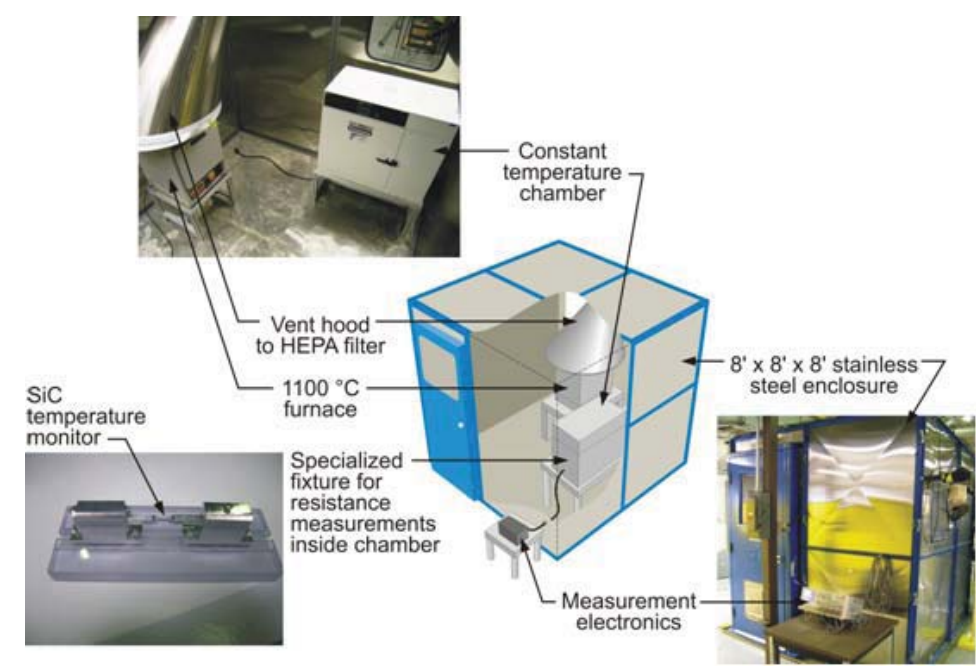

Figure 6-6. Setup for annealing and measuring electrical resistivity of $\mathrm{SiC}$ temperature monitors.

Reference 51 indicates that resistance measurements should be taken with SiC temperature monitors always placed with the same orientation. In addition to marking on the $\mathrm{SiC}$ monitors, special fixturing has been developed by INL to facilitate these measurements. A four point probe technique is used with the four points contacted to the sample through spring-loaded angled electrodes that hold the $\mathrm{SiC}$ carbide temperature monitor in place, as shown in Figure 6-6. Current and voltage are provided to the sample through wires that are threaded through the holes in the electrodes.

Temperature monitors, approximately $1 \mathrm{~mm}$ x $1 \mathrm{~mm}$ x $10 \mathrm{~mm}$, for ATR irradiations were fabricated from high grade ${ }^{a}$ (high density/high resistivity) SiC (SC-003) manufactured by Rohm and Haas. As noted in Section 4.8, Snead recommends using 'high grade' chemically vapor deposited (CVD) SiC. This material is fully dense $\left(3.203 \mathrm{~g} / \mathrm{cm}^{3}\right)$ and stoichiometric ATR capsules containing $\mathrm{SiC}$ temperature monitors near specimens for which peak temperature values are needed are being used to irradiate materials of interest for advanced reactor applications at a variety of temperatures (nominally $300{ }^{\circ} \mathrm{C}, 400{ }^{\circ} \mathrm{C}, 500{ }^{\circ} \mathrm{C}$, and $700{ }^{\circ} \mathrm{C}$ ) and total dose accumulations (nominally $3 \mathrm{dpa}$ and $6 \mathrm{dpa}$ ). In September 2008, such a capsule was inserted in the ATR East Flux Trap, where the fast flux is approximately $9.7 \times 10^{13} \mathrm{n} / \mathrm{cm}^{2}-\mathrm{s}(\mathrm{E}>1 \mathrm{MeV})$. Although a variety of materials are included in this capsule, a dose of $1 \mathrm{dpa}$ in stainless steel roughly corresponds to a fluence of $7 \times 10^{20} \mathrm{n} / \mathrm{cm}^{2}$. Some of the SiC monitors in this ATR capsules are expected to be removed and examined at the HTTL in December 2009.

To verify the operability of equipment installed at the HTTL, INL tested several samples made from two grades of SiC produced by Rohm and Haas: SC-002, which has an average resistivity of $1 \mathrm{ohm}-\mathrm{cm}$; and SC-003 which has an average resistivity of $8323 \mathrm{ohm}-\mathrm{cm}$ (actual vendor measurements for SC-003 varied between 2564 to 23,886 ohm-cm). Results indicate that

a. Low resistivity grade achieved by doping high resistivity grade with nitrogen. 
INL can successfully detect the $\mathrm{SiC}$ grade of $\mathrm{SiC}$ in a temperature monitor. In addition, INL was able to obtain consistent resistivity data for samples made from each grade of $\mathrm{SiC}$ (e.g., resistivity values were within $13 \%$ of the average measured value for each grade of $\mathrm{SiC}$ ). Furthermore, the measured values for SC-003 were within the range of values provided by the vendor for this run of material. To further verify the accuracy of the INL setup, a joint INL/ORNL effort has been initiated to perform comparison runs of irradiated $\mathrm{SiC}$ temperature monitors. Results from this comparison effort are expected to be available in October 2009.

\subsubsection{Fiber Optics}

As noted in Section 4.2.3, fiber optic sensors can measure a large range of physical, chemical and environmental variables such as temperature, pressure, shape/position, displacement, chemical concentration, moisture, acceleration, load, skin friction, flow and strain. A unique characteristic of these sensors is their potential to have one integrated unit that can detect multiple parameters. However, it is well known that optical fibers exhibit loss induced by exposure to neutron and gamma radiation. ${ }^{63}$ This is one of the primary reasons that fiber optic sensors, in general, have not been more widely explored for high-radiation applications. Furthermore, other radiationinduced effects have been reported, such as a shift in the wavelength of the reflection peak produced by exposure of typical Fiber Bragg Gratings (FBG) sensors to gamma radiation. ${ }^{64}$ Nonetheless, as reported by Liu, et al., ${ }^{65}$ the Nuclear Regulatory Commission (NRC) conducted a study (NUREG/CR-5501) that concluded that fiber optic sensors have unique advantages in nuclear power plant monitoring and control applications, making this technology worthy of further examination. The same group later examined the survivability of Extrinsic Fabry-Perot Interferometer (EFPI)-type temperature sensors in a nuclear power plant environment, reporting linear operation with a partially-recoverable shift in temperature bias after exposure to levels of $1.09 \times 10^{6} \mathrm{~Gy}$ gamma and $2.6 \times 10^{16} \mathrm{~cm}^{-2}(\mathrm{E}>1 \mathrm{MeV})$. Section 4.2 .3 reports results from a combined SCK$\mathrm{CEN}$ and CEA effort to explore the use of fiber optics for length detection.

Within the US, several organizations are also exploring the use of fiber optics as test reactor sensors. References 67 through 68 documents results from several activities completed by Luna Innovations Incorporated to assess the viability of specially-developed fiber optic sensors to survive nuclear reactor applications. This section summarizes these results as an example of one vendor that is pursuing the use of fiber optics for in-pile instrumentation.

Standard EFPI and FBG sensors constructed with fiber of various material compositions placed in-core at the at the University of Michigan's Ford nuclear reactor. Additionally, transmission measurements were made on 10-meter coils of four different fiber types located in two excore positions. Sensors and fibers were continuously monitored over a period of nearly 2 months. Total dose levels for the in-core samples reached $8.7 \times 10^{8}$ Gy gamma and $2 \times 10^{19} \mathrm{n} / \mathrm{cm}^{2}$ fast neutron $(\mathrm{E}>1 \mathrm{MeV})$ fluence. FBG sensors were fabricated in four fiber types with multiple levels of reflectivity. Two configurations of EFPI sensors were constructed using four different sensor materials. Fiber transmission testing included most of the FBG fiber types, as well as $830 \mathrm{~nm}$ single mode fiber used for EFPI sensors. As expected, the transmission of the fiber degraded as a 
function of total dose. $20 \%$ Ge-doped and SMF-28 fibers exhibited measurable transmission over a significant time scale at the $1310 \mathrm{~nm}$ wavelength, but only the SMF-28 fiber at the low-dose position remained above the instrument measurement limit at $1550 \mathrm{~nm}$.

Reference 68 reports results from irradiations of Luna fiber optic sensors optimized for high radiation / high temperature $\left(800^{\circ} \mathrm{C}\right)$ environments in drywells at the Ohio State University Research Reactor (OSURR) (one in-core in the Auxiliary Irradiation Facility (AIF) and one excore in a well labeled S2). The hybrid fiber optic pressure and temperature sensor design incorporated multiplexed optical interferometry, to facilitate direct temperature compensation of the pressure sensor. As illustrated in Figure 6-7, the same optical fiber was used to probe the displacement of a pressure-sensitive diaphragm, and the optical path length of a temperature transducer. An additional fiber optic sensor with a temperature transducer on its tip was placed inside each pressure sensor housing. For all fiber optic sensors in this experiment, a broad band optical source signal centered at $1310 \mathrm{~nm}$ was incident on the sensors through the fiber, and the reflected interference pattern was collected by a spectrometer. The peak or peaks in the fast Fourier transform of the interference pattern were used to calculate the optical path lengths, which in turn were calibrated into engineering units for pressure or temperature. Nearby thermocouples were also used to estimate the temperature of the pressure sensor housing.

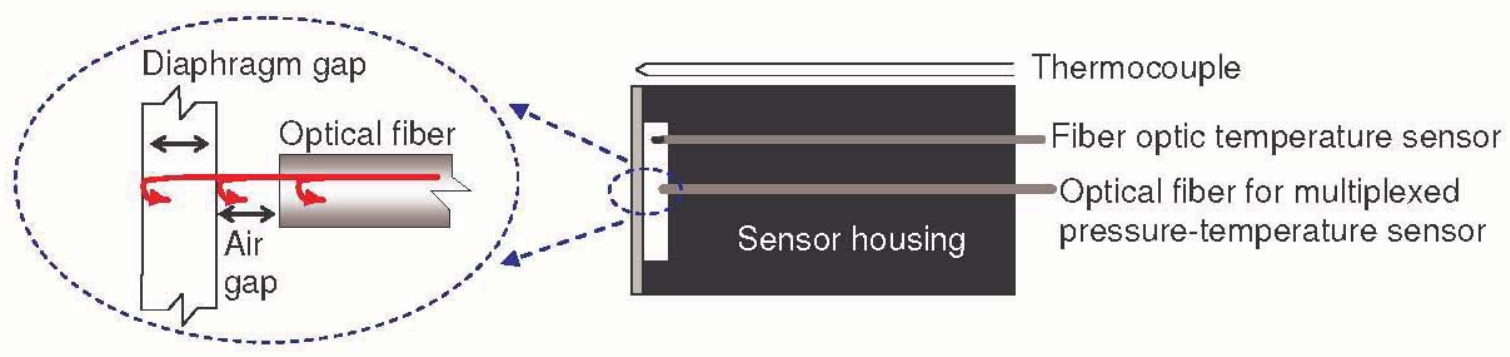

Figure 6-7. Fiber optic pressure sensor tip diagram.

During this entire endurance test, signal integrity and transmission through the optical fibers was sufficient for monitoring sensor response at these radiation levels. The average pressure sensitivity of $0.73 \pm 0.05 \mathrm{um} / \mathrm{bar}$ did not show significant long-term drift (Figure 6-8) during its exposure of $5.15 \mathrm{E} 18 \mathrm{n} / \mathrm{cm}^{2}$. Results indicate that reliable temperature compensation methods and algorithms are necessary for accurate pressure estimates with minimal drift and that the internal, but separate, fiber optic etalon temperature sensor included in this sensor provided the most reliable thermal compensation for the optical diaphragm style fiber optic pressure sensor.

During a project for the U.S. Air Force, Luna Innovations developed a method to monitor crack propagation in a composite patch. In order to locate and track small defects and stress concentrations, the density of strain sensors required prohibits the use of standard foil gages due to the massive cabling required. Using the distributed fiber optic approach, Luna developed a method to produce an array of sensors which successfully monitored crack propagation due to cyclic fatigue loading. 


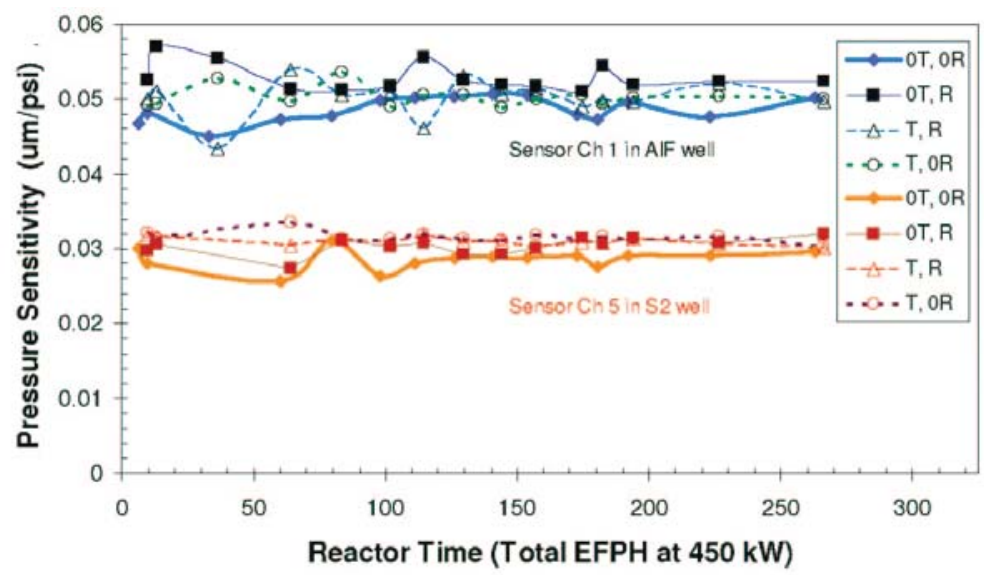

Figure 6-8. Sensitivity of pressure sensors in OSURR test ( $\mathrm{T}$ designates resistance heating, $\mathrm{R}$ designates gamma heating; $0 \mathrm{~T}$ or $0 \mathrm{R}$ designates absence of resistance heating or gamma heating, respectively).

In summary, test results suggests that Luna's optical fiber technology offer the potential to correct for decalibration due to radiation darkening of the fibers for limited time periods. However, longer term, higher flux level and higher temperature evaluations are needed. Luna Innovations teamed with INL on a proposal to fund these evaluations. ${ }^{69-70}$ Although economic factors precluded Luna from pursuing this irradiation at INL, several test rig design options were developed in Reference 70. As INL continues to monitor the results from other on-going CEA / fiber optic investigations (e.g., Luna irradiations at university research reactors, CEA-SCK-CEN irradiations of fiber optics at the BR-2 reactor, etc.) will be reviewed as INL considers whether to initiate additional activities related to fiber optics for in-pile instrumentation.

\subsubsection{Ultrasonic Thermometers}

Ultrasonic thermometers (UTs) were developed by INL staff for Power Burst Facility (PBF) fuel centerline temperature measurements. Research following these tests investigated improvements possible with single crystal tungsten sensors. Although UTs require expensive and complex signal processing, they are the only in-pile sensors capable of detecting temperatures above $2000{ }^{\circ} \mathrm{C}$. Advances in signal processing offer the potential to further improve the performance of UTs developed by INL. However, prompt initiation of these evaluations is absolutely critical to prevent the loss of remaining expertise in this capability as INL staff retires.

Recent discussions with representatives of the European Commission Joint Research Center suggest that a similar situation exists within Europe. ${ }^{71}$ Discussions are underway to document the status of UTs to prevent permanent loss of information regarding the design, fabrication, and operation of this technology. 


\subsection{Thermal Conductivity}

Currently, changes in fuel or material thermal conductivity during ATR irradiations are evaluated out-of-pile. However, INL and USU, with assistance from the IFE-HRP, are evaluating a two thermocouple steady-state thermal conductivity approach and a transient hot wire thermal conductivity method. Project research objectives include:

- Explore the benefits and limitations of the two-thermocouple steady-state and transient hot-wire methods as in-pile effective thermal conductivity measurement techniques

- Quantify accuracy and limitations of techniques by comparisons with standard laboratory material property measurement systems and thermal analyses from finite element code predictions.

The general setup used to complete laboratory evaluations of each approach is shown in Figure 69. Details about the setup for each approach and the status of evaluations are summarized in this section. Additional details may be found in References 72 through 74.

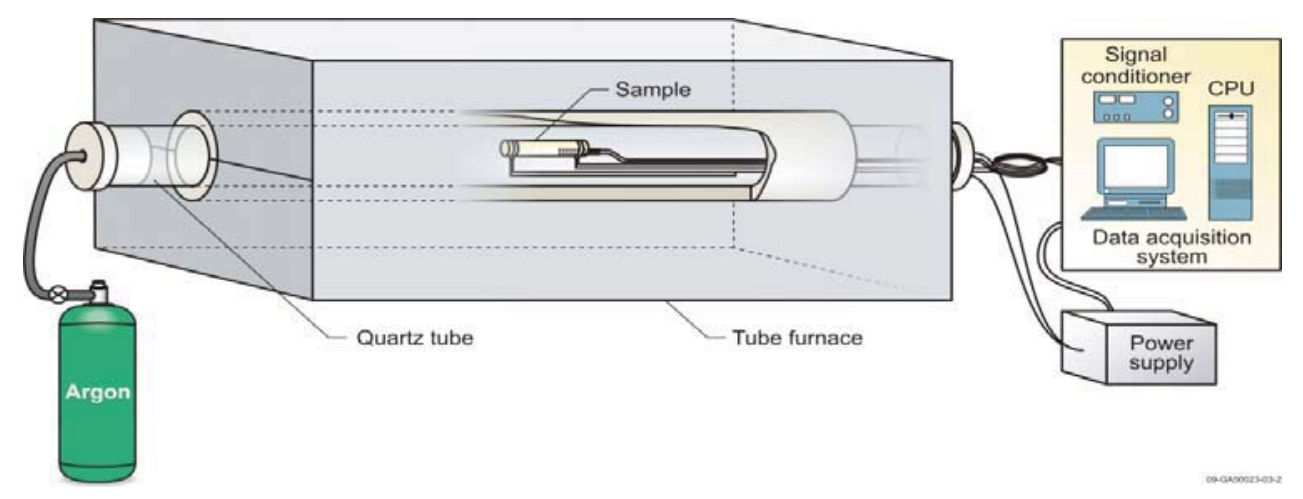

Figure 6-9. Configuration for evaluating in-pile thermal conductivity techniques.

\subsubsection{Degradation (via HTIR-TCs)}

Initial efforts focussed on the two-thermocouple method. Variations of this approach for detection of thermal conductivity changes in oxide and metal fuel during irradiation have been explored since 1960 (e.g., see References 75 through 77). Typically, all of these approaches have one (or more) thermocouples inserted near the center of the fuel rod and one exterior to the fuel (in the coolant or a structure outside the fuel element). Currently, the HBWR is the only test reactor where in-pile thermal fuel thermal conductivity measurements are still performed. As noted in Section 4.3.2, IFE-HRP is using this technique to assess the impact of burnup on thermal conductivity. HRP tests are typically performed with specially-designed fuel rods with a small as-fabricated fuel-to-clad gap to minimize the influence of gap conductance change (densification/swelling, fission gas release) on the fuel center temperature during irradiation. In addition, smaller diameter fuel pellets are also often used to increase burnup accumulation rate. 
The two thermocouple method is based on the principle of radial heat flow. The steady state thermal conductivity of a fuel rod, $k$, can be obtained from the two-thermocouple method by applying Fourier's Law in cylindrical coordinates.to obtain

$k=\frac{\dot{q} r^{2}}{4 \Delta T}$

where the thermal conductivity is calculated using the radial position of the thermocouple placed away from the sample centerline thermocouple, $r$; volumetric heat generation, $\dot{q}$; and measured temperature difference, $\Delta \mathrm{T}$. As noted above, this approach is typically implemented in-pile with one thermocouple in the center of the fuel and one located outside the fuel cladding (in the coolant). Hence, in-pile degradation of fuel during irradiation due to swelling, cracking, etc., typically leads to results being presented as simply an indication of thermal conductivity degradation (because the 'effective' thermal conductivity of the fuel, cladding, and gap are measured and one is really just detecting changes in the fuel that impact its thermal conductivity).

For this approach, USU/INL evaluations focused on estimating the thermal conductivity of a surrogate fuel rod using two thermocouples inserted in the rod, one to monitor centerline temperature and another to monitor temperature at a measured radial position within the rod. Although initial USU/INL evaluations were performed using Type K thermocouples, in-pile applications would incorporate the use of INL-developed High Temperature Irradiation Resistant Thermocouples (HTIR-TCs) discussed in Section 6.1. CFOAM25, a high temperature carbon structural foam manufactured by Touchstone Research Laboratory, was selected as the surrogate material in these evaluations. Although several candidate surrogate materials were initially explored, FY2009 investigations indicated that CFOAM25 was the only viable surrogate material identified with appropriate electrical resistivity, low thermal conductivity, and high temperature resistance to oxidation and melting. Although the limited room-temperature data from Touchstone were sufficient to select CFOAM25 as a surrogate material, temperature-dependent material property data were needed for this USU/INL effort. Temperature-dependent data were obtained using standard material property measurement systems (e.g., laser flash diffusivity, pushrod dilatometry, and differential scanning calorimetry) available at INL's High Temperature Test Laboratory (HTTL).

Figure 6-10 shows a schematic of the surrogate rod and test setup used to obtain data. Surrogate rods containing two thermocouples (Figure 6-10a) are positioned inside a tube furnace with an argon cover gas to provide a controlled sample test temperature (Figure 6-10b). Voltage and current from the power supply are supplied to the rod using Inconel electrodes connected to Inconel clamps. Leads attached to Inconel clamps at each end of the rod are used to measure the voltage drop across the rod. A precision current shunt is used to measure current within the experimental test loop. Volumetric heat generation is calculated using the measured current, I; and the sample voltage drop, V; sample dimensions, and the fact that power is the product of the current and voltage. Flow rates can be adjusted using valves to vary fluid conditions within the tube. The fluid inside the tube can either be air or an inert gas, such as argon. Signals are processed by a data acquisition system to give temperatures from thermocouples and power in the sample. 


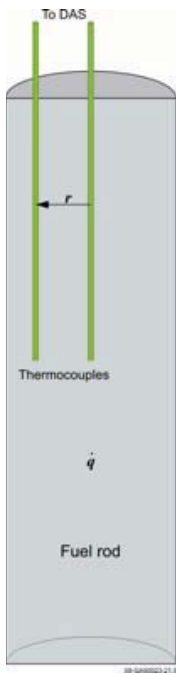

(a)

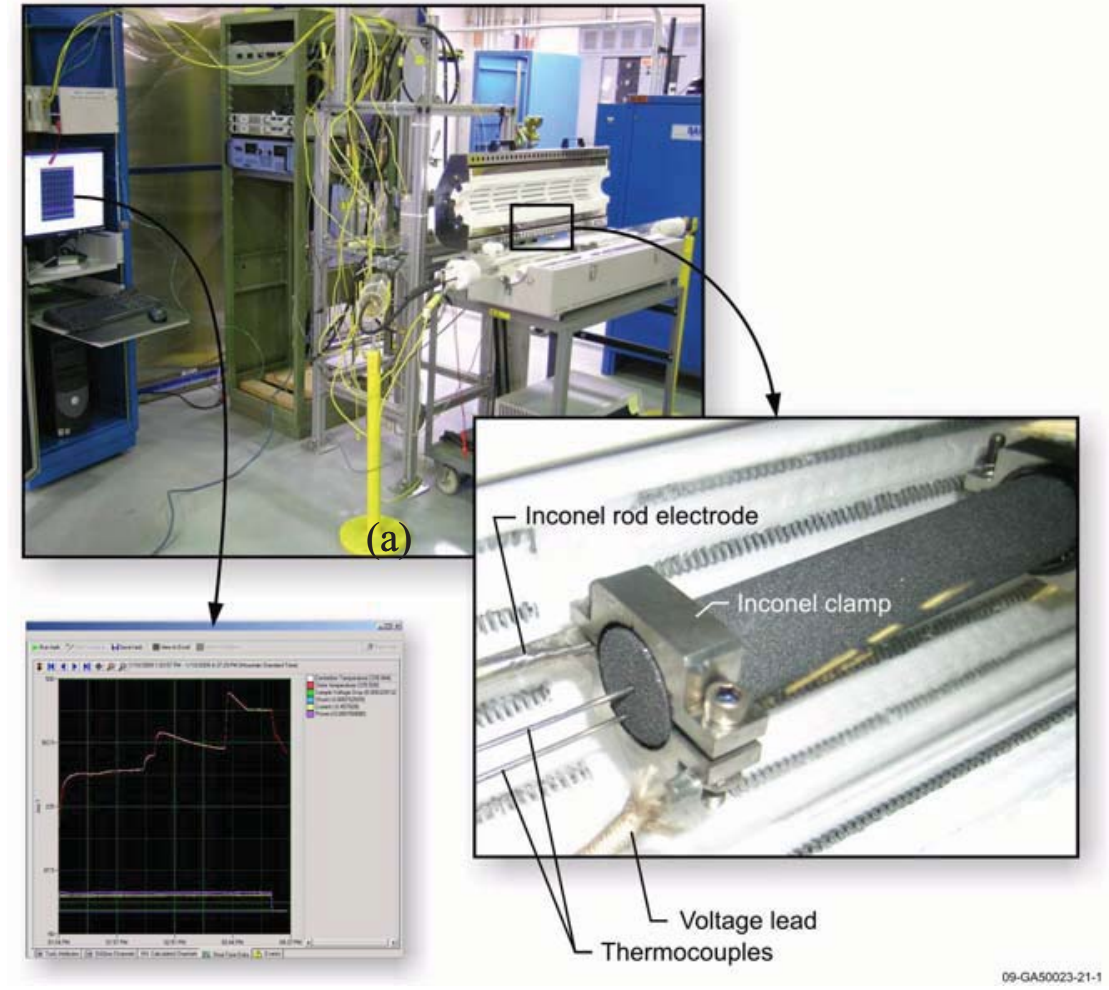

(b)

Figure 6-10. Setup for evaluating viability of multiple thermocouple method

Thermal conductivity testing began at INL's HTTL in January 2009. Testing initially focused on the $500{ }^{\circ} \mathrm{C}-700{ }^{\circ} \mathrm{C}$ temperature range. Results for tests with the supplied power held constant at $100 \mathrm{~W}$ are compared in Figure 6-11 with average rod effective thermal conductivity values obtained from material property measurements. Test data (shown as red dots in Figure 6-11) were within $2 \%-8 \%$ of the surrogate rod thermal conductivity values calculated from data obtained from material property measurement systems (the curve in Figure 6-11). During FY10, additional efforts will be completed to further assess the limitations and repeatability of this approach.

Using the Abaqus 6.8-2 code, ${ }^{86}$ Finite Element Analyses (FEA) are being completed to provide additional insights and extend experimental results. Initial FEA calculations were performed to help bound the potential effects of non-ideal contact thermal resistance between the thermocouple and surrogate rod material in laboratory test conditions. Temperature-dependent material property data for rod material and thermocouple constituents were input into Abaqus. Figure 6-12 shows results from analyses evaluating the change in surrogate rod thermal conductivity predicted when the assumption for gap coefficient varies from of $9376 \mathrm{~W} / \mathrm{m}^{2} \mathrm{~K}$ to $308 \mathrm{~W} / \mathrm{m}^{2} \mathrm{~K}$. As shown in Figure 6-12, this factor of 30 variation in assumed gap coefficient only affects surrogate fuel rod thermal conductivity estimates by $9 \%$. During FY10, FEA will be completed to gain additional insights about the accuracy and limitations of the two-thermocouple 


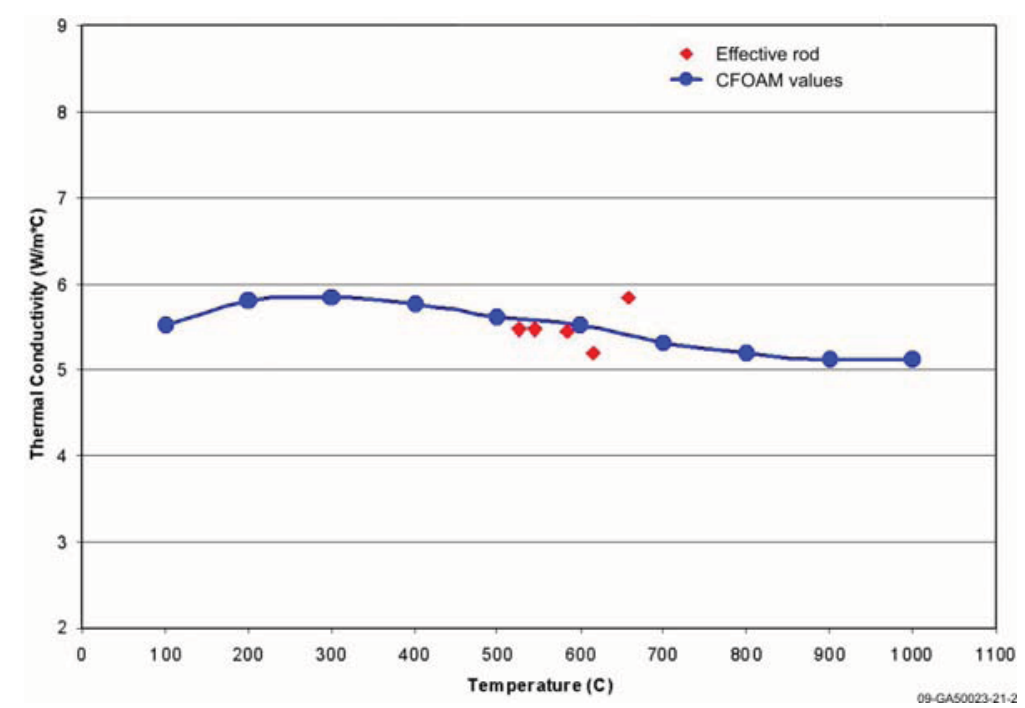

Figure 6-11. CFOAM thermal conductivity values obtained using two thermocouple approach (in red) compared with average values from standard laboratory material property measurement systems (in blue).

steady-state and hot-wire transient methods for estimating effective rod thermal conductivities for surrogate materials in laboratory test conditions and fuel rods during in-pile test conditions.

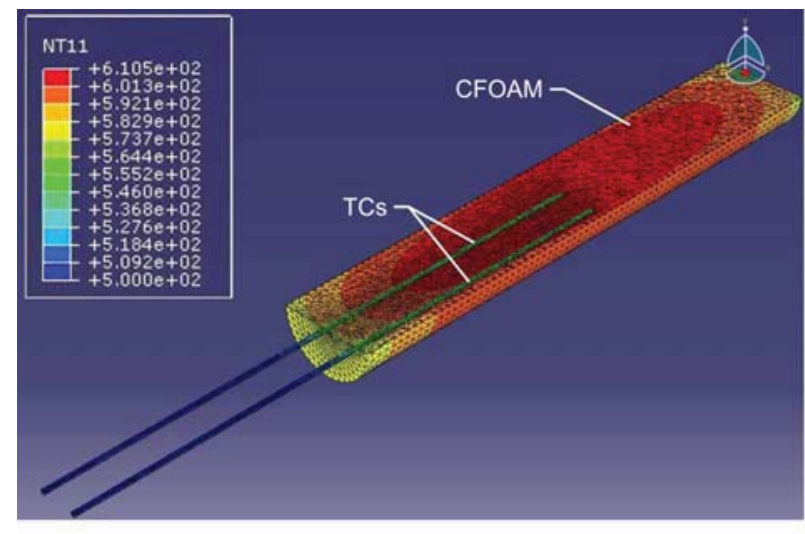

(a) gap coefficient of $308 \mathrm{~W} / \mathrm{m}^{2} \mathrm{~K}$

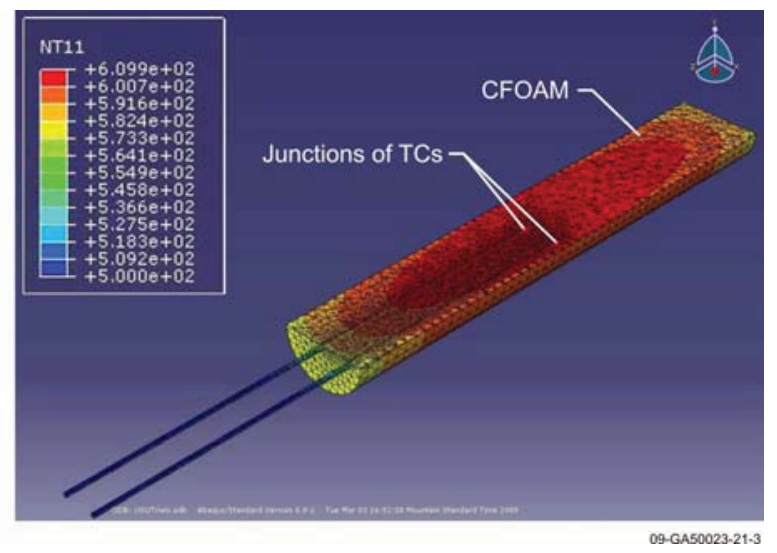

(b) gap coefficient of $9376 \mathrm{~W} / \mathrm{m}^{2} \mathrm{~K}$

Figure 6-12. Abaqus temperature predictions for different gap heat transfer coefficients.

\subsubsection{Hot Wire Method (via HTIR-TCs)}

The Transient Hot Wire Method (THWM) or line heat source method, was first suggested by Schleirmacher. ${ }^{78}$ Numerous references may be found in the literature describing applications of this method to measure the thermal conductivity of solids, fluids, and gases (e.g., see References 79 through 83). Today, several commercial vendors offer systems measuring thermal conductivity based on THWM techniques (e.g., see Reference 84). The THWM is applied by embedding a line heat source in the material whose thermal conductivity is to be measured. From 
a condition of equilibrium, the heat source is energized and heats the sample with constant power. The temperature response of the sample is a function of its thermal properties. The thermal conductivity is found from the temperature rise at a small distance from the heat source. Following a brief transient period, a plot of the temperature versus the natural logarithm of time becomes linear, as shown in Figure 6-13 (the time period between $t_{1}$ and $t_{2}$ ). The thermal conductivity for the sample can be calculated from the following relation:

$k=\frac{Q_{w} \ln \left(\frac{t_{2}-t_{o}}{t_{1}-t_{o}}\right)}{4 \pi\left(T_{2}-T_{1}\right)}$,

where the power dissipation by the heater wire, $Q_{w}$, is related to the thermocouple temperature at the time when the linear portion of the curve started, $T_{1}$, and the temperature when the linear portion of the response curve ended, $T_{2}$.

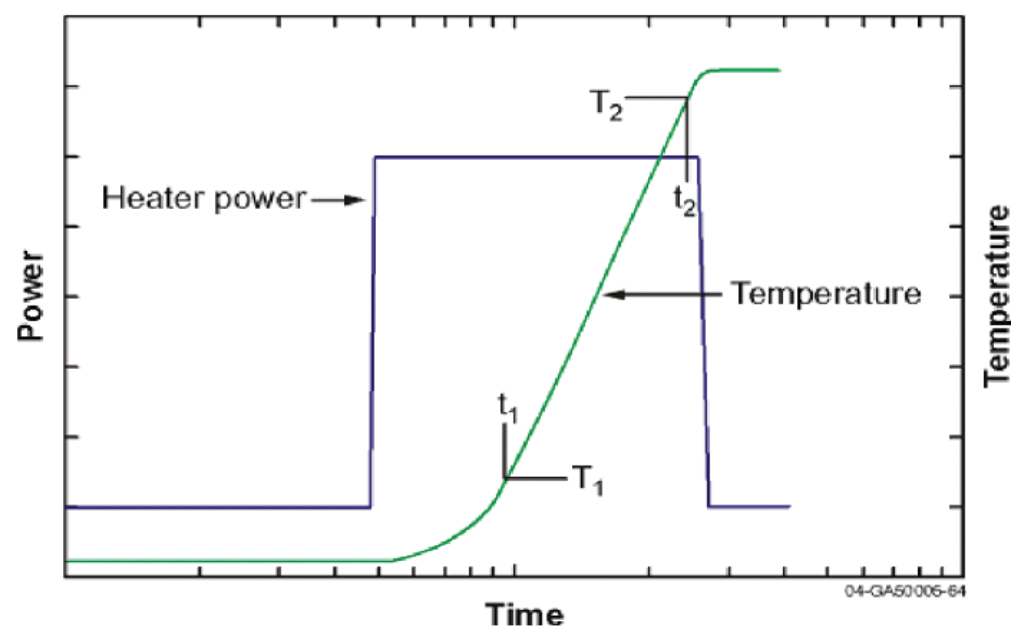

Figure 6-13. Typical time versus temperature plot for hot wire method

In these investigations, a new hot wire probe design, containing a resistance heater and thermocouple embedded in a single probe (see Figure 6-14a), has been developed based on ASTM D 5334 -05. Using the setup shown in Figure 6-14b, room temperature evaluations were completed on several materials (DELIN, particle board, quartz, etc.). As indicated in Table 6-2, rod effective thermal conductivities are, with the exception of Lexan, within $10 \%$ of values reported in the literature for the materials tested. During FY10, high temperature evaluations will be completed to assess the viability of this probe for in-pile fuel irradiations. 


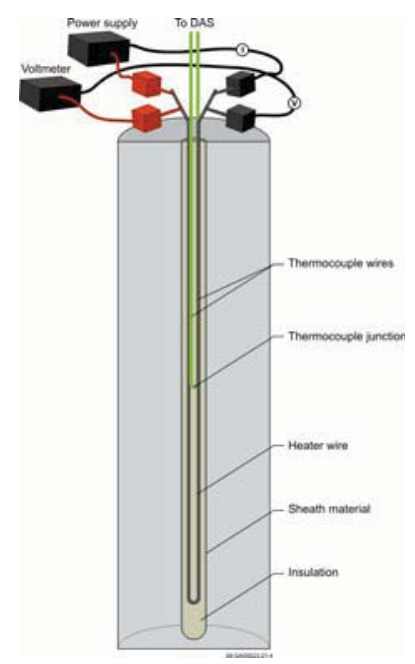

(a)

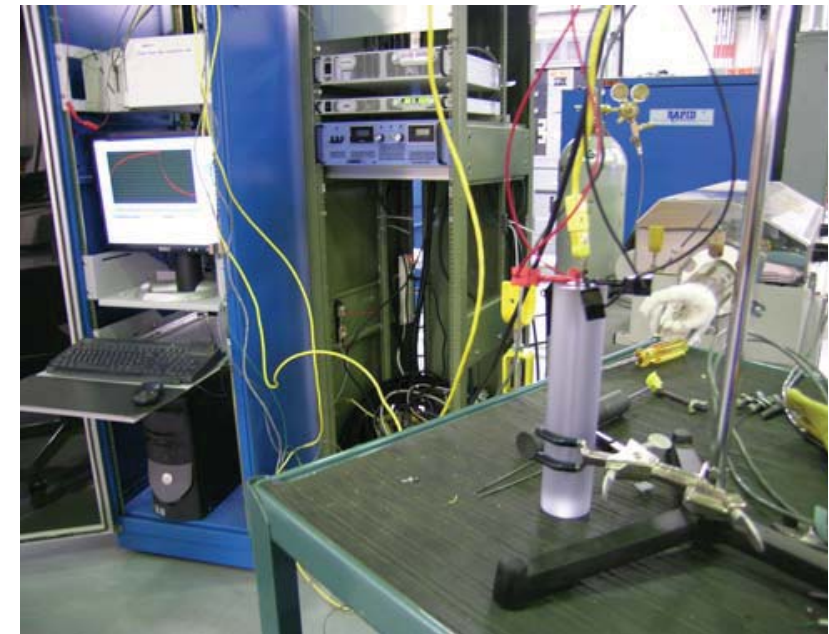

(b)

Figure 6-14. HTTL setup for room temperature evaluation of THWM.

Table 6-2. Room temperature results from THWM probe.

\begin{tabular}{|c|c|c|c|}
\hline Material & $\begin{array}{l}\text { Probe Average Measured Effective } \\
\text { Thermal Conductivity }\left(\mathrm{W} / \mathrm{m}^{2} \mathrm{~K}\right)\end{array}$ & \begin{tabular}{|c|} 
Average \\
Reported Value \\
$\left(\mathrm{W} / \mathrm{m}^{2} \mathrm{~K}\right)$
\end{tabular} & $\begin{array}{l}\text { Ratio of Reported to } \\
\text { USU/INL Measured Values }\end{array}$ \\
\hline $\mathrm{SiO}_{2}$ & 1.353 & 1.38 & 1.020 \\
\hline Delrin & 0.281 & 0.295 & 1.050 \\
\hline Lexan & 0.247 & 0.207 & 0.838 \\
\hline Acrylic & 0.215 & 0.216 & 1.005 \\
\hline Particle Board & 0.149 & 0.135 & 0.906 \\
\hline
\end{tabular}

\subsection{Displacement Sensors}

Geometry changes of samples irradiated in the ATR are also currently evaluated out-of-pile. However, INL is investigating several options that offer the potential to obtain real-time geometrical changes of samples during ATR irradiations. The objective of these efforts are to evaluate (and enhance, as needed) the viability of candidate sensors to detect dimensional changes of specimens during high temperature irradiations in ATR instrumented lead and PWR loop tests.

\subsubsection{LVDTs}

INL evaluations ${ }^{85}$ through 86 identified two candidate nuclear grade LVDT vendor designs that could meet ATR-specific customer requirements listed in Table 6-3. The first supplier, identified as Vendor A, can currently provide LVDTs qualified to a maximum operating temperature of only $350{ }^{\circ} \mathrm{C}$; the second supplier, identified as Vendor B, can currently provide only LVDTs with diameters exceeding listed ATR design limits. (Note that the Vendor A temperature limitation was 
established primarily because of instabilities associated with the sensor response as its coils pass through a material-specific Curie temperature at approximately $360^{\circ} \mathrm{C}$. Hence, including Vendor A LVDT was deemed appropriate because alternate materials, that are not susceptible to Curie temperature effects, could be incorporated into their sensor design. Likewise, Vendor B indicated that alternate components could be used in their sensor design so that it was smaller in diameter). In both cases, limited data were available to verify either manufacturer's claims regarding their performance at high temperature.

Table 6-3. Representative ATR test conditions compared with candidate LVDT characteristics

\begin{tabular}{|c|c|c|c|}
\hline \multirow{2}{*}{ Parameter } & \multirow{2}{*}{$\begin{array}{c}\text { ATR } \\
\text { Specification }\end{array}$} & \multicolumn{2}{|c|}{ Values for Candidate LVDTs } \\
\hline & & Vendor A & Vendor B \\
\hline Total LVDT Displacement (e.g., stroke), mm & $>+/-2.5$ & $+/-2.5-6.0$ & \\
\hline Resolution, mm & $10^{-2}$ & & \\
\hline Sensitivity, V/m & $>50$ & 60 & 51 \\
\hline Maximum operating temperature, $\mathrm{K}$ & 773 & $>773^{a}$ & 920 \\
\hline Normal operating pressure, MPa & $0.101-15.5$ & 15.5 & 16.5 \\
\hline Peak thermal flux, $\mathrm{E}<0.625 \mathrm{eV}$, neutrons $/ \mathrm{cm}^{2} \mathrm{~s}^{\mathrm{b}}$ & $3.6 \times 10^{14}$ & $3 \times 10^{13 c}$ & $N A^{d}$ \\
\hline Integrated thermal fluence, $\mathrm{E}<0.625 \mathrm{eV}$, neutrons $/ \mathrm{cm}^{2 \mathrm{~b}}$ & $8.5 \times 10^{21}$ & $N A^{e}$ & NA \\
\hline Peak fast flux, E >1 MeV, neutrons $/ \mathrm{cm}^{2} \mathrm{~s}^{\mathrm{b}}$ & $1.8 \times 10^{14}$ & $3 \times 10^{13}$ & NA \\
\hline Integrated fast fluence, $\mathrm{E}>1 \mathrm{MeV}$, neutrons $/ \mathrm{cm}^{2 \mathrm{~b}}$ & $4.3 \times 10^{21}$ & $\mathrm{NA}^{\mathrm{e}}$ & NA \\
\hline Integrated gamma exposure, $\gamma / \mathrm{cm}^{2 \mathrm{D}}$ & $9 \times 10^{22}$ & $N A^{e}$ & NA \\
\hline Maximum LVDT Diameter, mm & $12-25.4^{\dagger}$ & 12 & 25.4 \\
\hline Maximum LVDT Length, mm & 63.8 & 66 & 63.8 \\
\hline Test environment & $\begin{array}{c}\text { Water (to } \\
350 \quad{ }^{\circ} \mathrm{C} \text { ) and } \\
\text { Inert Gas } \\
(\text { Neon, Helium) } \\
\left.\text { to } 500{ }^{\circ} \mathrm{C}\right)\end{array}$ & Water or Inert Gas & $\begin{array}{l}\text { Water or Inert } \\
\text { Gas }\end{array}$ \\
\hline $\begin{array}{l}\text { Distance from test capsule to where soft extension cable } \\
\text { can be used, } m\end{array}$ & 12 & NA & NA \\
\hline Length of leads until $\mathrm{T}<200^{\circ} \mathrm{C}, \mathrm{m}$ & 7 & NA & NA \\
\hline
\end{tabular}

a. Some loss of accuracy occurs temporarily at the Curie temperature of $355^{\circ} \mathrm{C}(628 \mathrm{~K})$

b. Peak values; based on a NE lobe source power of $18 \mathrm{MW}$. Fluence is based on 3 years of operation at $75 \%$ utilization.

c. Typical operating values in Halden reactor.

d. Not available or applicable (depending on context).

e. LVDTs have functioned for more than 10 years in HBWR without problems.

f. Smaller diameter preferred.

During FY09, INL completed several tasks to compare candidate design performance. First, laboratory calibration tests were completed to compare candidate LVDT response at temperatures up to $500{ }^{\circ} \mathrm{C}$. Second, LVDT stability and reliability were assessed through long duration testing at $500{ }^{\circ} \mathrm{C}$. After these initial evaluations, a superior design was selected for additional evaluations. First, finite element analyses were completed to verify the impact of gamma heating on LVDT performance. Then, additional assessments were completed to evaluate any instabilities that may occur when the preferred LVDT design was exposed to its Curie temperature. 
Calibration and long duration high temperature evaluations were completed using specialized fixtures for LVDT positioning, vendor-specific LVDT signal conditioning equipment, and a computerized data acquisition system in conjunction with a high temperature tube furnace. The general arrangements for both calibration and long duration testing are depicted in Figure 6-15.
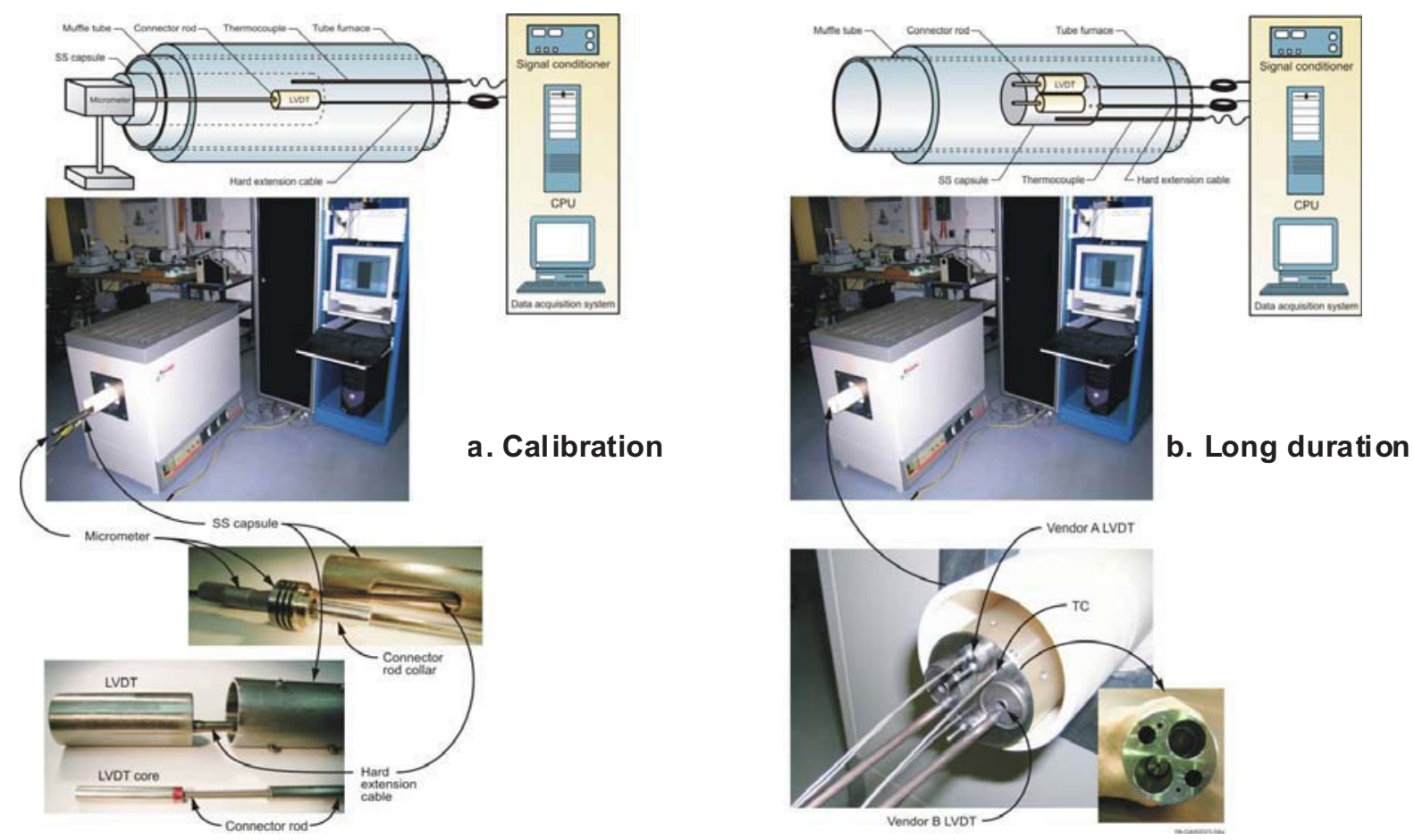

Figure 6-15. Setup for LVDT calibration and long duration performance evaluations.

Consistent with established practice, linear curve fits for such data at each temperature over the design range (of $+/-2.5 \mathrm{~mm}$ for both candidate LVDTs) were determined. Results for LVDT A1 at $500{ }^{\circ} \mathrm{C}$, as shown in Figure 6-16a, are typical. LVDT response data, a linear fit through that data, and the deviation of the data relative to the linear fit are all shown in the figure. It is worth noting that LVDT A1 has a maximum deviation of less than $+/-0.02 \mathrm{~mm}$ (or $+/-0.8 \%$ ) over its design range of $+/-2.5 \mathrm{~mm}$. Furthermore, its linear deviation is symmetric with respect to its null position. This is evident in that its deviation is $\sim 0$ at a displacement of 0 and the (absolute value of) deviations are approximately equal for equal but opposite displacements from null. Corresponding results for LVDT 1 from Vendor B (LVDT B1) are shown in Figure 6-16b. There are several notable differences apparent through comparison of curves in Figure 6-16. Specifically, the maximum linear deviation of LVDT B1 (at more than $0.044 \mathrm{~mm}$, or more than $1.8 \%$, over its design range of $\pm 2.5 \mathrm{~mm}$ ) is more than twice the LVDT A1 maximum deviation. Furthermore, the linear deviation of LVDT B1 is not symmetric with respect to its null position. In fact, its deviation is $\sim 0$ at a displacement of $\sim 1.2 \mathrm{~mm}$. Deviations at $\pm 2.5 \mathrm{~mm}$ are $\sim 0.017$ and $0.044 \mathrm{~mm}$, respectively. Hence, this LVDT does not exhibit the desired symmetric behavior. Both LVDTs should be capable of resolution in the $0.010 \mathrm{~mm}$ range, which is an ATR specification. However, 
LVDT A1 would be expected to have a lower degree of uncertainty (as compared to LVDT B1) because its deviation from linearity is relatively small.

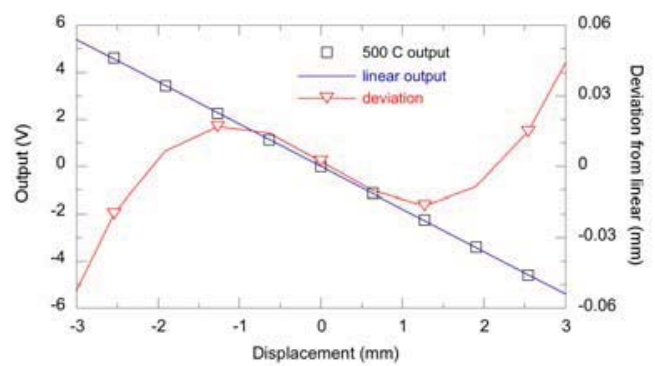

(a) LVDT 1 from Vendor A (LVDT A1)

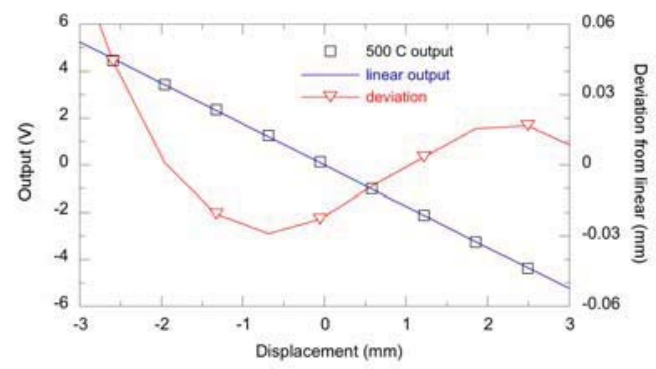

(b) LVDT 1 from Vendor B (LVDT B1)

Figure 6-16. Calibration data for 'standard' and 'non-standard' $500{ }^{\circ} \mathrm{C}$ calibration data.

Related evaluations indicated that the Vendor A LVDT sensitivity (e.g, $\mathrm{mV} / \mathrm{mm}$ ) was considerably higher than measured for Vendor B LVDTs at $500{ }^{\circ} \mathrm{C}$. Furthermore, the primary to secondary insulation resistance for LVDT B1 showed a sharp decrease after $300{ }^{\circ} \mathrm{C}$. At $500{ }^{\circ} \mathrm{C}$, primary to secondary insulation resistances of $\sim 40 \mathrm{ohms}$ were measured for LVDT B1, while the corresponding insulation resistance for LVDT A1 were measured in excess of $1 \times 10^{6} \mathrm{ohms}$.

LVDTs from both vendors were also subjected to long duration tests to reveal any tendencies for signal degradation or oscillation over time. Results for all four tested LVDTs are compared in Figure 6-17. (Note that an unplanned power outage interrupted data collection during the time period between $\sim 700$ and $\sim 760 \mathrm{~h}$. However, available information available indicates operation of the high temperature furnace was unaffected.) In this evaluation, all four LVDTs were configured in the test fixture with cores set as close to null positions as possible. Consequently, output for all four LVDTs would be expected to be remain near $0 \mathrm{Vdc}$ throughout the test. For comparison purposes, calibration data for each LVDT (at $500{ }^{\circ} \mathrm{C}$ ) was used to convert measured output voltage to an indicated displacement. Figure 6-17 presents the deviation of the indicated displacement, relative to the time 0 output, as a percentage of total linear travel (which is $5 \mathrm{~mm}$ for all sensors). Following this approach, a perfectly stable sensor would then register $0 \%$ deviation through time.

As indicated in this figure, Vendor A LVDTs were found to be very stable through $\sim 330 \mathrm{~h}$. Their maximum deviation during that period is equivalent to a displacement of $\sim 0.004 \mathrm{~mm}$ relative to their time 0 position. (Note that $\sim 25 \mathrm{~h}$ were set aside for stabilization at $500{ }^{\circ} \mathrm{C}$ before marking time 0.) However, some periodic fluctuations in the response of Vendor A LVDTs began to appear after $\sim 330 \mathrm{~h}$. Those fluctuations, primarily affecting LVDT A2, remained relatively small for more than $350 \mathrm{~h}$. Just before the unplanned power outage (at $700 \mathrm{~h}$ ), LVDT A2 fluctuations dramatically increased in both magnitude and duration. Shortly thereafter, LVDT A1 signal fluctuations increased; with relatively frequent oscillations until the end of the $1000 \mathrm{~h}$ test. Although the reason (or reasons) for the behavior of Vendor A LVDTs during the later part of this test are still under investigation, the vendor has indicated that they have observed similar trends as a result of insulation degradation and that they believe that tendencies for insulation degradation 


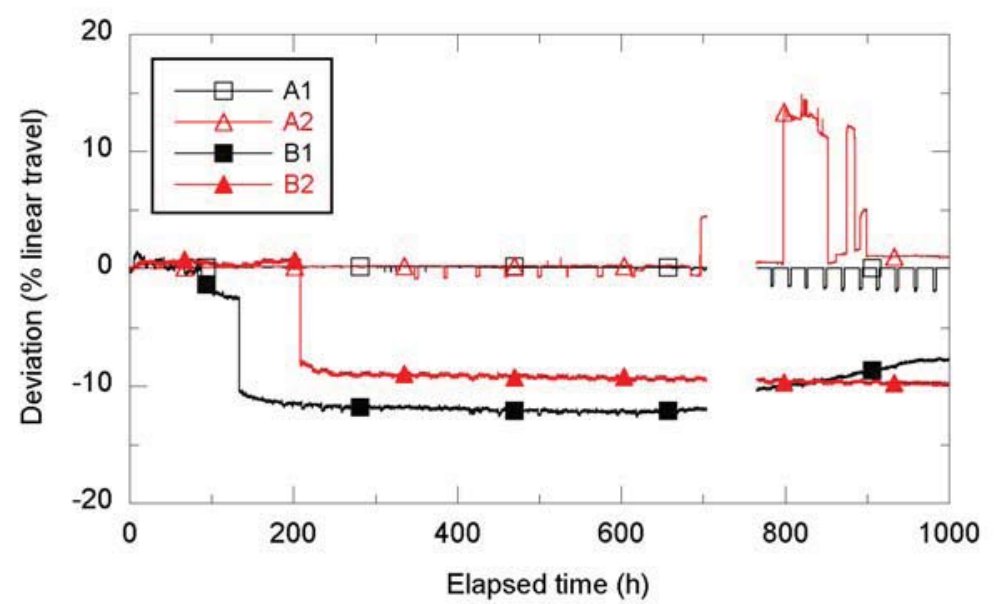

Figure 6-17. Comparison of LVDT response during long duration testing at $500{ }^{\circ} \mathrm{C}$.

may be minimized by changes in the heat treatment/curing process used in manufacturing. Further evaluation of this improved manufacturing process is anticipated.) Results for Vendor B LVDTs differ significantly compared to Vendor A. Specifically, Vendor B LVDTs show substantial oscillation (starting at time 0) in addition to (as yet unexplained) dramatic step changes in indicated deviations (near $130 \mathrm{~h}$ for LVDT B1 and near $210 \mathrm{~h}$ for LVDT B2). In fact, the LVDT B1 step change is equivalent to a displacement of $\sim 0.6 \mathrm{~mm}$, indicating a reduction in stability by a factor of $\sim 150$ compared to Vendor A LVDTs during the first $330 \mathrm{~h}$ of the test.

The superior performance of the Vendor A LVDTs has led INL to complete additional evaluations of sensors from this vendor, who has indicated that they may be identified as the IFE-HRP. First, finite element analyses were completed to verify the impact of gamma heating on LVDT performance. Results indicate that peak LVDT coil temperatures during irradiation from gamma heating at the center of the core in a flux trap will lead to maximum temperatures of $400{ }^{\circ} \mathrm{C}$. Second, additional assessments were completed between 300 and $420{ }^{\circ} \mathrm{C}$ to assess any instabilities that may occur when the preferred LVDT design was exposed to its Curie temperature. Representative results indicate that localized signal decreases of up to $50 \%$ may occur due to Curie temperature effects. However, these drops are typically limited to a $10{ }^{\circ} \mathrm{C}$ range. Vendor A, after seeing these results, is investigating several options to improve their LVDT performance at high temperature. During FY10, INL will complete laboratory evaluations of the improved Vendor A LVDTs.

\subsubsection{Ultrasonics}

Although LVDTs have been successfully deployed at other test reactors and are being investigated for ATR applications, ultrasonics offer the potential for a more compact, higher temperature, more accurate, and multi-dimensional real-time sensor for detecting geometry changes during irradiation. During FY09, INL and Pennsylvania State University (PSU) investigated the feasibility of ultrasonic testing (UT) for detecting geometry changes. 
UT utilizes high frequency sound waves to examine a given specimen. A transducer is used to convert an electrical signal to mechanical vibrations which transmits the ultrasonic waves into the specimen. After propagating through the specimen, the ultrasonic waves are either reflected back to the transmitter (pulse-echo mode) or are picked up by a second transducer (through-transmission mode). The received signal is then converted back into an electrical signal by one of the transducers. The recorded waveform can then be analyzed to determine various properties of the structure. For example, the time-of-flight in a creep specimen will increase due to specimen elongation. Also, the plastic deformation associated with creep can alter the frequency spectrum of the received signal.

The use of ultrasonic inspection techniques as an in-pile sensor is challenging for two reasons. First, typical operating conditions $\left(350^{\circ} \mathrm{C}\right)$ are well above the Curie temperature of conventional transducer materials ${ }^{87}$ and the transducer will stop functioning. Second, conventional transducers are typically not suitable for radiation exposure. Radiation can damage transducer materials and degrade their performance. ${ }^{88}$ through ${ }^{89}$ Furthermore, conventional transducers often contain elements, such as lead, lithium, and gold, that transmute into toxic substances.

One possible solution is to locate the transducer outside of the radiation environment and transmit the ultrasonic waves to the specimen via a wire waveguide. ${ }^{90}$ though 91 This is possible because of guided wave phenomena. Guided waves occur when the ultrasonic waves interact with the boundaries (surfaces) of a specimen and constructive interference leads to a unique wave structure. Because the boundaries of the specimen contain the ultrasonic energy, a specimen can be interrogated at the end of a very long waveguide. Figure 6-18 shows a conceptual design of this approach. Using the equipment shown in Figure 6-19, bench-top tests were completed to investigate this design. The setup includes five components: the magnetostrictive transducer (e.g., driver coil), the Remendur guide, a coupling, the stainless steel wave guide, and the sample. Initial evaluations considered the sample geometry shown in Figure 6-19 because prior evaluations ${ }^{90}$ indicate that this acoustic horn enhances the signal. Evaluations included several different sets of electronics to optimize the signal.

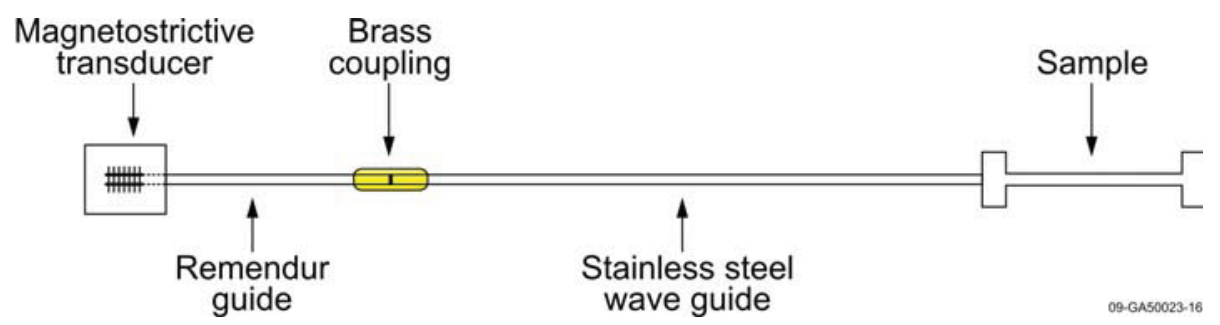

Figure 6-18. Typical setup for detecting sample length changes with an ultrasonic transducer.

Testing demonstrated that energy can be transmitted into the sample and can be received in both pulse-echo and through-transmission mode. (A through transmission signal was monitored using a contact piezo $1.5 \mathrm{MHz}$ broadband transducer). Testing also demonstrated that the use of a magnetostrictive sleeve (Figure 6-20 shows candidate designs) eliminated the need for a brass 


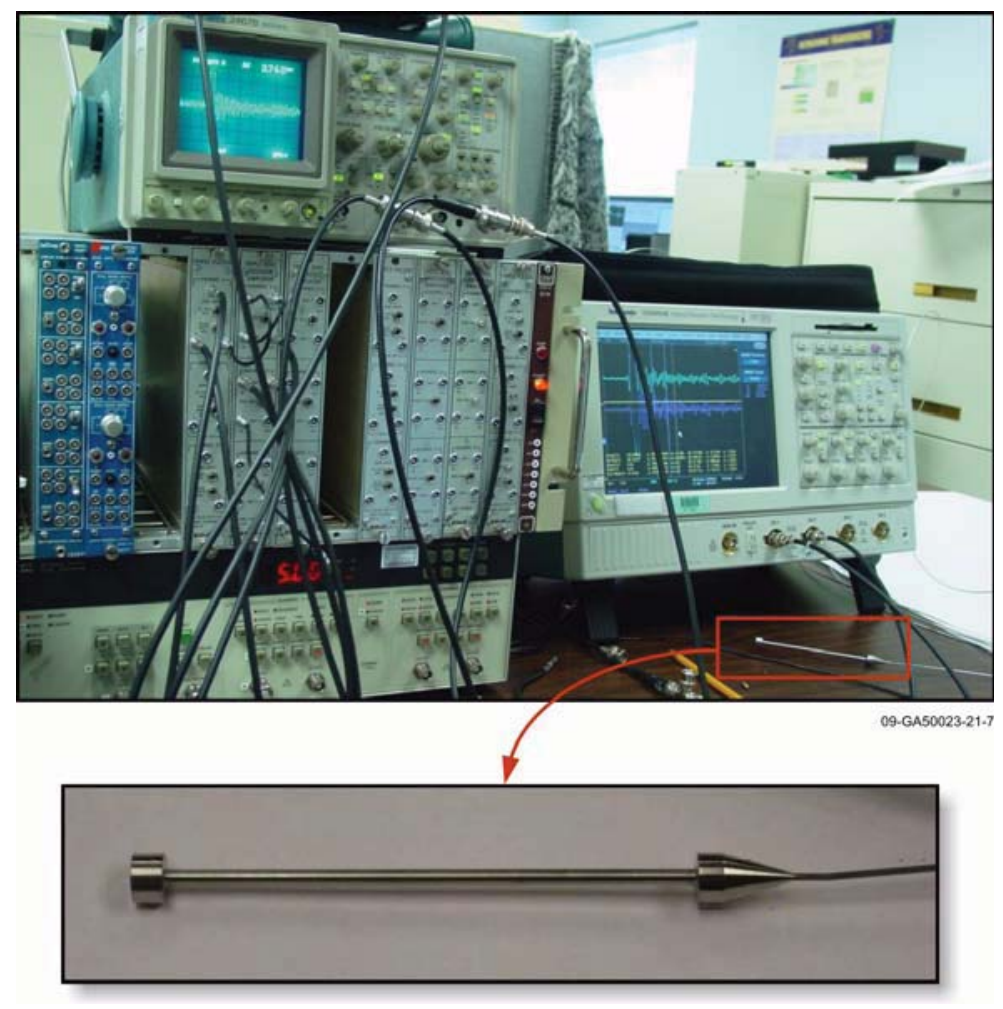

Figure 6-19. UT testing equipment evaluating specimen attached to acoustic horn and $30 \mathrm{ft}$ wave guide.

joint to connect magnetostrictive material to stainless steel. However, results suggest that the laser weld used to join the acoustic horn to the 30 foot wave guide hinders transmission and reception of the signal. In fact, additional optimization efforts are needed for most of the components shown in Figure 6-18. For example, alternate coupling methods should be explored in which the magnetostrictive transducer is directly coupled to a stainless steel wave guide. Alternate wave guide materials, such as molybdenum or Inconel, should also be explored that have higher temperature and better repeatability characteristics. In addition, efforts are needed to optimize the design of the acoustic horn for specimens of interest to ATR customers. Ultimately, prior to ATR testing, this technology should be evaluated at PWR temperatures and pressures in an autoclave.
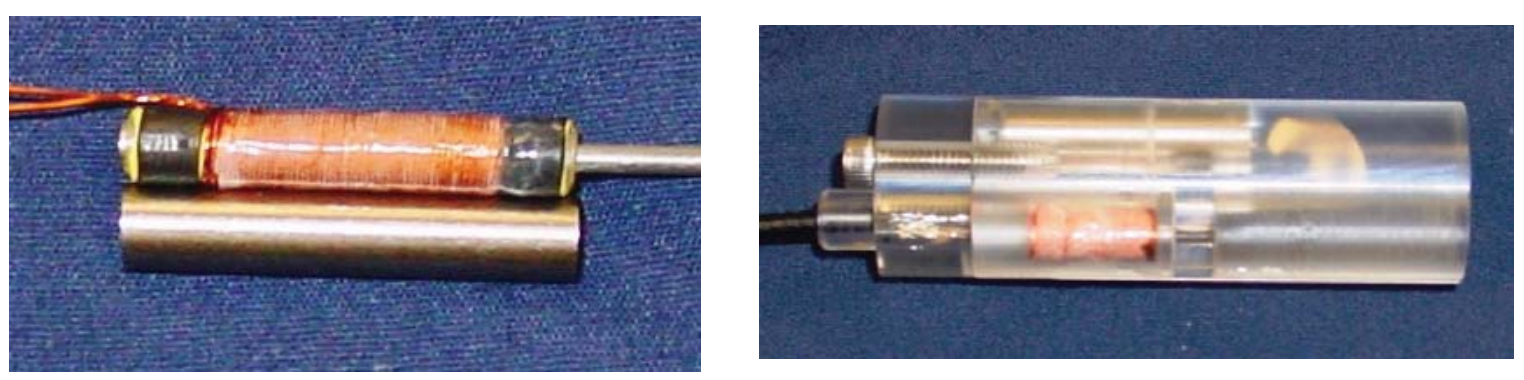

Figure 6-20. Candidate magnetostrictive sleeve designs investigated. 


\subsection{Mechanical Property Evaluations}

Several methods, in various stages of development, offer the potential to provide users new techniques for obtaining mechanical property data during irradiation. As part of the U.S. gas reactor development program, a pushrod method is being deployed that can provide real-time data to users about the load being transmitted to samples during testing. In addition, development efforts have been initiated to provide users real-time detection of elongation for a fixed load and crack growth with a variable load.

\subsubsection{Monitored Pushrod Load}

Although no sensors are included to provide real-time data on sample dimensional changes, the ATR instrumented capsule for evaluating graphite performance ${ }^{92}$ contains specialized components that can detect the compression applied to samples during irradiation. Figure 6-21 shows major components of this design. In this capsule, matched pairs of stressed and unstressed samples will be irradiated, and their dimensions will be compared after irradiation. Rams in this design are located above the core away from high neutron and gamma fields. The rams' force is transmitted by stainless steel pushrods. Graphite pushrods are attached to the stainless steel pushrods to transmit the force inside the high-temperature graphite body. The force on the graphite channel is monitored by an in-line load cell between the stainless steel and graphite pushrods. The load cell juncture is located at an elevation above the core. The pressure within each pneumatic piston will be continuously monitored to maintain the design stress level. A second pneumatic ram, which is located at the bottom of the capsule below the core, is capable of displacing the graphite sample stack. During reactor outages, when the load from the ram above the core is removed, the graphite specimen stack is "upset" by displacement from the lower rams. This procedure will assure that the graphite stack is not jammed in the channel and, thus, that the applied load is actually being transmitted to all of the stressed specimens in the channel. In-line load cells, which are located away from the core, are used to measure applied loads on the graphite columns.

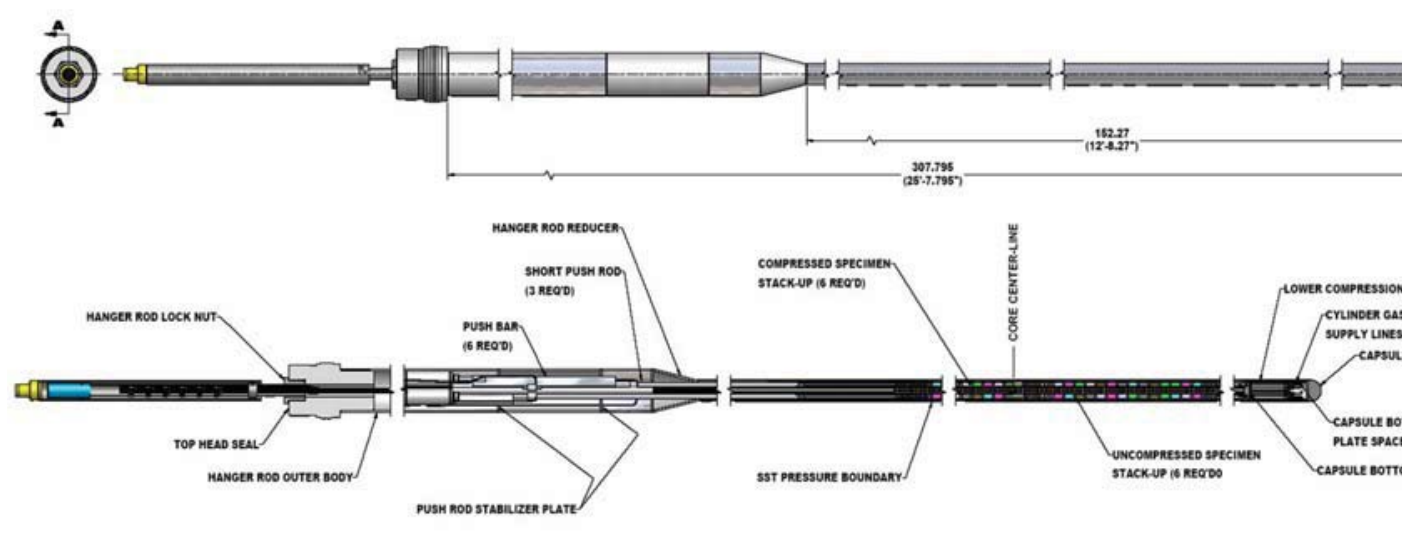

Figure 6-21. Sketch of the AGC-1 in-pile tube assembly 


\subsubsection{In-Pile Loading and with Monitored Sample Deformation for LWR conditions}

During FY08, efforts were initiated to develop instrumented creep testing of specimens in Light Water Reactor (LWR) coolant conditions in the ATR. A new creep test instrument has been developed to have similar capabilities of those currently used at the HBWR, e.g., applied load 92$350 \mathrm{MPa}$ at the temperatures between 290 and $370{ }^{\circ} \mathrm{C}$ up to at least 2 dpa. ${ }^{93}$ During FY09, efforts focussed on finalizing a design that could be tested in an autoclave at INL's High Temperature Test Laboratory (HTTL) and ultimately incorporated into an ATR PWR loop.

Figure 6-22 shows major components of the proposed test rig design developed by INL in collaboration with the IFE-HRP. As indicated in this figure, major components include a tensile specimen, a bellows that will apply a load to the specimen when it is subjected to external pressure, an LVDT fabricated by IFE-HRP (Vendor A in the Section 6.3.1 description of LVDT evaluations completed by INL), and fixturing to connect these components.

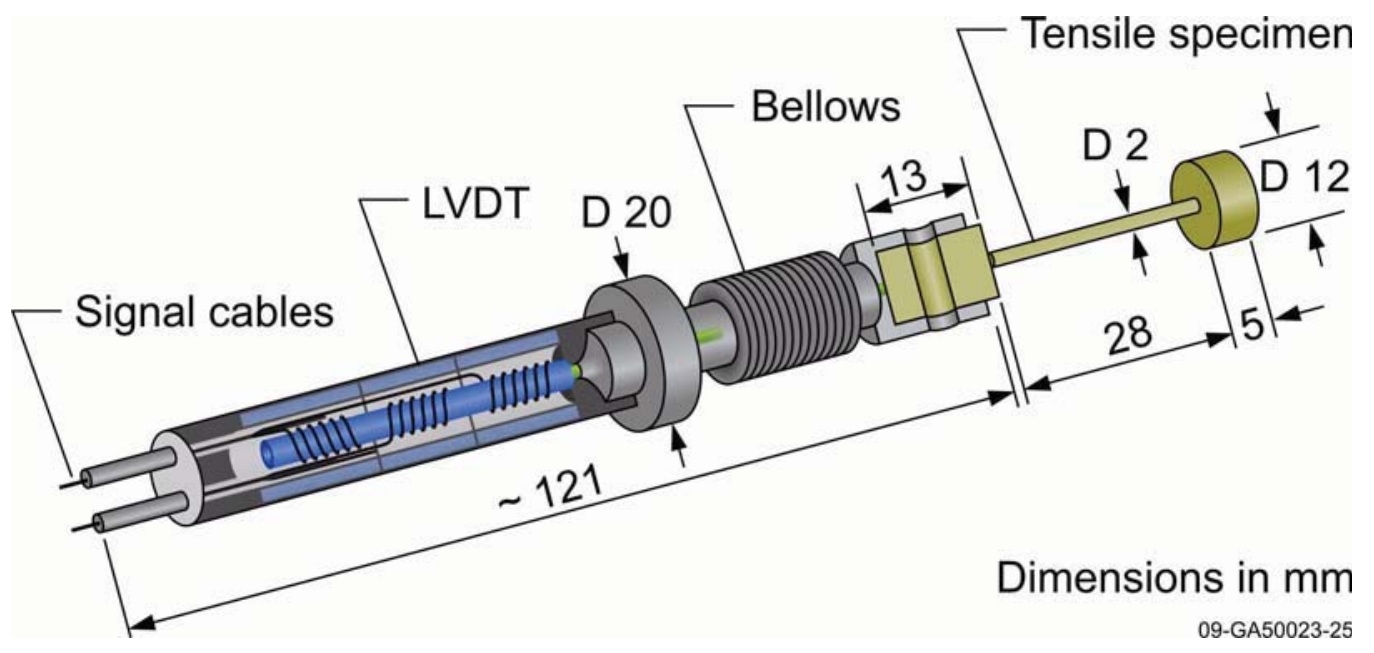

Figure 6-22. Creep test rig design.

An unaged (e.g., not precipitate-hardened) Inconel 718 hydro-formed metal bellows, manufactured by Miniflex, has been chosen with the specifications listed in Table 6-4. Although bellows could be fabricated from other materials (e.g., Inconel 625, Inconel X-750 or stainless steel), Inconel 718 was selected because of its superior mechanical properties (e.g., yield strength, ductility, and radiation resistance). 
Table 6-4. Bellow specifications for creep test rig

\begin{tabular}{|l|c|}
\hline Part Number & $\mathbf{I 7 1 8 - 3 2 0 - 1 1 0 - 7 9 0}$ \\
\hline Convolution ID / Convolution OD, cm (inches) & $0.719 / 1.295(0.283 / 0.510)$ \\
\hline Wall Thickness, cm (inches) & $0.02794(0.0110)$ \\
\hline Neck O.D. / Neck I.D. cm (inches) & $0.818 / 0.759(0.322 / 0.299)$ \\
\hline Neck Length, cm (inches) & $0.376(0.148)$ \\
\hline Convolution Free Length, cm (inches) & $2.134(0.840)$ \\
\hline Maximum Deflection (compression) & 0.146 \\
\hline Spring Rate, kg/cm (lbs./inch) & $14.1(790)$ \\
\hline Effective Area, cm ${ }^{2}$ (sq.inch) & $0.794(0.123)$ \\
\hline Squirm Rating (P.S.I.G) & $26.2(3800)$ \\
\hline Burst Rating (P.S.I.G) & $55.2(8000)$ \\
\hline Number of Convolutions & 13 \\
\hline
\end{tabular}

Specimen size is determined based on anticipated loads during creep testing at LWR pressures. The radius for candidate specimens can be estimated from the peak force that will be exerted by the bellows on a specimen. Using the effective bellow area $\left(0.794 \mathrm{~cm}^{2} / 0.123 \mathrm{in}^{2}\right.$ from Table 6-4) and the peak system pressure (2300 psi from Table 6-5), the peak force that will be exerted by the bellows is $\left(2300 \mathrm{psi}^{*} 0.123 \mathrm{in}^{2}\right)$ or $282.9 \mathrm{lb}_{\mathrm{f}}$. The stress exerted on a tensile specimen for this force is a function of its gauge area. which in turn can be related to its radius. Proposed specimen radii for testing at nominal PWR pressure (e.g., 2250 psi) are shown in Figure 6-23. For the desired range of stress loads (90-350 MPa), the specimen radius should range between approximately 1.1 to $2.1 \mathrm{~mm}$ to obtain such stresses. For initial testing, it is proposed using specimens with a radii of 1.1, 1.5, and $2 \mathrm{~mm}$. During FY10, a test plan will be developed that identifies the range of specimen geometries and materials for testing.

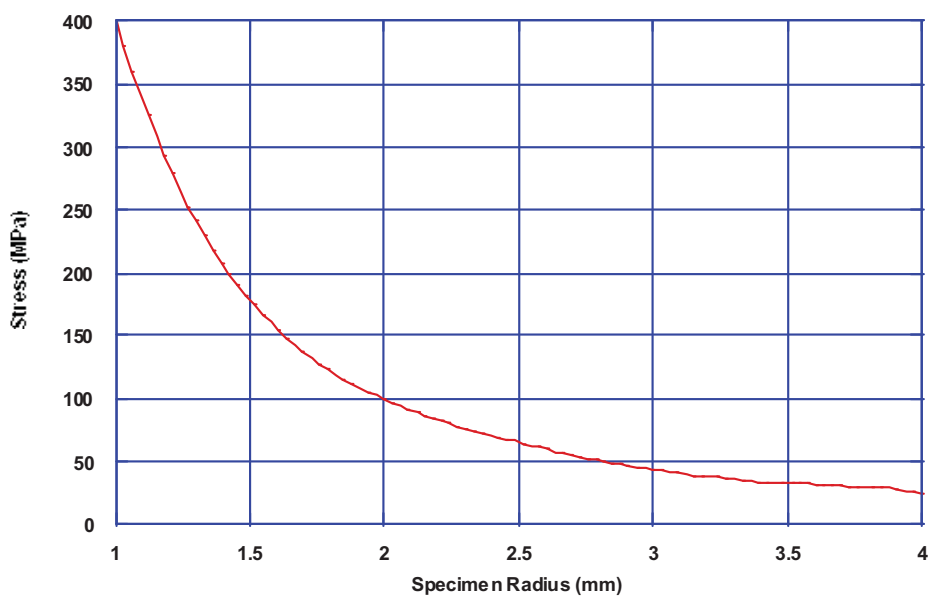

Figure 6-23. Estimated stress for candidate specimen sizes assuming 2250 psi test pressure. 
The LVDT will be provided by IFE-HRP. As discussed in Section 4, an LVDT consists of one primary coil and two secondary coils with a ferromagnetic core in the center of the coil system. The primary coil is activated by a $400 \mathrm{~Hz}$ constant current generator, and the position of the magnetically permeable core in relation to the secondary coils affects the balance of the voltage signal from the secondary coils. The position of the core can be measured with an accuracy of $\pm 1 \mu \mathrm{m}$. The IFE-HRP has installed more than 2200 LVDTs in different test rigs in the HBWR. A failure rate of less than $10 \%$ after 5 year of operation is expected for their LVDTs operating in BWR, PWR or CANDU conditions. Although IFE-HRP is not certified to the ISO 9001, they manufacture sensors following ISO 9001 requirements. Instrumentation provided by IFE HRP will be delivered with certificate of completion, assembly drawings, certificates of all materials used in the fixtures, welding qualifications, calibrations, documents, photos, etc. During FY10, INL will interact with Quality Assurance (QA) personnel to insure that the proposed fixture and sensors can be tested in the ATR NSUF PWR loop. Preliminary discussions with QA personnel indicate that the IFE-HRP sensors will meet ATR NSUF instrumentation checkout requirements. However, it is recognized that individual customers using such sensors may request more rigorous QA requirements.

As discussed in Section 6.2, calculations were completed to assess the impact on gamma heating on LVDT temperatures during irradiations at several irradiation locations in the ATR. Results indicate that peak LVDT temperatures may reach $400{ }^{\circ} \mathrm{C}$ if this sensor were placed at the peak flux location within the ATR core (e.g., at the center of the center flux trap at full power). As noted in Section 4, LVDTs have run for long durations in the HBWR at $350{ }^{\circ} \mathrm{C}$ without experiencing degradation. Therefore, temperatures of $400{ }^{\circ} \mathrm{C}$ may not be of concern. Furthermore, it is anticipated that the actual position of the LVDT (offset by $121 \mathrm{~mm}$ from the tensile specimen that is placed at a higher flux location) will lead to lower peak LVDT temperatures. Detailed calculations should be completed once the specific location of an irradiation in the ATR is determined. If peak temperatures are of concern, the LVDT vendor (IFEHRP) is in the process of altering LVDT fabrication processes such that these sensors can withstand higher temperatures.

Anticipated ATR PWR loop and PWR operating conditions will be simulated in a laboratory setting using an autoclave. Proposed coolant conditions for autoclave testing are listed in Table 6-5.

Table 6-5. Experimental parameters for autoclave coolant

\begin{tabular}{|c|c|}
\hline Coolant & Pressurized $\mathrm{H}_{2} \mathrm{O}$ \\
\hline Temperature $\left({ }^{\circ} \mathrm{C}\right)$ & $280-350$ \\
\hline System pressure $\mathrm{MPa}(\mathrm{psi})$ & $15.51-15.86(2250-2300)$ \\
\hline \multicolumn{2}{|l|}{ Coolant chemistry } \\
\hline Oxygen $\left(25^{\circ} \mathrm{C}\right), \mathrm{ppm}$ & $<0.005$ \\
\hline Hydrogen (D2), ppm & $2.2-4.4$ \\
\hline $\mathrm{pH}\left(\right.$ at $\left.25^{\circ} \mathrm{C}\right)$ & $4.2-10.5$ \\
\hline
\end{tabular}


Figure 6-24 shows the positioning of the test rig in an existing autoclave at the HTTL. Test startup will be initiated by completing the following steps:

- Place fixture in the autoclave

- Fill autoclave with cold water. Test water chemistry and adjust, as needed, to insure that the $\mathrm{pH}$ at pressure is within the values specified in Table 6-5

- Secure lid on autoclave and assemble tubing.

- Using the pump, pressurize the autoclave to the pressure level established by the back pressure regulator.

With the pump running the autoclave will be vented through the two vent valves until it is liquid solid. Heat up of the autoclave will then begin. The autoclave will be manually vented periodically during heat up to remove any air that may come out of solution. Several degrees of subcooling will be maintained in the autoclave. The pump will operate continuously throughout the test period to make up for any fluid loss. The back pressure regulator will maintain the pressure constant throughout the test period and can be used to adjust the system pressure if so desired.).

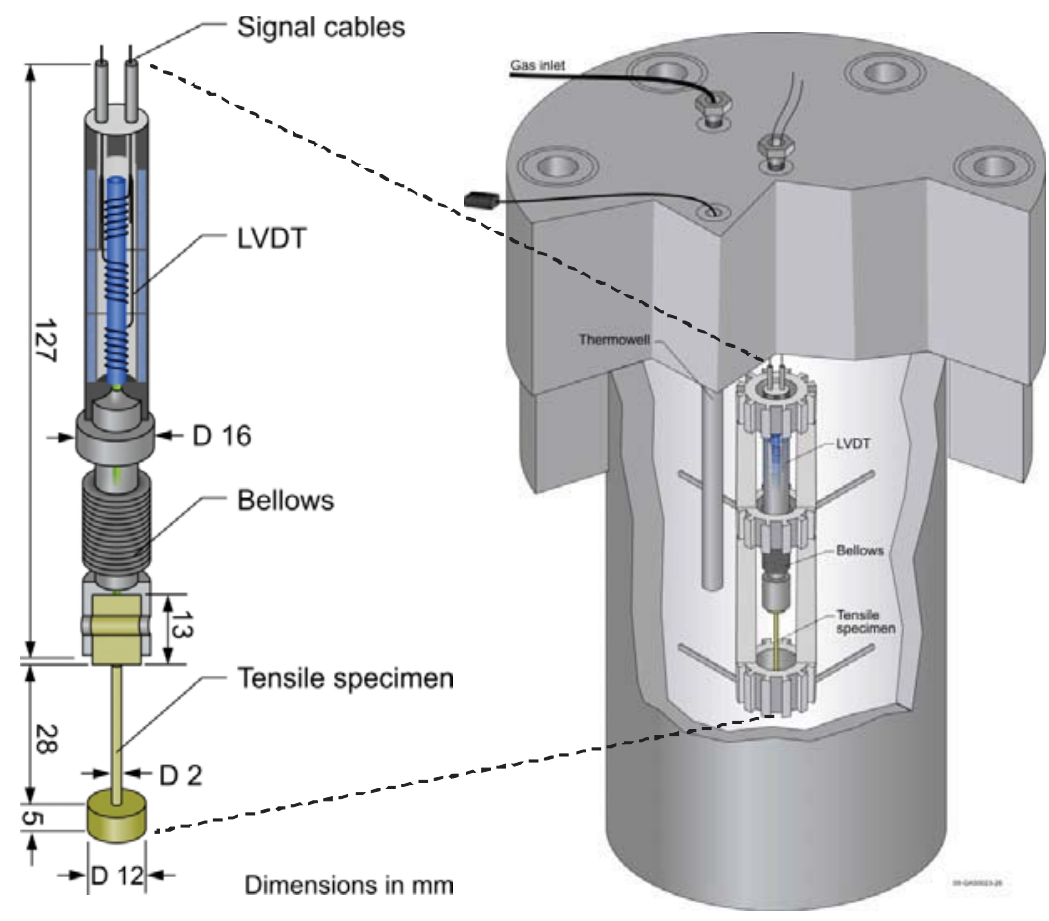

Figure 6-24. Schematic of test rig positioned in autoclave for testing.

Autoclave tests will be conducted at these conditions for $1000 \mathrm{hrs}$. During testing, coolant will be periodically sampled, and $\mathrm{pH}$ will be recorded. LVDT signals from an IFE-HRP signal processing unit and TC signals will be monitored using LabView based software on a PC.

The signal processing system available from IFE-HRP excites the primary coil with 400$1000 \mathrm{~Hz}, 20-50 \mathrm{~mA}$ constant current. With this constant current system, the input voltage to the 


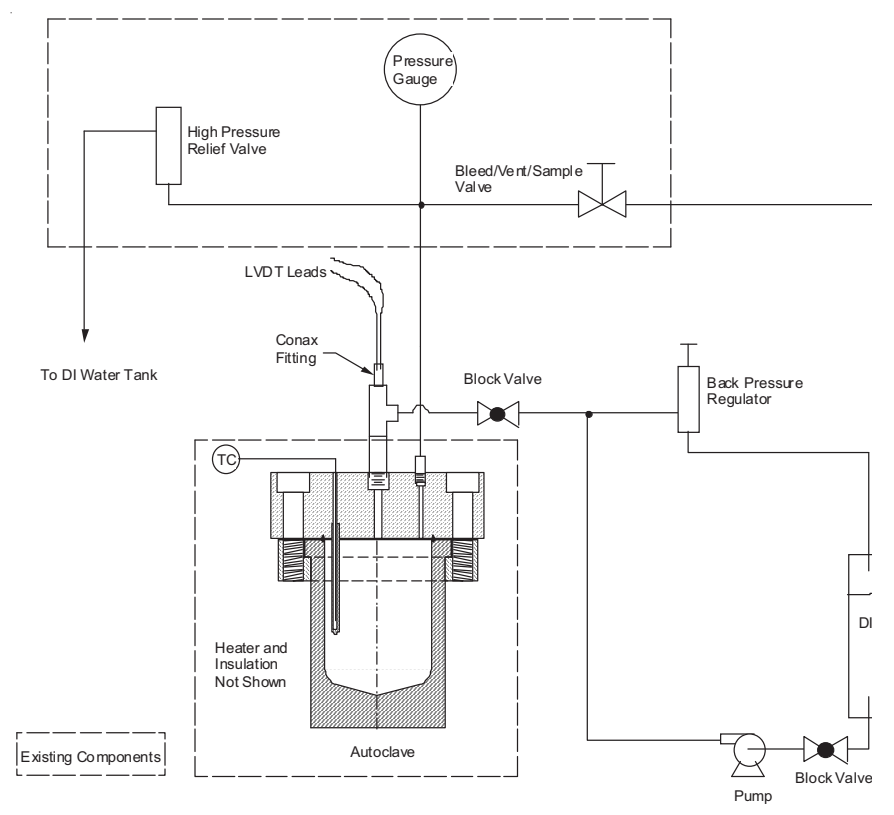

Figure 6-25. Pumping system to pressurize autoclave coolant.

LVDT is directly proportional to the wire/coil resistance of the LVDT. At room temperature, a typical resistance is $\sim 90 \mathrm{ohm}$ for the primary coil and 16 meter of cable. At temperature, typical values are $200 \mathrm{ohm}$ at $350{ }^{\circ} \mathrm{C} .200 \mathrm{ohms}$ at $50 \mathrm{~mA}$ equals to a voltage of 10VAC. The secondary voltages that are transmitted back to the data acquisition system are very low, typically less than 1 VAC (but the output from the electronics unit is higher due to the electronic gain in the unit). Note that the input and output signals from the LVDT are pure sinusoidal.

After testing, the autoclave will be disassembled and components visually inspected to assess what, if any, damage occurred during testing. Specimen elongation will be measured and compared with data obtained during testing.

\subsubsection{In-Pile Crack Growth Detection}

As discussed in Section 4.3.6, the Halden Boiling Water Reactor (HBWR) is capable of performing irradiations with on-line crack propagation monitoring. HBWR tests employ an inverse Direct Current Potential Drop (DCPD) method. The technique consists of introducing a precisely controlled current across the specimen and measuring the drop in voltage at different axial locations (which increases as crack length increases). In recent years, the HRP approach for in-core crack monitoring has been modified to also incorporate dynamic loading of the specimen during irradiation. HBWR testing has provided considerable in-pile data for BWR chemistry and irradiation conditions. Until recently, it was believed that the current database on environmentally assisted cracking (EAC), coupled with theoretical understanding and modeling, was sufficient to avoid additional expensive in-core crack growth experiments for BWR conditions. However, as new materials become of interest and as currently in service materials reach higher and higher 
fluences, this conclusion no longer holds. Furthermore, several important EAC problems in PWRs have been less extensively studied than their BWR counterparts; and there is considerable interest in obtaining crack growth data under conditions of simultaneous irradiation and mechanical stress. To facilitate such tests being performed at INL's Advanced Test Reactor (ATR), INL funded MIT to complete an initial effort to review the state of the art in-core crack growth measurement with the objective of recommending a conceptual design for implementation in the ATR.

As discussed in Reference 96, the two major classes of in-pile crack growth experiments can be grouped by the type of specimen employed: smooth bars or well-defined pre-cracked specimens. Smooth bar tests are generally operated at quite high loads and strain rates and are generally driven to failure. Examples include slow strain rate tests (which are rarely carried out in-core) and constant load tests. Constant load tests are "integrated time-to-failure" studies that are usually dominated by crack initiation time and do not give significant information on crack growth rates. Pre-cracked specimen tests, in contrast, are designed to only give information about crack growth rates. A sharp crack is introduced in the specimen before installation in the reactor, and the crack growth rate is determined as a function of parameters such as stress intensity factor and water chemistry. For ATR applications, it has been decided to pursue crack growth experiments. Such experiments are significantly more complex in terms of specimen preparation, in-core instrumentation requirements, and in-core experiment conduct. Hence, it is believed that once a crack growth testing methodology is established, one could rapidly deploy a smooth-bar, constant load test capability, if it were desired.

The major aspects of choosing a crack growth measurement technique are: specimen geometry, loading mode (active or passive) and crack length measurement technique. Crack length measurement by the switched DC potential drop (DCPD) technique is very well established and has become a de facto standard for in-core measurements. It is applicable to most specimen geometries, although specimen extensions are often used to provide adequate space to connect current leads and voltage probes. As discussed in Reference 96, this method has been applied in several research and test reactors. In addition, this technique has been applied in-core and in recirculation piping autoclaves of commercial BWRs. Some out-of-core measurements have used AC potential drop, but there do not appear to be significant advantages for this technique. Another method frequently applied in out-of-core tests is to measure "crack tip opening displacement" (COD) using a strain gauge. This is a very delicate procedure requiring elements that are not readily adaptable to in-core environments. Thus, DCPD is proposed as the reference method for evaluation because of its prior in-core experience and its robust and reliable performance in appropriately designed and constructed systems.

Choices for specimen geometry and loading mode are inter-related and are much less straightforward than the choice of crack length measurement method. Several types of passively loaded specimens have been used for in-core and out-of-core crack growth studies. A typical double cantilever beam (DCB) crack growth specimen is shown in Figure 6-26. The tapered shape of the specimen provides for relatively constant stress intensity factor as the crack grows. Note 
that in this specimen, the current and potential drop probes are routed through mineral insulated (MI) cables that are welded to the integral specimen connection box. After the probes are welded to the specimen arms, the slots are sealed with a welded cover.

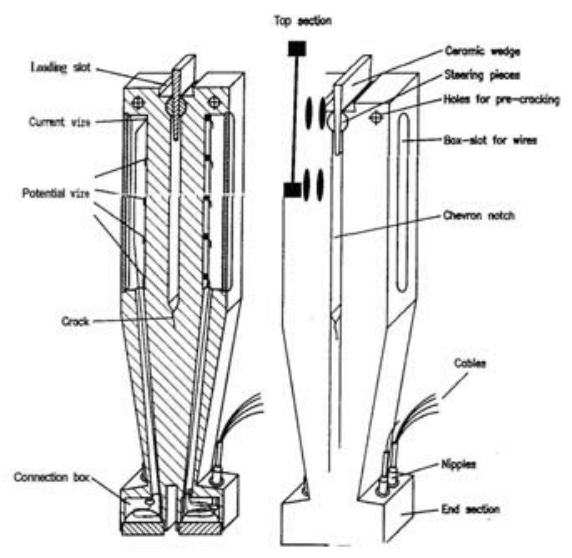

Figure 6-26. Section and exterior views of a passively loaded, double cantilever beam crack growth specimen used for in-core EAC experiments

Passively loaded specimens are easier to use for in-core crack growth measurement applications. The load is independent of system pressure; there is no active loading mechanism to maintain and control; and the DCPD crack length measurement can be readily set up for computerized control and data acquisition with little experimenter intervention. However, this ease of use is obtained at the cost of the ability to control the stress intensity at the crack tip. In practice, this can lead to a variety of problems. The wedge loading mechanism is susceptible to slippage, resulting in accidental reduction of the stress intensity. Even if the design loading and stress intensity are maintained, they may not be sufficient to cause cracking under the experimental conditions. In either case, specimens may show no, low, or erratic crack growth, making it difficult to achieve the objectives of experiments designed to investigate the effect of various parameters on crack growth rate. Passive loading also precludes the use of experimental protocols that initiate crack growth only under the desired set of prototypical conditions (full temperature and reactor power and appropriate coolant chemistry, for example.) This can reduce the useful of life of the specimens and make post-irradiation evaluation of crack growth mechanisms more difficult. Passive loading may allow for more specimens in a given facility depending on the space requirements for the loading mechanism, although even passively loaded specimens tend to be quite large and require numerous instrumentation feed-throughs.

These considerations led to the conclusion that actively loaded specimens for in-core crack growth measurements should be pursued, despite their added complexity. There is, of course, a great deal of overlap in the techniques and capabilities required to perform either actively or passively loaded crack growth measurements. In either case, a complicated specimen must be machined from appropriate materials (ultimately, pre-irradiated materials may be used for ATR irradiations), a fatigue pre-crack must be initiated, instrumentation cables must be attached, and the specimen must be fixtured for exposure in an in-core loop. 
The use of active loading simplifies the specimen design because it is not necessary to use a geometry that attempts to compensate for changes in crack tip stress intensity as the crack grows. Rather, stress intensity can be controlled by changes in applied load. Adaptations of the compact tension specimen geometry developed and specified for fracture toughness testing are commonly used for EAC growth rate studies. Other types of specimens are used for crack initiation studies, where simpler tests with larger numbers of specimens are required. In order to make use of the existing data base of crack growth data for Compact Tension (CT) type specimens (and in line with the practice used at other facilities for doing in-core crack growth measurements), we propose using CT-type geometry. Note that the geometric constraints for EAC testing are less stringent than those for fracture toughness testing, and this allows for greater flexibility in specimen design to meet space constraints. In particular, specimen thickness for crack growth specimens is often less than that required for valid fracture toughness testing.

Active in-core loading of specimens can be achieved in a variety of ways. Out-of-core autoclave testing of this type most commonly uses a standard mechanical testing machine with the pull-rod fed through a seal into the autoclave volume. This method has been applied in-core at the MITR, but it is probably not appropriate for long-term testing such as that generally required for crack growth measurements because of limitations on independent loading of more than one specimen. While a number of specimens can be loaded in series, and provisions can be made to continue loading other specimens after one or more have failed, all the specimens must be subjected to the same load. This generally applies to any method that requires transmission of a load from outside the core region into the in-core space, given that in-core testing locations are inevitably long and narrow and must accommodate crack-growth-sized specimens in an axial train. Note that the ability to independently control the load on a number of specimens helps insure that appropriate crack growth rates can be established in all specimens.

The de facto standard solution to this problem is to use a loading system based on high pressure miniature bellows with internal gas pressurization to apply controlled loads in core. Small diameter gas lines can readily be fed into in-core spaces and relatively large loads can be generated. The Halden approach uses a bellows in conjunction with a leveraged loading unit to provide a mechanical advantage of about 2.5 times between the bellows load and the load applied to the crack growth specimen. In this approach, the internal bellows pressure is raised above the system pressure in order to apply a tensile load and a mechanical stop is used to prevent compressive loading if bellows pressure is lost.

A conceptual layout for a crack growth test rig containing two crack growth specimens and associated ECP electrodes is shown in Figure 6-27. This unit would be installed in an in-core PWR loops. Cables and thermocouples are not shown for clarity, but the design will allow passage of the six instrumentation cables (e.g., the gas line for the lower specimen, the two ECP cables, and two thermocouples) past the upper specimen and ultimately, out of the test reactor.

For initial autoclave testing, only one crack growth specimen and associated auxiliary systems would be tested. An isometric drawing of the crack growth specimen is shown in Figure 6-27 with preliminary values for dimensions. The design of the specimen follows the 


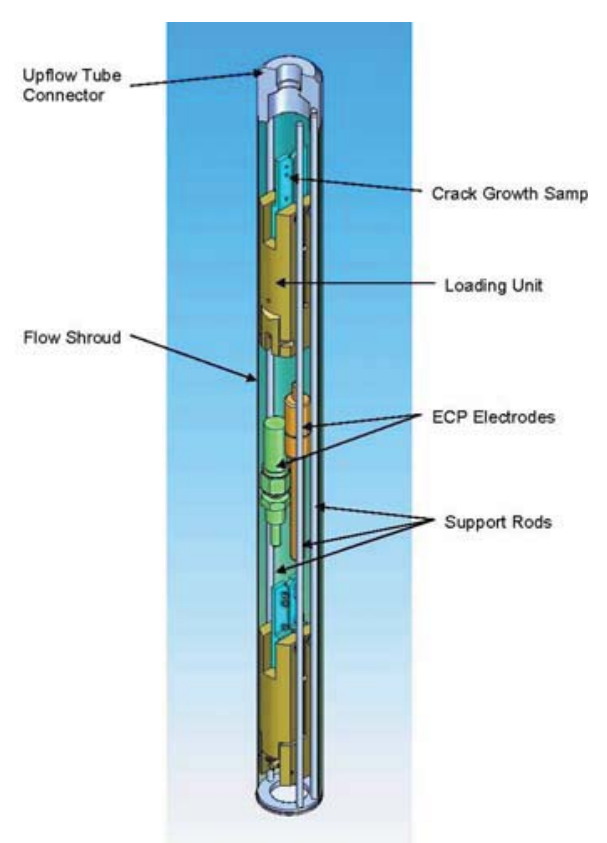

Figure 6-27. Cutaway 3-D rendering of an in-core crack growth measurement test rig incorporating two crack growth specimens with two ECP electrodes. Note that this design is for the MITR, but it is anticipated that a similar concept would easily fit within an ATR PWR loop.

requirements of ASTM E399-086 with the exception of the specimen thickness as discussed above. The posts shown are to facilitate connection of the mineral-insulated cable DCPD leads. Knife edges are provided to measure crack tip opening displacement during loading tests and fatigue pre-cracking (out of core).
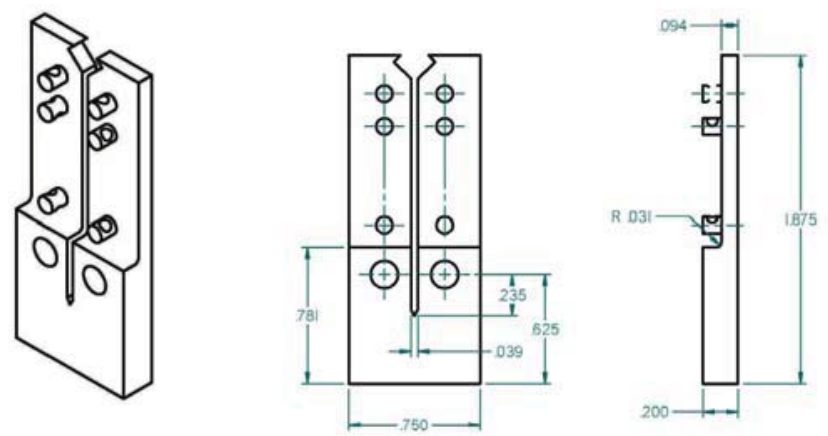

Figure 6-28. Isometric and dimensioned drawing of proposed crack growth specimen.

Figure 6-29 shows an isometric view of the proposed loading system with a specimen installed. Proposed dimensions for this system are also shown. The loading system incorporates a 
customized miniature bellows assembly manufactured by Mini-flex Corporation. Specifications for the bellows are given in Table 6-6.

Table 6-6. Bellow Specification for Use in In-Pile Crack Growth Test Rig

\begin{tabular}{|c|c|}
\hline Material & Inconel 718 \\
\hline Bellows length & $0.84 \mathrm{~cm}(0.33 \mathrm{in})$ \\
\hline Overall length & $1.55 \mathrm{~cm}(0.61 \mathrm{in})$ \\
\hline OD /ID & $(0.493 \mathrm{in} / 0.298 \mathrm{in})$ \\
\hline Effective area & $0.794 \mathrm{~cm}^{2}\left(0.123 \mathrm{in}^{2}\right)$ \\
\hline Stroke & $0.19 \mathrm{~cm}(0.075 \mathrm{in})$ \\
\hline Spring rate & $116.1 \mathrm{~kg} / \mathrm{cm}(650 \mathrm{lb} / \mathrm{in})$ \\
\hline P-max & $20.7 \mathrm{MPa}(3,000 \mathrm{psi})$ \\
\hline
\end{tabular}
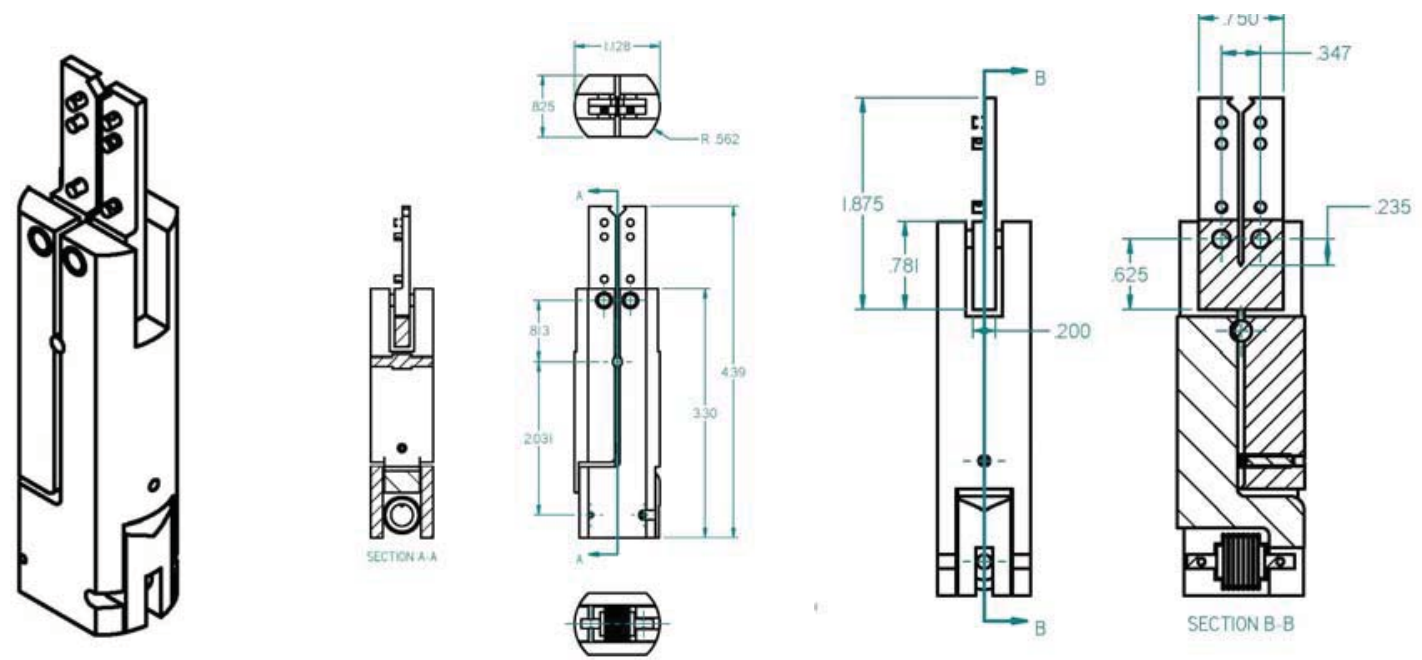

Figure 6-29. Isometric and dimensioned drawing of proposed crack growth specimen.

Several systems will be required to operate and monitor crack growth measurement samples. Descriptions with preliminary specifications for their performance are provided below.

- Bellows pressurization system

The difference between the pressure in the bellows and the loop system pressure will set the load applied to the crack growth specimen. Note that at this time, because of concerns about potential voiding in a PWR loop, the pressurizing medium and system design have not yet been finalized. However, for a crack tip stress intensity of $30 \mathrm{MPa} / \mathrm{m}$ (a typical value for crack growth testing in sensitized stainless steels), a bellows internal pressure of $15.5 \mathrm{MPa}$ (2240 psi) will be required. If the system pressure is $11.0 \mathrm{MPa}(1600 \mathrm{psi})$, this corresponds to a total bellows internal pressure of $26.5 \mathrm{MPa}$ (3840 psi). Thus, a pressurization system capable of controlling pressures in the range of 27.6-34,5 (4,000 - 5,000 psi) will be required. The system should accept a system pressure signal and provide feedback control of the bellows-system pressure differential at a determined set point. Flow limitation, leak detection, and high and low pressure alarms will also be required. 
- DCPD crack length and ECP measurement system

This system consists of a 1 amp power supply with relays for reversing potential applied to the sample, together with a high impedance voltmeter interfaced to a computer data acquisition system. The data acquisition system must be programmable to perform periodic DCPD measurements, applying an appropriate algorithm to calculate the crack length from the measured potentials and to measure and record ECP during intervals where DCPD current is not applied to the samples.

- Mechanical Loading System

An appropriate mechanical testing system will be required to produce a fatigue pre-crack in the crack growth measurement sample. For eventual application to pre-irradiated materials this system will need to be installed in a hot cell. A system capable of applying loads of up to approximately $1500 \mathrm{lbf}$ will be adequate for most specimens. Apparatus for measuring crack tip opening displacement may also be required.

If funding is allocated, a multi-year development program has proposed to finalize the design described in this section, complete laboratory tests in an autoclave, and demonstrate in-pile capabilities by completing irradiation testing at the MITR. Results from this three year effort will then be used to finalize a design for ATR testing.

\subsection{Summary}

As indicated in this section, INL has initiated efforts to obtain new sensors for detecting key parameters (e.g., temperature, length, diameter, etc.). As discussed in Section 5, initial efforts are focussing on sensors that can provide data needed for ATR NSUF users and on "lower risk" technologies that are already deployed at other MTRs. These initial efforts have led to two new sensors becoming available to ATR users: the doped Mo/Nb HTIR-TCs (Section 6.1.1) and silicon carbide temperature monitors (Section 6.1.2). During FY10, it is anticipated that ongoing efforts to evaluate a creep test rig in an autoclave at the HTTL will yield a fixture ready for deployment in an ATR PWR loop. In addition, ongoing efforts for developing an inpile technique for detecting changes in average thermal conductivity are anticipated to become closer for inpile evaluation. During FY10, efforts will also be initiated to evaluate the viability of using miniature fission chambers developed by CEA and other flux detection systems (e.g., SPNDs) at the ATR-C. In addition, efforts to explore the use of ultrasonic transducers for in-pile detection of elongation and crack growth will be initiated. Based on funding availability, efforts may also be initiated to further develop the crack growth conceptual design described in Section 6.4. 


\section{REFERENCES}

1. "FY2009 Advanced Test Reactor National Scientific User Facility User's Guide," INL/EXT-0713577, Idaho National Laboratory, 2008.

2. S. B. Grover, "Irradiation Facilities at the Advanced Test Reactor," Transactions of the 11th International Topical meeting on Research Reactor Fuel Management and Meeting of the International Group on Reactor Research, March 2007, Lyon, France.

3. R. V. Furstenau and S. Blaine Grover, "The Advanced Test Reactor Irradiation Facilities and Capabilities," Proceedings of the Americas Nuclear Energy Symposium 2002 (ANES 2002), October 2002.

4. F. M. Marshall, "Advanced Test Reactor Capabilities and Future Operating Plans," presented at Test Research and training Reactors (TRTR) Annual Meeting, September 2005, Gaithersburg, MD.

5. C. J. Stanley and F. M. Marshall, "Advanced Test Reactor - A National Scientific User Facility," proceedings ICONE2008-48426, May 11-15, 2008, Orlando, Florida, USA.

6. International Atomic Energy Agency, "Nuclear Research Reactors in the World," www.iaea.or.at/worldatom/rrdb/, accessed January 10, 2008.

7. H. Böck and M. Villa, "Survey of Research Reactors," prepared for the IAEA Course on Safety, Management, and Utilization of Research Reactors, Bratislava-Vienna, March 2001.

8. G. Bignan and J-P Chauvin, "JHR Project - A New High Performance Test Reactor in Europe Status June 2008," presentation at the Idaho National Laboratory, Idaho Falls, ID, June 2008.

9. H. Thoresen and S. Solstad, An overview of nuclear fuels and materials research at the OECD Halden Reactor Project, seminar presented at the Idaho National Laboratory, Idaho Falls, ID, July $15,2008$.

10. J. Guidez, D. Iracane, and P. Ledermann, "Research Reactor Needs, Nuclear Engineering International, December 2007, p. 12.

11. J. Ahlf, "The High Flux Reactor Petten - Present Status and Prospects," Conf. 9002100, p 43.

12. J.F. Villard, "Innovative in-pile instrumentation developments for irradiation experiments in MTRs," IGORR 10, Gaithersburg, Sept. 2005.

13. J. F. Villard, "INSNU Project - Instrumentation for Irradiation Experiments in Research Reactors," presentation at the Idaho National Laboratory, Idaho Falls, ID, June 2008.

14. J. F. Villard, "INSNU Project - Instrumentation for Irradiation Experiments in Research Reactors," presentation at CEA-Cadarache, Cadarche, France, October 2008.

15. J-F Villard and M. Schyns, "Advanced In-Pile Measurements of Fast Flux, Dimensions, and Fission Gas Release," Proceedings of the ANS NPIC HMIT 2009 Topical Meeting on Nuclear Plant Instrumentation, Controls, and Human Machine Interface Technology, Knoxville, TN, April 2009. 
16. D. Iracane, G. Bignan, Ph. Guimbal, and J-F. Villard, "Advanced Instrumentation for Irradiation Experiments in Material Testing Reactors (MTRs)," Proceedings of the First International Conference on Advancements in Nuclear Instrumentation, Measurement Methods and their Applications (ANIMMA), Marseille, France, June 2009.

17. C. Blandin, S. Breaud, JM. Laurens, L. Oriol, L. Vermeeren, M. Weber "In-pile CFUZ53 sub-miniature fission chambers qualification in BR2 under PWR conditions - 10 th International Group on Research Reactors (IGORR) meeting, Gaithersburg (USA), September 2005.

18. S. Fourrez, G. Bailleul, M. Kollen, JF. Villard, "Characterisation of a thermocouple for high temperature measurement under irradiation - Definition and properties of the Molybdenum Niobium thermocouple, 12 th International Metrology Congress, Lyon (France), June 2005.

19. J. F. Villard, S. Fourrez, "High temperature measurement needs for irradiation experiments in Material Testing Reactors - Development of a new type of thermocouple and interest of high temperature fixed points for its characterisation and in-pile qualification," Physikalisch-Technische Bundesanstalt Seminar on High-temperature fixed-points for industrial and scientific applications, Berlin (Germany), April 2005.

20. G. Cheymol, H. Long, J-F. Villard, and B. Brichard, "High Level Gamma and Neutron Irradiation of Silica Optical Fibers in CEA OSIRIS Nuclear Reactor," IEEE Transactions on Nuclear Science, Vol. 55, No. 4, August 2008, pp 2252-2258.

21. M. F. Narbey, D. Baron, G Despaux, JM Saurel, "Determination of the composition of a gas mixture in a nuclear fuel rod by an acoustic method," Journal of the British Institute of Non-Destructive Testing (INSIGHT), 42, 603-605 (2000).

22. J.Y. Ferrandis, G. Leveque, F. Augereau, E. Rosenkrantz, D. Baron, J-F. Villard, "An ultrasonic sensor for pressure and fission-gas release measurements in fuel rods for pressurised water reactors, 9th International conference on CANDU fuel, Belleville (Canada), September 2005.

23. F. Augereau, J.-Y. Ferrandis, J.-F. Villard, D. Fourmentel, M. Dierckx, and J. Wagemans, "Effect of intense neutron dose irradiation on piezoceramics," Transactions from Acoustics '08, June 29July 4, 2008, Paris, France.

24. F. Algaber, JY. Ferrandis, F. Augereau, J-F. Villard, "PZT Materials under Gamma irradiation," 4thEuropean Workshop on Piezoelectric Materials, Montpellier (France), July 2004.

25. Studiecentrum voor Kernenergie - Centre d'Étude de l'énergie Nucléaire (SCK·CEN) website (www.sckcen.be), last visited January 31, 2007.

26. Moilanen, P., Tahtinen, S., Singh, B.N.; and Jacquet, P., "In-Situ Investigation of the Mechanical Performance and Life Time of Copper - Final report on design, construction, and calibration of test module for in-reactor tensile tests in BR-2 reactor," VTT Report BTUO 76-031127, October 27, 2004.

27. B. Aarset, "In-reactor Instrumentation for Fuel Behavior Studies at the OECD Halden Reactor Project," Proceedings from the Conference on Fast, Thermal, and Fusion Reactor Experiments, $\mathrm{p}$ 1-85 through 1-96, April 12-15, 1982, Salt Lake City, Utah. 
28. O. Aarrestad and H. Thoresen, "Fuel Rod Performance Measurements and Re-Instrumentation Capabilities at the Halden Project," In-core instrumentation and core assessment: proceedings of a Specialists' Meeting, Mito-shi, Japan, 14-17 October, 1996.

29. C. Vitanza, "On-line fuel rod performance measurements and fuel inspection applications," Kerntechnik, 56, 1991, pp 124-130.

30. S. Solstad, HRP, email to J. Rempe, INL, February 6, 2008.

31. W. Wiesenack, "Experimental Techniques and Results Related to High Burn-up Investigations at the OECD Halden Reactor Project, Proceedings of a Technical Committee Meeting held in Pembroke, Ontario, Canada, April 28 - May 1, 1992, IAEA-TECDOC-697, p. 118.

32. P. Bennett, "In-core Measurements of Fuel-Clad Interactions at the Halden Reactor," IAEA Technical Meeting on Fuel Rod Instrumentation and In-Pile Measurement Techniques, Halden, Norway, 3-5 September 2007.

33. P. Bennett and T. Karlsen, "In-core Corrosion Monitoring in the Halden Test Reactor," Energy Materials: Materials Science and Engineering for Energy Systems, 3, 2, June 2008, pp. 81-90.

34. S. Solstad and R. Van Nieuwenhove, "Instrument Capabilities and Developments at the Halden Reactor Project," Proceedings of the ANS NPIC HMIT 2009 Topical Meeting on Nuclear Plant Instrumentation, Controls, and Human Machine Interface Technology, Knoxville, TN, April 2009.

35. K. Tsuchiya, "Irradiation Technology Development in JMTR" and "New JMTR," presentation and handouts provided to J. Rempe at JAEA meeting, September 29, 2009, Oarai, Japan.

36. M. Narui, T. Shikama, M. Yamasaki, and H. Matsui, "Development of High-Temperature Irradiation Techniques Utilizing the Japan Materials Testing Reactor," Basic Studies in the Field of High Temperature Engineering, Second Information Exchange Meeting, Paris, France, 10-12 October, 2001, pp. 145-152.

37. T. Shibata, T. Kikuchi, S. Miyamoto, K. Ogura, and Y. Ishigaki, "Development of the I-I TYpe Irradiation Equipment for the HTTR," Basic Studies in the Field of High Temperature Engineering, Second Information Exchange Meeting, Paris, France, 10-12 October, 2001, pp. 191-199.

38. T. Shikama, M. Narui, T. Kakuta, M. Ishitsuka, K. Hayashi, T. Sagawa, and T. Hoshiya, "Application of Optical Diagnostics in High-Temperature Gas-Cooled Systems," Basic Studies in the Field of High Temperature Engineering, Second Information Exchange Meeting, Paris, France, 10-12 October, 2001, pp. 153-160.

39. C. Mori, A. Uritanit, T. Kakuta, M. Katagiri, T. Shikama, M. Naikazawa, T. Iguchi, J. Kawarabayashi, I. Kimura, H. Kobayashi, and S. Hayashi, "Measurement Method of In-core Neutron and Gamma-Ray Distributions with Scintillator Optical Fibre Detector and Self -Powered Detector," Basic Studies in the Field of High Temperature Engineering, Second Information Exchange Meeting, Paris, France, 10-12 October, 2001, pp. 161-196. 
40. J. Markgraf, D. Perry, and J. Oudaert, "LWR Fuel Rod Testing Facilities in High Flux Reactor (HFR) Petten for Investigation of Power Cycling and Ramping Behavior," Res Mechanica, 13, $1985,187-210$.

41. Email from K. Bakker, NRG, to J. Rempe, INL, dated December 11, 2007.

42. K. Bakker, NRG, discussions with J. Rempe, INL, at Petten, Netherlands, October 2008.

43. P. Blanchard, P. May, and H. Scheurer, "A Machine for the Fatigue Testing of CT type samples in the HFR," Fusion Technology 1982, Proceedings of the 12th Symposium, 2, pp 749-752, 1983.

44. M. A. Fütterer, et al., "Next generation fuel irradiation capability in the High Flux Reactor Petten," Journal of Nuclear Materials," 392, 2009, pp 184-191.

45. B. G. Kim, et al., "Status and Perspective of Material Irradiation Tests in the HANARO, paper and presentation from the 1st International Symposium on Materials Testing Reactors, JAEA-Oarai, Japan, July 2008.

46. B. G. Kim, K-N Choo, J. M. Sohn, S. J. Park, K.Kim and Y. J. Kim, "Instrumentations for Materials Irradiation Tests in HANARO," Proceedings of the ANS NPIC HMIT 2009 Topical Meeting on Nuclear Plant Instrumentation, Controls, and Human Machine Interface Technology, Knoxville, TN, April 2009.

47. W. Strydom, NESCA, "In-Pile Instrumentation," personal communication to J. Rempe, INL, email, dated February 5, 2008.

48. G. Proctor, "In-Reactor Pressure Vessel Measurements for the PBMR DPP," 3rd International Topical Meeting on High Temperature Reactor Technology (HTR2006), Johannesburg, South Africa, October 1-4, 2006.

49. N. F. Pravdyuk, V. A. Nikolaenko, V. I. Kapuchin, V.N. Kusnetsov, in: Ed. D. J. Littler, Proceedings of the Properties of Reactor Materials and the Effects of Radiation Damage, Butterworths, 1962, p. 57.

50. L L. Snead, A. M. Williams, and A. L. Qualls, "Revisiting the use of SiC as a Post Irradiation Temperature Monitor," Effects of Radiation on Materials, ASTM STP 1447, M L. Grossbeck, Ed, ASTM International, West Conshohocken, PA, 2003.

51. L. Snead, ORNL, email to J. Rempe, INL, dated July 31, 2008.

52. L. Snead, ORNL, email to J. Rempe, INL, dated October 15, 2009.

53. J. Rempe, D. Knudson, K. Condie, J. Daw, H. Ban, B. Fox, G. E. Kohse, S. C. Wilkins, "New Sensors for In-Pile Testing at the ATR NSUF," Proceedings of the First International Conference on Advancements in Nuclear Instrumentation, Measurement Methods and their Applications (ANIMMA), Marseille, France, June 2009.

54. J. Rempe and M. Meyer, "ATR NSUF Instrumentation Enhancement Efforts," Proceedings of the ANS NPIC HMIT 2009 Topical Meeting on Nuclear Plant Instrumentation, Controls, and Human Machine Interface Technology, Knoxville, TN, April 2009. 
55. J. L. Rempe, D. L. Knudson, K. G. Condie, and S. C. Wilkins, "Thermocouples for High-Temperature In-Pile Testing," Nuclear Technology, 156, No. 3, December 2006, pp 320-331.

56. J. L. Rempe, D. L. Knudson, K. G. Condie, and S. C. Wilkins, "High Temperature Thermocouple Design and Fabrication" US patent filed by Battelle Energy Alliance on behalf of DOE (Serial Number3.

57. J. L. Rempe, D. L. Knudson, K. G. Condie, S. C. Wilkins, J. C. Crepeau, and J. E. Daw, "Options Extending the Applicability of High Temperature Irradiation Resistant Thermocouples," invited paper for NURETH12 Special Edition, Nuclear Technology, 167, July 2009, pp 169-177.

58. J. L. Rempe, D. L. Knudson, K. G. Condie, and S. C. Wilkins, "Long Duration Performance of High Temperature Irradiation Resistant Thermocouples," Proceedings of the 2007 International Congress on Advances in Nuclear Power Plants (ICAPP'07), Nice, France, May 13-18, 2007.

59. D. L. Knudson, J. L. Rempe, K. G. Condie, S. C. Wilkins, J. E. Daw, and J. C. Crepeau, "High Temperature Irradiation Resistant Thermocouples - A Low Cost Sensor for In-Pile Testing at High Temperatures," Paper 8222, Proceeding of the 2008 International Congress on Advances in Nuclear Power Plants (ICAPP '08), Anaheim, CA, June 8-12, 2008.

60. J. E. Daw, J. L. Rempe, D. L. Knudson, S. C. Wilkins, and J. C. Crepeau, "High Temperature Irradiation-Resistant Thermocouple Performance Improvements," ANS NPIC HMIT 2009 Topical Meeting on Nuclear Plant Instrumentation, Controls, and Human Machine Interface Technology, Knoxville, TN, April 2009.

61. J. E. Daw, J. L. Rempe, D. L. Knudson, S. C. Wilkins, Alternate HTIR-TC Configuration Long Term Evaluation at $1500{ }^{\circ} \mathrm{C}$, INL/LTD-09-16476, July 2009.

62. J. Rempe, D. Knudson, K. Condie, J. Daw, and S. C. Wilkins, "New Sensors for In-Pile Temperature Detection at the ATR NSUF," Proceedings of the 13th International Topical Meeting on Nuclear Reactor Thermal-Hydraulics (NURETH13), Kanazawa, Japan, October 2009.

63. A. N. Paolantonio, "Fiber Optic Half-Life," Electro-Optical Systems Design, August 1982, pp. 3341 (1982).

64. A. I. Gusarov, F. Berghmans, O. Deparis, A. F. Fernandez, Y. Defosse, P. Megret, M. Decreton and M. Blondel, "High Total Dose Radiation Effects on Temperature Sensing Fiber Bragg Gratings," Phot. Technol. Lett., 11, 9, pp. 1159-1161 (1999).

65. H. Liu, D. W. Miller and J. W. Talnagi, "Gamma Radiation Resistant Fabry-Perot Fiber Optic Sensors," Rev. of Sci. Instrum., 73, 8, pp. 3112-3118 (2002).

66. H. Liu, D. W. Miller and J. W. Talnagi, "Neutron Radiation Effects on Fabry-Perot Fiber Optic Sensors," Nuclear Instrum. and Meth. in Phys. Res. A, 507, pp. 691-702 (2003).

67. Bob Fielder, Luna Innovations, Director Optical Systems Group, Development of High-Temperature, Radiation Resistant Fiber Optic Sensors, presentation at Idaho National Laboratory, Idaho Falls, ID, July 25, 2008. 
68. Bryan D. Dickerson, Matthew A. Davis, Matthew E. Palmer, and Robert S. Fielder, "Temperature Compensated Fiber Optic Pressure Sensor under Combined High Temperature and High Fluence," ANS NPIC HMIT 2009 Topical Meeting on Nuclear Plant Instrumentation, Controls, and Human Machine Interface Technology, Knoxville, TN, April 2009.

69. M. Palmer, Assistant Director, Optical Systems Group, Luna Innovations, email to J. Rempe, INL, May 12, 2008.

70. Idaho National Laboratory, Proposal to LUNA Innovations for Irradiation of Optical Fibers, February 2009.

71. M. Laurie and M. Fütterer, EU JRC, email discussions with J. Rempe, INL, July through August 2009.

72. B. Fox, H. Ban, J. Daw, K. Condie, D.Knudson, and J. Rempe, Evaluation of Candidate In-Pile Thermal Conductivity Techniques, INL/EXT-09-16039, May 2009.

73. B. Fox, H. Ban, J. Rempe, J. Daw, K. Condie, and D. Knudson, "In-Pile Thermal Conductivity Measurement Method for Nuclear Fuels," 30th International Thermal Conductivity Conference and 18th International Thermal Expansion Symposium, Pittsburgh, PA, August 29-September 2, 2009.

74. B. Fox, H. Ban, J. Rempe, D. Knudson, and J. Daw, "Development of an In-pile Technique for Fuel Thermal Conductivity Measurement," Proceedings of the ANS NPIC HMIT 2009 Topical Meeting on Nuclear Plant Instrumentation, Controls, and Human Machine Interface Technology, Knoxville, TN, April 2009.

75. I. Cohen, B. Lustman, and J. D. Eichenberg, "Measurement of the Thermal Conductivity of MetalClad URanium Oxide Rods during Irradiation,” Journal of Nuclear Materials, 3, No 3 (1961), pp 331-353.

76. W.N. Beck and R. J. Fousek, "Fission Gas Release and Thermal Conductivity Measurements on U-5 wt\% F Irradiated in CP-5," Trans. American Nuclear Society, 30, 528, 1978.

77. P. R. Betten, "In-Core Measurements of Uranium-5 wt\% Fissium Alloy Thermal Conductivity," Transactions of the American Nuclear Society, 50, pp. 239-240, November 1985.

78. A. L. E. F. Schleirmacher, Vher die Warmeleitungder gase, Weidemann Ann. Phys. 34, p. 625, 1988.

79. M. S. Baghe-Khandan, Y. Choi, and M. R. Okos, "Improved Line Heat Source Thermal Conductivity Probe," Journal of Food Science, 45, p 1430-1432, 1981.

80. J.J. Healy, J. J. de Groot, and J. Kestin, “The Theory of the Transient Hot-Wire Method for Measuring Thermal Conductivity," Physica, 82C, pp 392-408, 1976.

81. X-G Liang, "The Boundary Induced Error on the Measurement of Thermal Conductivity by Transient Hot Wire Method,” Measurement Science Technology, 6, pp 467-471, 1995. 
82. P. Prelovsek and B. Uran, "Generalized Hot Wire Method for Thermal Conductivity Measurements,” J. Phs. E: Sci. Instrum., 17, 1984.

83. K. Manohar, D. W. Yarbrough, and J. R. Booth, "Measurement of Apparent Thermal Conductivity by the Thermal Probe Method," Journal of Testing and Evaluation, September 2000.

84. Anter Corporation, see www.anter.com

85. D. L. Knudson and J. L. Rempe, "LVDT Evaluations for ATR Irradiations," Proceedings of the ANS NPIC HMIT 2009 Topical Meeting on Nuclear Plant Instrumentation, Controls, and Human Machine Interface Technology, Knoxville, TN, April 2009.

86. D. Knudson report summarizing LVDT tests.

87. to://www.americanpiezo.com/

88. Toacsan, M. I., Ioachim, A., Nedelcu, L. and Alexandru, H. V., "Accelerated ageing of PZT-type ceramics," Progress in Solid State Chemistry 35, 531-537 (2007).

89. Broomfield, G. H., "The effect of low-fluence neutron irradiation on sliver-electroded lead-zirconate-titanante piezoelectric ceramics," J of Nuclear Materials 91, 23-34 (1980).

90. Guers, M. J. and Tittmann, B. R., "Finite element analysis of ultrasonic methods for in-situ monitoring of an ASTM creep specimen" Review of Progress in Quantitative Nondestructive Evaluation, 28, 1394-1401 (2009).

91. Guers, M. J. and Tittmann, B. R., "Influence of temperature on in-situ guided wave inspection and health monitoring of a rectangular bar specimen," Proc. of SPIE 7295, 72950N (2009).

92. R. Bratton, “AGC-1 Irradiation Experiment Test Plan,” INL/EXT-06-11102, May 2006.

93. H. Thoresen and S. Solstad, presentations at INL, July 2008, Idaho Falls, ID.

94. FUEL MATERIAL TECHNOLOGY REPORT, Volume 1 Prepared by Brian Cox, Friedrich Garzarolli, Ron Adamson, Peter Rudling, Alfred Strasser, Advanced Nuclear Technology International, Krongjutarvägen 2C SE-730 50 Skultuna Sweden, October 2006.

95. V. G. Kritsky, Water chemistry and corrosion of nuclear power plant structural materials, ANS, La Grange Park, Illinois USA, 1991.

96. Gordon Kohse and Yakov Ostrovsky, "Report on Development of In-core Crack Growth Monitors for Use in MITR and ATR,” MIT-NRL 2009-1, July 2009. 
INL/EXT-08-13985 